
\title{
R Research Soure \\ The Primary Breaking Pattern of Main Roof Above the First Working Face Based on Main Bending Moment
}

Baogui Yang

haigang yang ( $\square$ haigangy@163.com )

China University of Mining and Technology(Beijing), Beijing 100083, China https://orcid.org/00000001-7101-0765

Xiaofeng Lu

CUMTB

\section{Research}

Keywords: main bending moment, the breaking pattern, the first working face, main roof, plate with four fixed sides

Posted Date: December 17th, 2020

DOl: https://doi.org/10.21203/rs.3.rs-127355/v1

License: (c) (i) This work is licensed under a Creative Commons Attribution 4.0 International License. Read Full License 


\title{
The primary breaking pattern of main roof above the first working face based
}

\section{on main bending moment}

\author{
Yang Baogui, Yang Haigang*, Lu Xiaofeng \\ School of Energy and Mining Engineering, China University of Mining and Technology(Beijing), Beijing 100083, China
}

\begin{abstract}
Scientific mining is based on breaking regularity of roof above underground working face in coal mine. In order to explore the primary breaking pattern of main roof above the first working face, on account of theory of thin elastic plate, development of the breaking in each region of main roof is analyzed and the breaking sequence of each region is explored in virtue of main bending moment taken as the breaking parameter. The results indicate that the first broken point of main roof is midpoint of the long side. The breaking, which occurs on the top surface of main roof, is caused by the second main bending moment. The fracture in long side region starts from midpoint of the long side and develops along the length direction of the working face. The fracture in middle region starts from the center of main roof and develops along the length direction of the working face. The fracture in short side region starts from midpoint of the short side and develops along advance direction of the working face. There always is an extreme value order of control moment in each region, $M_{c}>M_{z}>M_{d}$, when a single parameter is within a reasonable range. Due to this, the breaking sequence is the long side region, the middle region and the short side region although they end up with the same breaking pattern O-X. $M_{c}, M_{z}$ and $M_{d}$ depend on the advance distance of working face and increase linearly with transverse loading. Besides, the short side of main roof becomes stable with the increase of the length of working face. Revealing the primary breaking pattern of main roof above the first working face contributes to learning breaking behavior of main roof and providing theoretical support for design of the working face and roof management.
\end{abstract}

Key words main bending moment, the breaking pattern, the first working face, main roof, plate with four fixed sides

\section{Introduction}

Although exploitation of coal resources can bring valuable coal products for people, it may also raise some thorny issues in the mining operations. For example, strata movement not only pose a serious threat to the safety of mining production of the working face and adjacent stopes, but also can result in ground surface subsidence or even collapse. Revealing the laws of strata movement can contribute to addressing these problems and promote the development of mining technology. Because the movement of strata is closely related to the failure rule of the roof, it is crucial important to learn the failure pattern of the roof (Qian and Xu 2019; Zuo et al. 2019).
Several researchers have used the plate model to study the failure rule of the roof. For example, Zhao et al. (2018) have given analytic solution of their plate model, and presented the evolution of boundary condition of main roof on the base of calculating results of the bending moment. The model developed by $\mathrm{Yu}(2018)$ has shown that the midpoint of the long side in the thin plate with four simply clamped edges, and the midpoint of the clamped side in the thin plate with three simply clamped edges are more likely to break. Based on the stress and the bending moment in $\mathrm{X}$ direction and deflection of the roof, Xue et al. (2016) have investigated initial and periodic collapse behavior of the roof burdened with underground pressure. Yang et al. (2015)' results, which were based on the stress in $\mathrm{Y}$ direction of the thin plate have indicated that the centre and the midpoint of the long 
side in the roof with four simply clamped edges are prone to break when initial collapse happens. Wang and Gao (2015) have presented inner failure mechanism of the roof according to calculated values of the bending moment and the stress in both $\mathrm{X}$ and $\mathrm{Y}$ direction, and shear stress of variable length of the working face. Liu and Li (2014)' theoretical analysis and numerical simulation results have given stress distribution of the island coal face and the evolution of the breaking roof with time. Pu et al. (2011) have analyzed the bending moment of the thin plate with four simply clamped edges, and they have obtained the collapsing, developing and transferring pattern of the roof. Zhang et al. (2010) have presented stress distribution of initial and periodic collapse obtained by using ANSYS, and revealed failure mechanism of the roof with highly inclined up-dip working face. Similarly, taking advantage of Mathcad software and then getting the contour line of the stress in both $\mathrm{X}$ and Y direction of the roof, Li et al. (2008) have showed the initial and periodic collapse pattern. Wang et al. (2008) have built the elastic plate model based on the roof supported by pillars, and showed the failure pattern in different stages in the light of the bending moment value. Wang et al. (2005) have calculated stress in the thin plates with four simply clamped edges and three simply clamped edges. They have had a good explanation of segmental, stage and migration pressure, which happens in hard strata. On the base of analyzing stress distribution of the roof in Bai Laping, a coal mine, Tang and Ye (2003) have drawn the conclusion that the first broken point of main roof is midpoint of the long clamped side.

Some studies (Zhao et al. 2018; Yu 2018; Xue et al. 2016; Yang et al. 2015; Wang and Gao 2015; Liu and Li 2014; Pu et al. 2011; Zhang et al. 2010; Li et al. 2008; Wang et al. 2008; Wang et al. 2005; Tang and Ye 2003) mentioned above were carried out under the assumption that normal stress reaching the critical values causes failure of the roof. It is not reasonable since the maximum value of normal stress is first principal stress, and sometimes stress in both $\mathrm{X}$ and $\mathrm{Y}$ direction are not the maximum value of normal stress. Similarly, the main moment is the true cause of failure of the roof when the bending moment is taken as the failure criteria. Besides, some previous works (Zhao et al. 2018; Xue et al. 2016; Wang and Gao 2015; Zhang et al. 2010; Wang et al. 2008; Wang et al. 2005) are limited to broken points of the roof instead of the whole development process of the roof failure. In consideration of theses limits, this study will be conducted. Firstly, the paper obtains distribution of the main bending moment and failure direction of broken points, and subsequently discusses the development of failure regions of main roof. Finally, parameter effect analysis is used to explore the breaking sequence of each region, and to get the primary breaking pattern of main roof above the first working face.

\section{Development and analysis of the}

\section{model}

Beginning at open-off cut, the working face is advancing. As a result of it, stress applied on the immediate roof is increasing until stress reaches the maximum value, and then the immediate roof collapses. Similarly, after that, main roof also experiences the first collapse with the increasing exposure roof surface, and fitful collapse of the immediate roof. Several studies (Zhao et al. 2018; Yu 2018; Xue et al. 2016; Yang et al. 2015; Wang and Gao 2015; Liu and Li 2014; Pu et al. 2011; Zhang et al. 2010; Li et al. 2008; Wang et al. 2008; Wang et al. 2005; Tang and Ye 2003; He et al. 2017) show that mechanical behavior of the roof above underground working face can be studied by using the thin elastic plate theory.

\subsection{Deflection surface equation}

Before the first collapse, main roof can be simplified to a thin elastic plate, and its four sides are restricted by coal, the immediate roof, and overlying strata, which are regarded as fixed boundaries in the paper, and have no movement.

As showed in Fig.1, a thin elastic plate model with four fixed boundaries is built, and its $\mathrm{x}, \mathrm{y}$ and $\mathrm{z}$ axis coincide with length, width and height direction of the working face, respectively. $S$ denotes advanced distance of the working face, and $t$ is the length. It is noted that $s<t . \mathrm{F}_{1}, \mathrm{~F}_{2}, \mathrm{G}_{1}$ and $\mathrm{G}_{2}$ are midpoints of its corresponding side, and $\mathrm{O}$ is the central point of main 
roof.
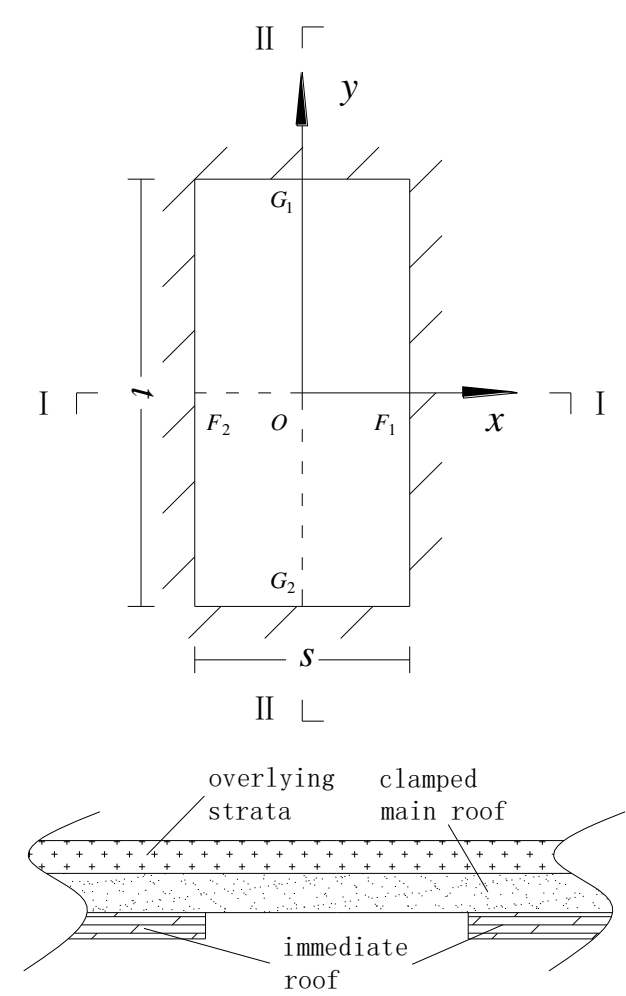

I - I

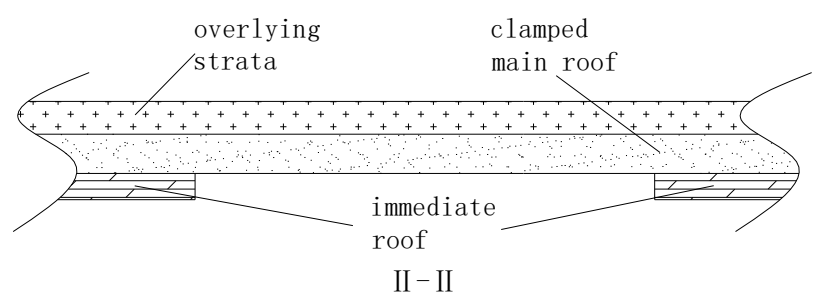

Fig.1 Mechanical model of rectangular thin elastic plate with four fixed boundaries

According to the thin elastic plate theory (Xu 2006; Timshenko and Goodier 1970; Timshenko and Woinowsky-krieger 1959), the fixed boundary condition is presented as follows:

$$
\begin{aligned}
& \left.\omega\right|_{x= \pm \frac{s}{2}}=0,\left.\frac{\partial \omega}{\partial x}\right|_{x= \pm \frac{s}{2}}=0 \\
& \left.\omega\right|_{y= \pm \frac{t}{2}}=0,\left.\frac{\partial \omega}{\partial y}\right|_{y= \pm \frac{t}{2}}=0
\end{aligned}
$$

Where $\omega$ is deflection of the thin plate.

The trial function of the above equation can be written as:

$$
\left.\omega=q x^{2}-\frac{s^{2}}{4}\right)^{2}\left(y^{2}-\frac{t^{2}}{4}\right)^{2}
$$

Where $C$ is a parameter.

Since the equation of (3) satisfies displacement boundary conditions and inner force boundary conditions from (1) and (2), according to Galerkin method, there is:

$$
C=\frac{49 q}{\left.87 s^{4}+4 s^{2} t^{2}+7 t^{4}\right) D}
$$

Where $D$ is bending stiffness of the thin elastic plate. Consequently, the deflection surface equation of the thin elastic fixed plate can be written as:

$$
\omega=\frac{49 q}{\left.87 s^{4}+4 s^{2} t^{2}+7 t^{4}\right) D}\left(x^{2}-\frac{s^{2}}{4}\right)^{2}\left(y^{2}-\frac{t^{2}}{4}\right)^{2}
$$

\subsection{Failure criteria}

According to rock mechanical theory (Qian et al. 2010; Sun et al. 2009), when $M_{u}$ is used as ultimate moment of main roof, the failure criteria is presented as follows;

$$
\max \left\{|M|,\left|M_{2}\right|\right\}=\left|M_{u}\right|
$$

The equation of (6) shows that main roof collapses when main bending moment of a point in main roof reaches the maximum absolute value.

According to elastic thin plate theory (Xu 2006), plate stress can be expressed as function of $\omega$ and bending moment $M_{x}$ and $M_{y}$, and torque $M_{x y}$ can be calculated as:

$$
\begin{aligned}
& M_{x}=-Q\left(\frac{\partial^{2} \omega}{\partial x^{2}}+v \frac{\partial^{2} \omega}{\partial y^{2}}\right) \\
& M_{y}=-Q\left(\frac{\partial^{2} \omega}{\partial y^{2}}+v \frac{\partial^{2} \omega}{\partial x^{2}}\right) \\
& M_{x y}=-Q(1-v) \frac{\partial^{2} \omega}{\partial x \partial y}
\end{aligned}
$$

In addition to main bending moment $M_{1}$ and $M_{2}$, they can be expressed as:

$$
M_{1}, M_{2}=\frac{M_{x}+M_{y}}{2} \pm \sqrt{\left(\frac{M_{x}-M_{y}}{2}\right)^{2}+M_{x y}{ }^{2}}
$$


Where $M_{1}+M_{2}=M_{x}+M_{y}$. Normal direction of action surface of $M_{1}$ is vertical to that of $M_{2}$, and the included angle $(\alpha)$ between the former one and $\mathrm{x}$ direction can be calculated as

$$
\begin{aligned}
& M_{1}=-\frac{\not(1+v)}{2}\left(\frac{\partial^{2} \omega}{\partial x^{2}}+\frac{\partial^{2} \omega}{\partial y^{2}}\right)+\frac{\not 1-v)}{2} \sqrt{\left(\frac{\partial^{2} \omega}{\partial y^{2}}-\frac{\partial^{2} \omega}{\partial x^{2}}\right)^{2}+4\left(\frac{\partial^{2} \omega}{\partial x \partial y}\right)^{2}} \\
& M_{2}=-\frac{\not 1+v)}{2}\left(\frac{\partial^{2} \omega}{\partial x^{2}}+\frac{\partial^{2} \omega}{\partial y^{2}}\right)-\frac{\not 1-v)}{2} \sqrt{\left(\frac{\partial^{2} \omega}{\partial y^{2}}-\frac{\partial^{2} \omega}{\partial x^{2}}\right)^{2}+4\left(\frac{\partial^{2} \omega}{\partial x \partial y}\right)^{2}}
\end{aligned}
$$

Since bending moment and torque are internal force applied on unit width, their dimension and unit are $\mathrm{LMT}^{-2}$ and $\mathrm{MN}$, respectively, instead of $\mathrm{L}^{2} \mathrm{MT}^{-2}$ and $\mathrm{MN} \cdot \mathrm{m}$ (Xu 2006).

\subsection{Analysis of the model}

To intuitively analyze failure behavior of main roof, some date from the KOU Zidong coal is used in this paper ( $s=40 \mathrm{~m}, t=360 \mathrm{~m}, q=0.25 \mathrm{MPa}$ (Yu 2018; He et al. 2017), $E=30 \mathrm{GPa}, v=0.2$ and $h=6 \mathrm{~m}$, where $q, E, v$ and $h$ are lateral load, elastic modulus, Poisson's ratio and thickness of main roof, respectively).
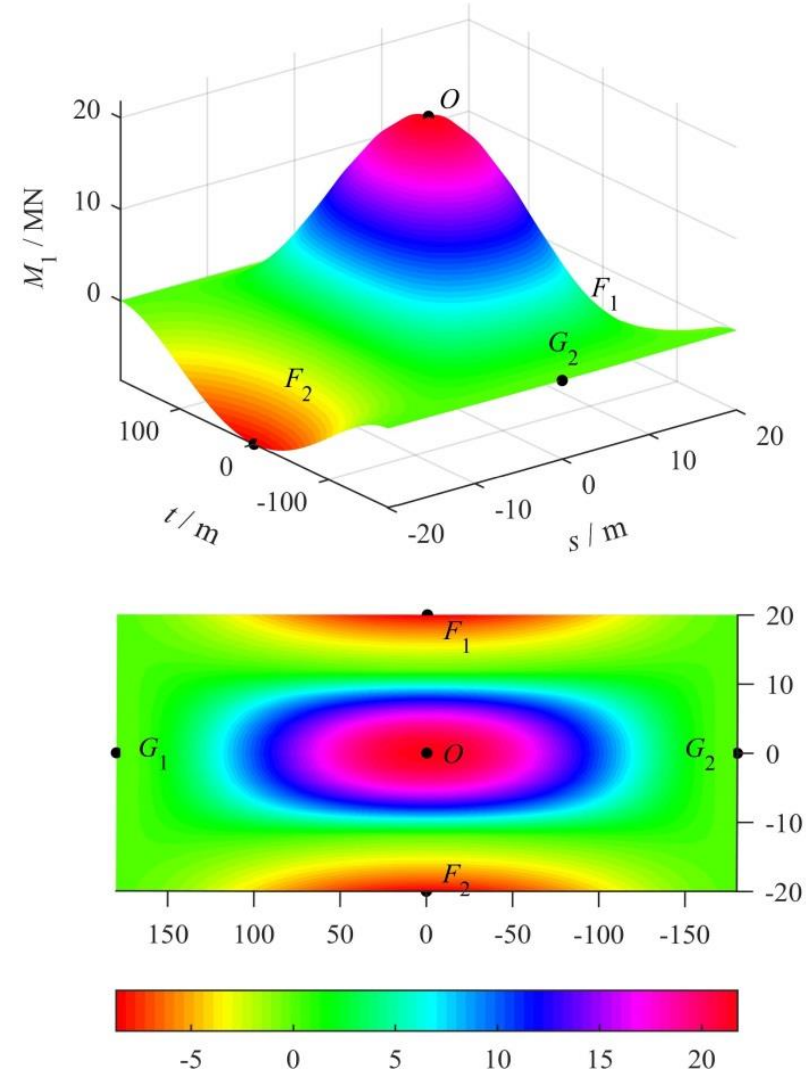

(a) The first principal bending moment
Fig. 2 is distribution of main bending moment. As showed in Fig.2, the maximum absolute value of the main bending moment (the second principal moment) happens in $F_{1}$ or $F_{2}$, and is $-43.44 \mathrm{MN}$. Substituting it into the function of first principal stress (Sun et al. 2009) yields tensile stress of main roof surface (i.e. 7.24 MPa). The value and the advanced distance $(40 \mathrm{~m})$ equal approximately to the ultimate tensile stress and first collapse distance, respectively, which indicates reliability of the model and rationality of used parameters.
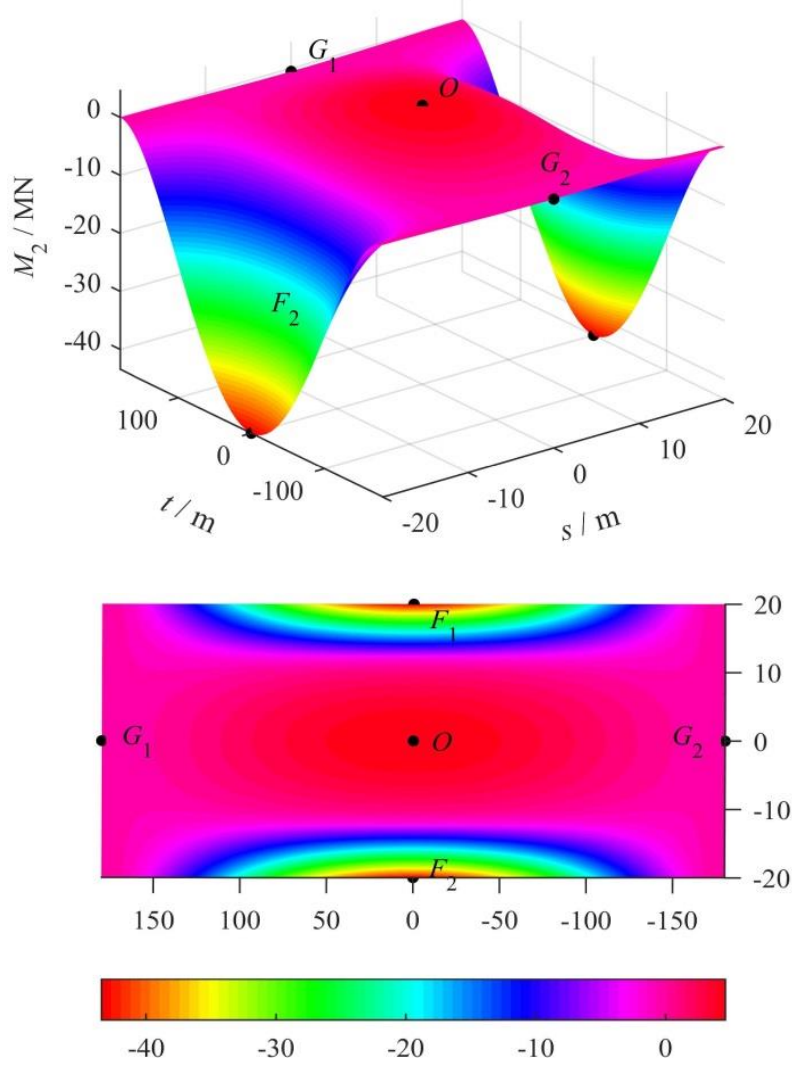

(b) The second principal bending moment 
Fig.2 Distribution of main bending moment

From Fig.2 (a), it can be seen that maximum and minimum value of the first principal bending moment happens in points $\mathrm{O}(21.77 \mathrm{MN})$ and $\mathrm{F}_{1}$ (or $\mathrm{F}_{2},-8.69$ $\mathrm{MN})$, respectively. Since the absolute value of 21.77 is greater than -8.69 , according to Eq. (6), the point $\mathrm{O}$ is more likely to be the failure point of main roof. Similarly, $\mathrm{F}_{1}$ ( or $\mathrm{F}_{2},-43.43 \mathrm{MN}$ ) is the failure point of main roof in Fig.2 (b), which is caused by the second principal bending moment. By comparing the results from Fig.2 (a) and Fig.2 (b), it can be concluded that $\mathrm{F}_{1}$ (or $\mathrm{F}_{2},-43.43 \mathrm{MN}$ ) is the failure point of main roof. Given that negative bending moment denotes main roof' bending downward, there is tensile stress in the upper half of main roof, and compressive stress in the lower half in Fig.2. Collapse happens in the upper surface of the roof in this case while it happens in the lower surface if the first principal bending moment value of the point $\mathrm{O}$ reaches ultimate moment.

\section{The development of failure of each}

\section{region}

From the discussion made above, five extreme points $\left(F_{1}, F_{2}, O, G_{1}\right.$ and $\mathrm{G}_{2}$ ) and $F_{1}$ (or $F_{2},-43.43 \mathrm{MN}$ ), which is more likely to become failure, are obtained. In this section, failure patterns will be analyzed. To simplify the problem, main roof is divided into three parts, which are the short side region, the middle region and the long side region, as showed in Fig.3.

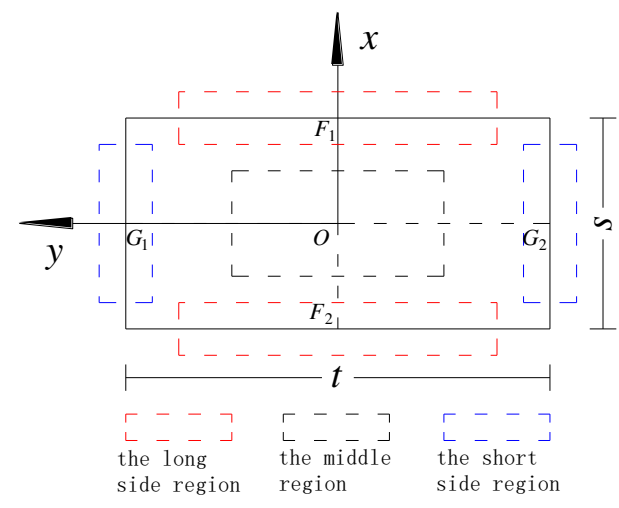

Fig.3 Region division of main roof

Since main roof collapses when main bending moment of a point in main roof reaches the maximum absolute value ( $M_{k}$, the controlled bending moment) according to Eq. (6), and the sign of the bending moment represents just bending direction, the focus of the paper is absolute value of main bending moment.

\subsection{Failure of the long side region}

Fig.4 (b) shows variation of $M_{k}$ (the second principal moment)of some points. Their locations can be got through orient angle $\beta\left(0,30,60\right.$ and $\left.90^{\circ}\right)$ and distance $d(1,2,3,4,5$ and $6 \mathrm{~m})$ between the targeted point and $\mathrm{F}_{2}$, as presented in Fig.4 (a).

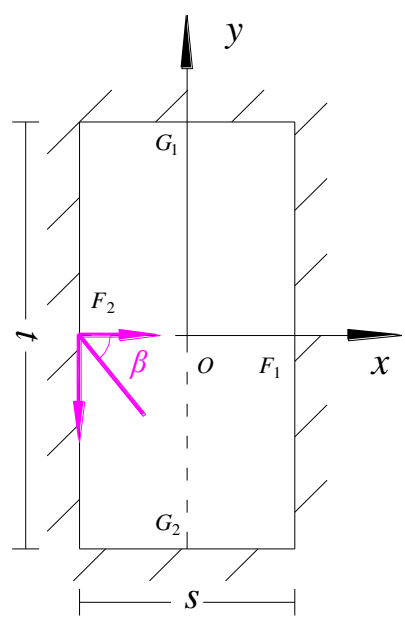

(a)

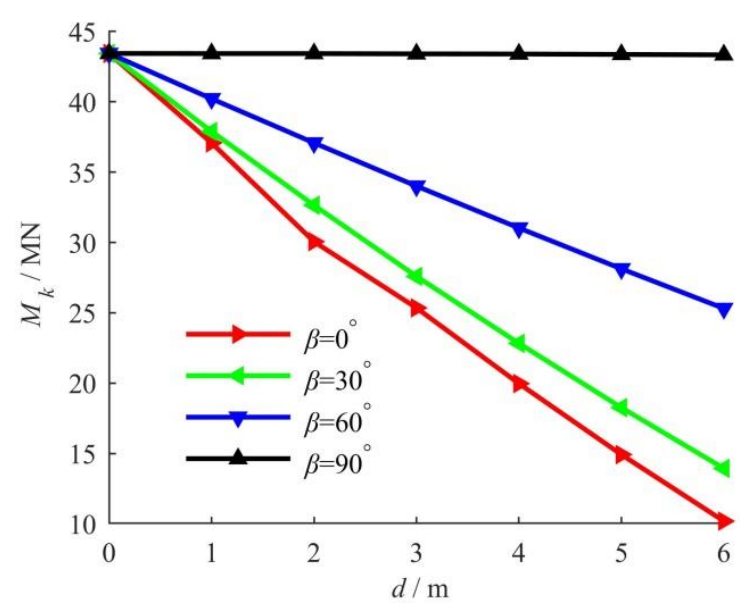

(b)

Fig.4 Variation of $M_{k}$ of the long side region

From Fig.4 (b), it can be seen that when $\beta$ keeps constant, $M_{k}$ linearly decreases with the increase of distance $d$. $M_{k}$ varies from 37.08 , to 37.89 , then to 40.22 and finally to $43.43 \mathrm{MN}$, if distance $d$ keeps $1 \mathrm{~m}$ and $\beta$ is $0,30,60$ and $90^{\circ}$, respectively. $M_{k}$ increment of these points, compared with the point $F_{2}$, is 6.36 , 5.55, 3.22 and $0.01 \mathrm{MN}$. $M_{k}$ varies greatly along advanced direction of the working face while varying slightly along length direction of the working face. 
When distance $d$ is $6 \mathrm{~m}$, and $\beta$ is 0 and $90^{\circ}, M_{k}$ is approximately 10 and $43 \mathrm{MN}$, respectively, which indicates that after failure of $F_{2}$, points along length direction of the working face are more likely to break. Due to the symmetry axis of $\mathrm{x}$, there is similar distribution of main bending moment in the upper half of main roof.

Failure direction can be determined by calculating Eq. (11). For example, there are $\tan \alpha=\infty$ and $\alpha= \pm 90^{\circ}$ about points on the long side of main roof, which means that normal direction of action surface of $M_{1}$ is vertical to that of $M_{2}$ and $\mathrm{x}$ direction, which are parallel to each other. Failure of the points on the long side is caused by the second principal moment. In this way, there is tension damage along $\mathrm{x}$ direction in these points of main roof.

In fact, since $M_{x y}$ of the points on the long side is 0 $\mathrm{MN}$, and $M_{x}$ and $M_{y}$ are main bending moment according to the definition of main bending moment, normal direction of action surface is $\mathrm{x}$ direction and $\mathrm{y}$ direction. $M_{x}$ is the second principal bending moment if the bigger one among $M_{x}$ and $M_{y}$ is $M_{y}$. Similarly, the failure situation along $\mathrm{x}$ direction of the points on the long side can also be obtained. Distribution of torque is shown in Fig.5.

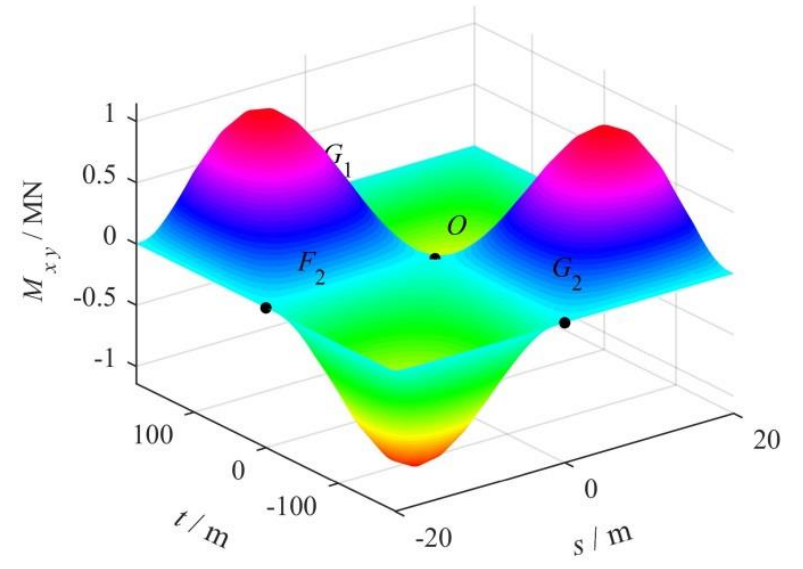

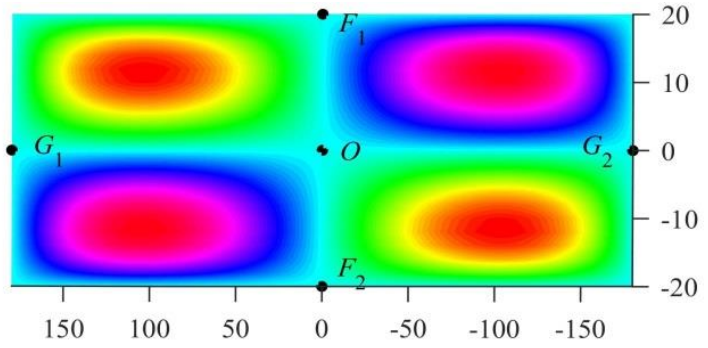

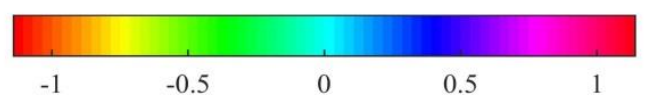

Fig.5 Distribution of torque

From Fig.5, it can be draw that $M_{x y}$ of points on the long side and the short side of main roof is $0 \mathrm{MN}$. The main bending moment of these points is corresponding $M_{x}$ and $M_{y}$. The first and the second principal moment can be determined by value of $M_{x}$ and $M_{y}$. While Mxy of points on main roof is not $0 \mathrm{MN}$, normal direction of action surface of main bending moment can be calculated by Eq. (11).

The obtained failure pattern above is that after failure of $F_{2}$, points along length direction of the working face will successively break. Meanwhile, the same failure pattern will happen in the upper half of the main owing to the symmetry axis of $\mathrm{x}$.

\subsection{Failure of the middle region}

Fig.6 (b) gives variation of $M_{k}$ (the first principal moment) of some points. Their locations can be got through orient angle $\beta\left(0,30,60\right.$ and $\left.90^{\circ}\right)$ and distance $d(1,2,3,4,5$ and $6 \mathrm{~m})$ between the targeted point and reference point $\mathrm{O}$, as presented in Fig.6 (a).

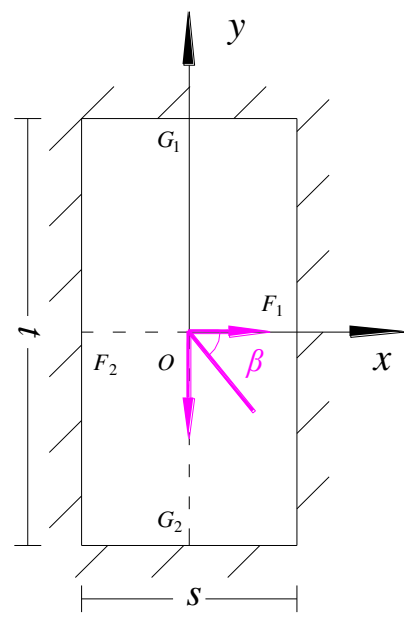

(a) 


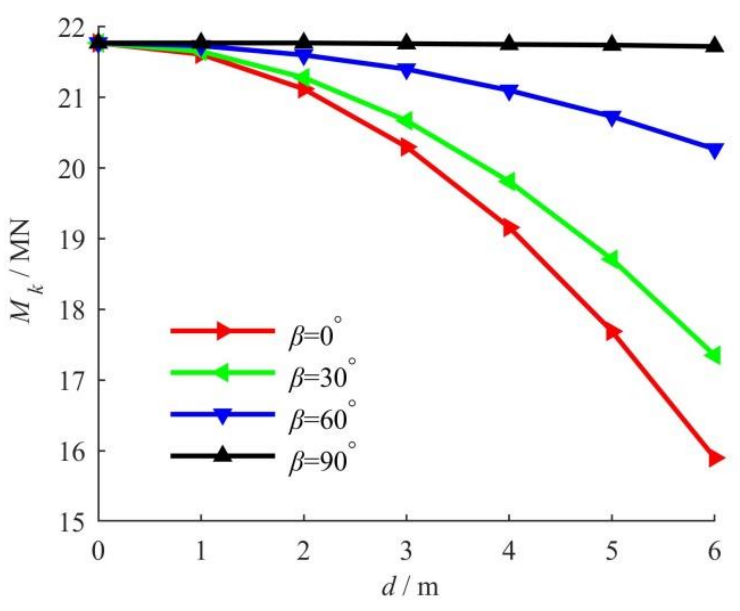

(b)

Fig. 6 Variation of $M_{k}$ of the middle region

Fig.6 (b) illustrates that when $\beta$ is constant, there is remarkable decrease of $M_{k}$ associated with the increase of distance $d$. $M_{k}$ varies from 21.61, to 21.65, then to 21.73 and finally to $21.77 \mathrm{MN}$ when distance $d$ is $1 \mathrm{~m}$ and $\beta$ is $0,30,60$ and $90^{\circ}$, respectively. $M_{k}$ increment of these points, compared with the point $\mathrm{O}$, is $0.16,0.12,0.04$ and $0.00 \mathrm{MN} . M_{k}$ varies significantly along advanced direction of the working face while varying slightly along length direction of the working face. When distance $d$ is $6 \mathrm{~m}$, and $\beta$ is 0 and $90^{\circ}, M_{k}$ is approximately 16 and $21 \mathrm{MN}$, respectively, which suggests that after failure of $\mathrm{O}$, points along length direction of the working face are more likely to break while points along advanced direction keeps stable. Owing to the symmetry distribution of $M_{k}$, main bending moment in other three quadrants of main roof has the same pattern. So, after failure of $\mathrm{O}$, points on long symmetry axis of main roof will break.

From Fig 5, it can be found that $M_{x y}$ of points on the long symmetry axis of main roof is null, and $M_{x}$ is the first principal bending moment since the bigger one among $M_{x}$ and $M_{y}$ is $M_{x}$. The first principal bending moment causes failure of points on the long symmetry axis of main roof. So, tensile failure will happen in these points along $\mathrm{x}$ direction.

The obtained result above is that after failure of $\mathrm{O}$, points along length direction of the working face will successively break.

\subsection{Failure of the short side region}

Fig.7 (b) presents variation of $M_{k}$ (the second principal moment) of some points. Their locations can be got through orient angle $\beta\left(0,30,60\right.$ and $\left.90^{\circ}\right)$ and distance $d(1,2,3,4,5$ and $6 \mathrm{~m})$ between the targeted point and reference point $\mathrm{G}_{1}$, as presented in Fig.7 (a). $\mathrm{G}_{1}$ (or $\mathrm{G}_{2}$ ) is more likely to break in the short side region.
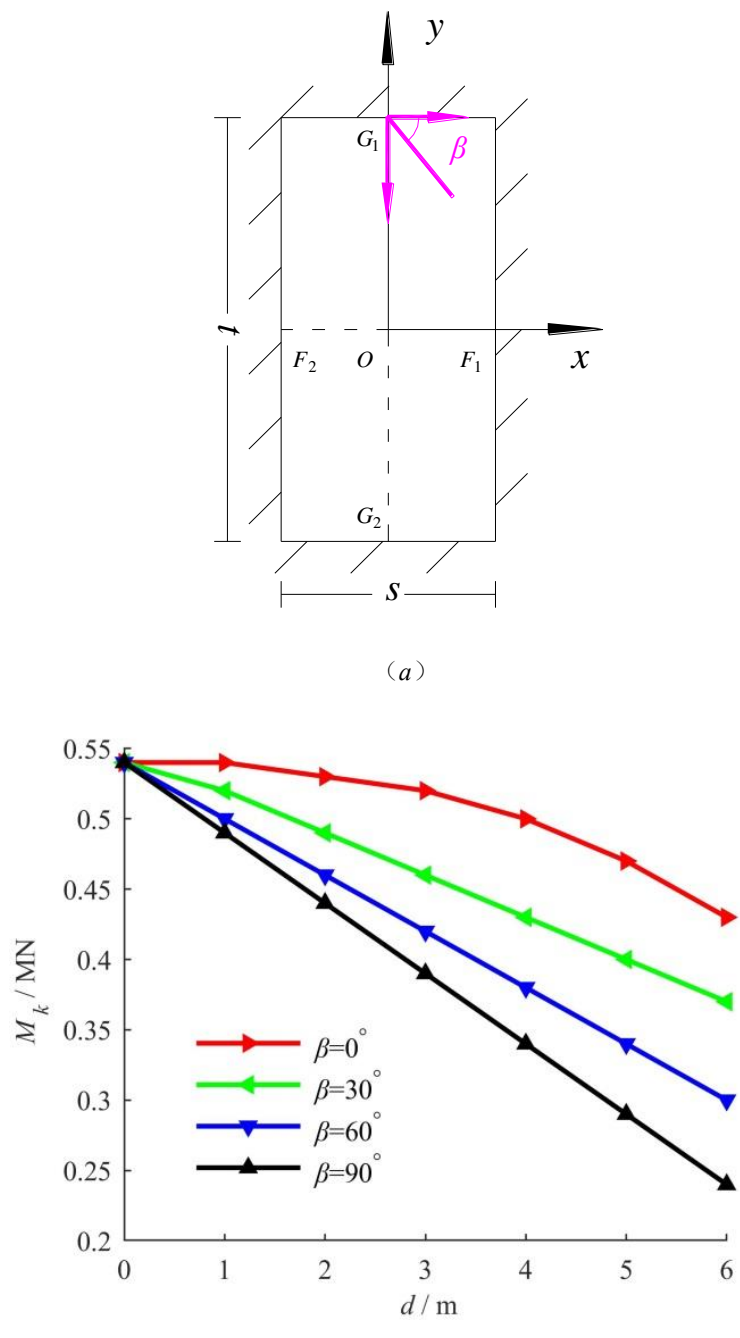

(b)

Fig. 7 Variation of $M_{k}$ of the short side region

Fig.7 (b) indicates that if $\beta$ is constant, there is linearity decrease of $M_{k}$ associated with the increase of distance $d$. $M_{k}$ varies from 0.54 , to 0.52 , then to 0.50 and finally to $0.49 \mathrm{MN}$ if distance $d$ is $1 \mathrm{~m}$ and $\beta$ is 0 , 30, 60 and $90^{\circ}$, respectively. $M_{k}$ increment of these points, compared with the reference point, is $0.00,0.02$, 0.04 and $0.05 \mathrm{MN}$. $M_{k}$ varies slightly along advanced direction of the working face while varying significantly along length direction of the working face. When distance $d$ is $6 \mathrm{~m}$, and $\beta$ is 0 and $90^{\circ}, M_{k}$ is approximately 0.25 and $0.40 \mathrm{MN}$, respectively, which suggests that after failure of $\mathrm{G}_{1}$ ( or $\mathrm{G}_{2}$ ), points along 
advanced direction of the working face are more likely to break while points along length direction keeps stable. Owing to the symmetry distribution of $M_{k}$, main bending moment in the left side of main roof has the same pattern. So, after failure of $\mathrm{G}_{1}$ (or $\mathrm{G}_{2}$ ), points on the short side of main roof will break.

From Fig 5, it can be found that $M_{x y}$ of points on the long symmetry axis of main roof is null, and $M_{y}$ is the second principal bending moment since the bigger one among $M_{x}$ and $M_{y}$ is $M_{x}$. The second principal bending moment causes failure of points on the short symmetry axis of main roof. So, tensile failure will happen in these points along y direction.

The obtained result above is that after failure of $\mathrm{G}_{1}$, points along advanced direction of the working face will successively break. Meanwhile, the same failure pattern will happen in the other side of the main owing to the symmetry axis.

\section{Analysis of breaking sequence of}

\section{each region}

After getting the failure evolution of each region, breaking sequence will be discussed below. Since the points in which $M_{k}$ reaches extremum is the breaking points, and their breaking sequence represents corresponding region', extremum of $M_{k}$ of these points will be analyzed.

Substituting Eq. (5) into Eq. (12) and (13) yields

$$
\begin{aligned}
& M=\frac{49 q(1+v) A-49 q(v-1) \sqrt{B^{2}+64 x^{2} y^{2}\left(\frac{s^{2}}{4}-x^{2}\right)^{2}\left(\frac{t^{2}}{4}-y^{2}\right)^{2}}}{28 s^{4}+16 s^{2} t^{2}+2 q^{4}} \\
& M_{2}=\frac{49 q(1+v) A+49 q(v-1) \sqrt{B^{2}+64 x^{2} y^{2}\left(\frac{s^{2}}{4}-x^{2}\right)^{2}\left(\frac{t^{2}}{4}-y^{2}\right)^{2}}}{28 s^{4}+16 s^{2} t^{2}+28 q^{4}}
\end{aligned}
$$

Where, $A=\left(\frac{s^{2}}{4}-x^{2}\right)\left(\frac{t^{2}}{4}-y^{2}\right)\left(\frac{s^{2}}{4}+\frac{t^{2}}{4}-x^{2}-y^{2}\right)-2 y^{2}\left(\frac{s^{2}}{4}-x^{2}\right)^{2}-2 x^{2}\left(\frac{t^{2}}{4}-y^{2}\right)^{2}$,

$$
B=\left(\frac{s^{2}}{4}-x^{2}\right)\left(\frac{t^{2}}{4}-y^{2}\right)\left(\frac{s^{2}}{4}-\frac{t^{2}}{4}-x^{2}+y^{2}\right)-2 y^{2}\left(\frac{s^{2}}{4}-x^{2}\right)^{2}+2 x^{2}\left(\frac{t^{2}}{4}-y^{2}\right)^{2}
$$

From Eq. (14) and Eq. (15), it can be seen that $M, M_{2}=f(s, t, q, v, x, y)$, which shows that the

first principal moment $\left(M_{1}\right)$ and the first principal moment $\left(M_{2}\right)$ is function of advanced distance of the working face, length of the working face, lateral load and Poisson's ratio. Extremum of $M_{k}$ of the long side region, the middle region and the short side region is represented by $M_{c}$ (the second principal bending moment, corresponding to the point of $\mathrm{F}_{1}$ (or $\mathrm{F}_{2}$ )), $M_{z}$ (the first principal bending moment, corresponding to the point of $\mathrm{O}$ ) and $M_{d}$ (the second principal bending moment, corresponding to the point of $\mathrm{G}_{1}\left(\right.$ or $\left.\mathrm{G}_{2}\right)$ ).

\subsection{The effect of advanced distance of the working} face

Before the first collapse, advanced distance of the working face is equal to width of main roof. Affected by geological conditions and mining technology, main roof initially collapses when the advanced distance of the working face reaches 30 to $60 \mathrm{~m}$. The effect of advanced distance of the working face on extremum of $M_{k}$ of each region is presented in Fig.8. 


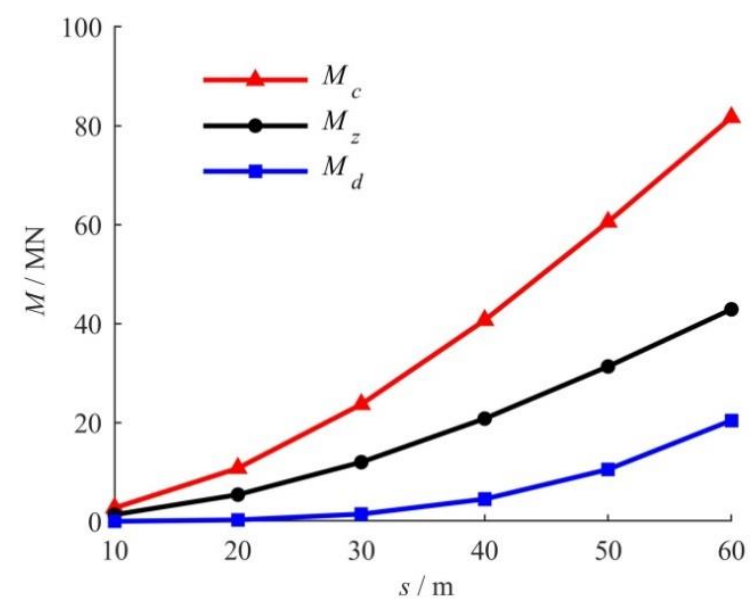

Fig. 8 The effect of $s$

Fig. 8 indicates that with the increase of advanced distance of the working face, $M_{c}, M_{z}$ and $M_{d}$ increase too, and this trend becomes increasingly apparent, which suggests that advanced distance of the working face has a noticeable effect on $M_{c}, M_{z}$ and $M_{d}$. When advanced distance of the working face keeps constant, there is $M_{c}>M_{z}>M_{d}$. It proves that failure of main roof begins at the point of $F_{1}$ (or $F_{2}$ ), develops at the point of $\mathrm{O}$, and then at the point of $\mathrm{G}_{1}$ (or $\left.\mathrm{G}_{2}\right)$. The gap between the values of $M_{c}$ when advanced distance of the working face is $10(2.73 \mathrm{MN})$ and $60 \mathrm{~m}(96.83$ $\mathrm{MN})$, respectively, suggests that the main bending moment is governed by advanced distance of the working face. This is accordant with reality. The similar pattern can also be found when $M_{c}$ is replaced by $M_{z}$ and $M_{d}$.

\subsection{The effect of length of the working face}

Length of the working face is equal to length of main roof. Due to satisfactory performances in both economic and efficient terms, the longwall face has achieved breakthroughs in length for recent years. For example, Length of the working face in some mines with good geological conditions even reached $350 \mathrm{~m}$, which is far greater than length that previous ones can have, such as $80 \mathrm{~m}$. The evolution of $M_{k}$ of each region with length of the working face is presented in Fig.9.

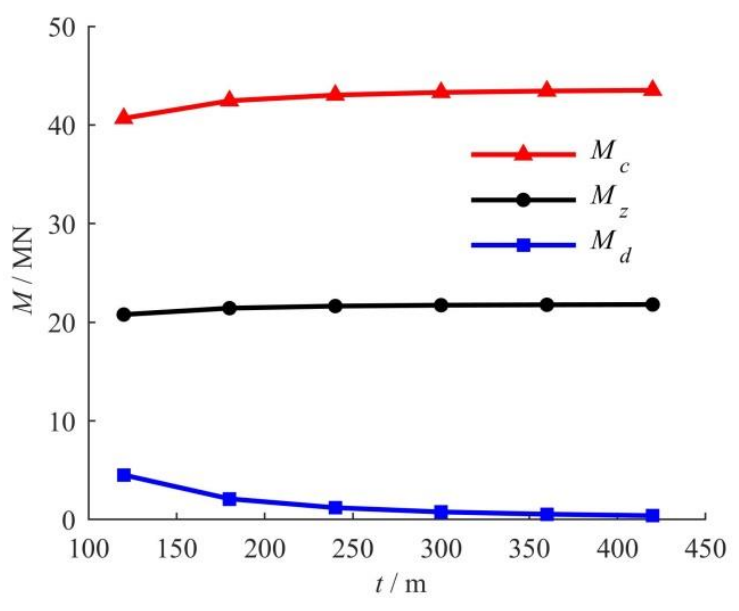

Fig.9 The effect of $t$

Fig. 9 presents that with the increase of length of the working face, $M_{c}$ and $M_{z}$ increase while $M_{d}$ decreases. But both these two trends become less apparent in the second half of the curves when length of the working face exceeds $240 \mathrm{~m}$, which indicates that length of the working face exerts a marginal effect on $M_{c}, M_{z}$ and $M_{d}$ when it reaches a critical value. The decrease trend of $M_{d}$ with the increase of length of the working face suggests that the point of $\mathrm{G}_{1}$ (or $\mathrm{G}_{2}$ ) is less likely to break. When length of the working face keeps constant, there is $M_{c}>M_{z}>M_{d}$. It shows that failure of main roof begins at the point of $F_{1}$ (or $F_{2}$ ), develops at the point of $\mathrm{O}$, and then at the point of $\mathrm{G}_{1}$ (or $\mathrm{G}_{2}$ ). Besides, small increment of $M_{c}$ and $M_{z}$ with the increase of length of the working face partly explains continual breakthroughs in length of the working face these years.

\subsection{The effect of lateral load}

Before the first collapse of main roof, overlying strata is in a higher position owing to support from main roof. When the working face is advancing, load from overlying strata is small given that main roof bends, and abscission layer happens. Fig.10 gives the effect of lateral load $(q)$ on $M_{c}, M_{d}$ and $M_{z}$. 


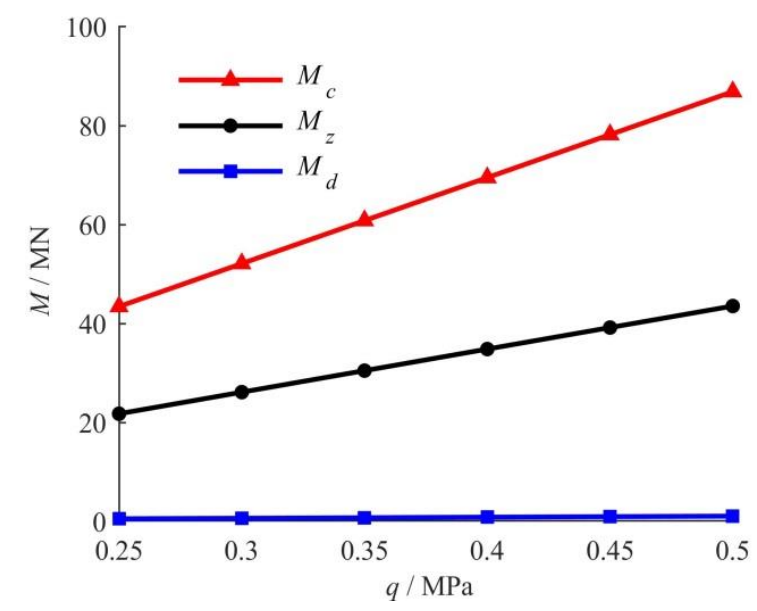

Fig. 10 The effect of $q$

From Fig.10 it can be seen that with the increase of lateral load, there is linearly increasing $M_{c}, M_{d}$ and $M_{z}$, and the increasing sensitivity of $M_{c}, M_{d}$ and $M_{z}$ successively reduces. Increment $(0.05 \mathrm{MPa})$ of lateral load causes increase of $M_{c}(8.68 \mathrm{MN}), M_{d}(4.36 \mathrm{MN})$ and $M_{z}(0.10 \mathrm{MN})$. When lateral load keeps constant, there also is $M_{c}>M_{z}>M_{d}$. It shows that failure of main roof begins at the point of $F_{1}$ (or $F_{2}$ ), develops at the point of $\mathrm{O}$, and then at the point of $\mathrm{G}_{1}$ ( or $\left.\mathrm{G}_{2}\right)$.

\subsection{The effect of Poisson's ratio}

Poisson's ratio has positive correlation with material strength. Poisson's ratio of main roof, overlying strata and coal successively increases, respectively. Fig.11 shows the effect of Poisson's ratio $(v)$ on $M_{c}, M_{d}$ and $M_{z}$.

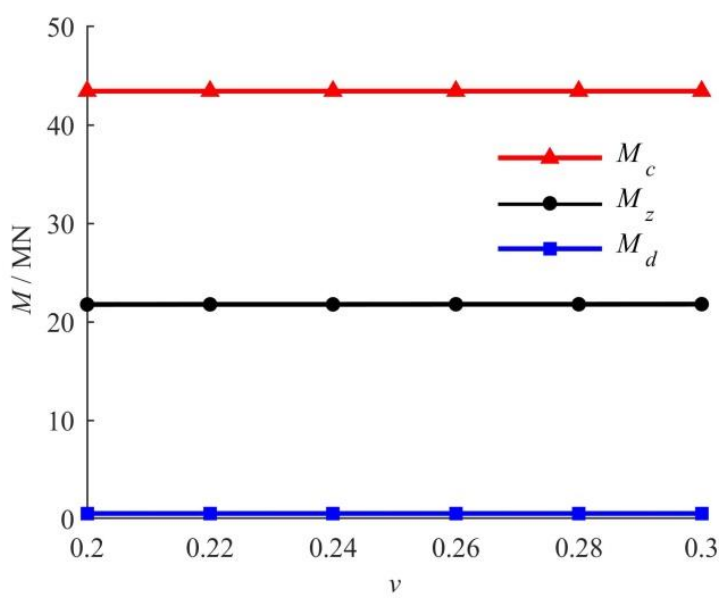

Fig. 11 The effect of $v$

From Fig.11 it can be obtained that in spite of the increase of Poisson's ratio, $M_{c}(43.43 \mathrm{MN})$ and $M_{d}$ $(0.54 \mathrm{MN})$ keeps constant. This is mainly due to the fact that Poisson's ratio can be eliminated according to Eq. (15) and coordinate of $F_{1}$ (or $F_{2}$ ) and $G_{1}$ (or $G_{2}$ ). With the increase of Poisson's ratio, $M_{z}$ also increases despite of small increment, which can nearly be seen as a constant. When Poisson's ratio keeps constant, there also is $M_{c}>M_{z}>M_{d}$. It indicates that failure of main roof begins at the point of $F_{1}$ (or $F_{2}$ ), develops at the point of $\mathrm{O}$, and then at the point of $\mathrm{G}_{1}\left(\right.$ or $\left.\mathrm{G}_{2}\right)$.

\section{The breaking pattern of main roof}

The working face is dynamic, and progressively approaches the main transportation road. The primary breaking pattern of main roof above the first working face shown in Fig.12 is obtained according to the development of failure of each region and breaking sequence of each region.

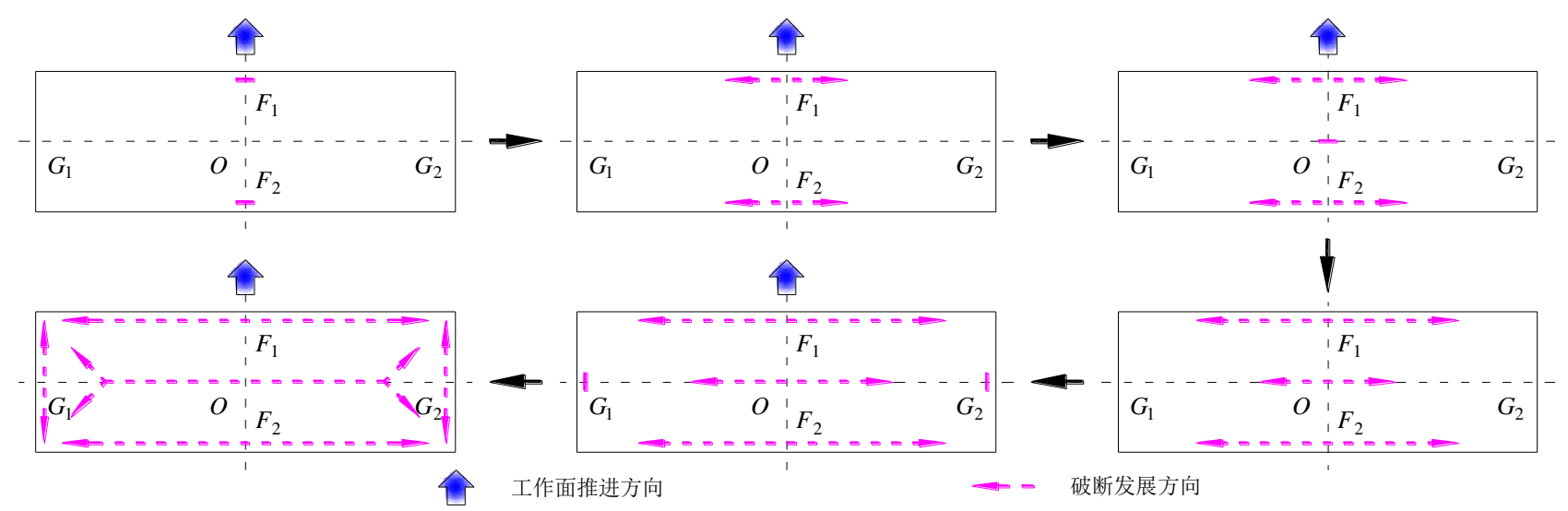

Fig. 12 The primary breaking pattern of main roof above the first working face 
Fig.12 shows that after failure of $\mathrm{F}_{1}$ (or $\mathrm{F}_{2}$ ), points along length direction of the working face will successively break. With the advancing working face, $M_{k}$ of the point of $\mathrm{O}$ reaches ultimate moment, and then it collapses with the points along the long symmetry axis. After the similar failure happens in the point of $\mathrm{G}_{1}$ (or $\mathrm{G}_{2}$ ), there is formation of breaking pattern O-X (Zuo et al. 2019; Pu et al. 2011; Qian et al. 2010). Due to relative difference of $M_{k}$ of each region of main roof, there is no probability that the long side firstly collapse, then the long symmetry axis, and finally the long symmetry axis.

\section{Conclusions}

(1) The first broken point of main roof is midpoint of the long side. The breaking, which occurs on the top surface of main roof, is caused by the second main bending moment.

(2) The failure in long side region starts from midpoint of the long side and develops along the length direction of the working face. The failure in middle region starts from the center of main roof and develops along the length direction of the working face. The failure in short side region starts from midpoint of the short side and develops along advance direction of the working face. The long side region firstly collapse, then the middle region, and finally the short side region. Together, there is formation of breaking pattern $\mathrm{O}-\mathrm{X}$.

(3) $M_{c}, M_{d}$ and $M_{z}$ are governed by advanced distance of the working face while length of the working face and Poisson's ratio have limited effect on $M_{c}, M_{d}$ and $M_{z}$. The short side of main roof is less likely to failure with the increase of length of the working face. $M_{c}, M_{d}$ and $M_{z}$ linearly increase with the increase of lateral load.

Acknowledgements This work was supported by the National Key Research and Development Plan(Grant No. 2017YFC0603002)

Open Access This article is licensed under a Creative Commons Attribution 4.0 International License, which permits use, sharing, adaptation, distribution and reproduction in any medium or format, as long as you give appropriate credit to the original author(s) and the source, provide a link to the Creative Commons licence, and indicate if changes were made. The images or other third party material in this article are included in the article's Creative Commons licence, unless indicated otherwise in a credit line to the material. If material is not included in the article's Creative Commons licence and your intended use is not permitted by statutory regulation or exceeds the permitted use, you will need to obtain permission directly from the copyright holder. To view a copy of this licence, visit http://creativecommons. org/licenses/by/4.0/.

\section{References}

Qian MG, Xu JL (2019) Behaviors of strata movement in coal mining. Journal of China Coal Society 44(4):973-984

Zuo JP, Yu ML, Hu SY, Song HQ, Wei X, Shi Y, Zuo SH (2019) Experimental investigation on fracture mode of different thick rock strata. Journal of Mining and Strata Control Engineering 1(1):013007.

Zhao XD, Gao XR, Chen Y, Wang SD (2018) Symplectic solutions to a thin plate model for the first weighting of main roof in a longwall mining working face. Rock and Soil Mechanics 39(12):4342-4350

Yu H (2018) Numerical investigation on the basic roof weighting step of the first mining face based on thin plate theory. Science Technology and Engineering 18(21):195-199

Xue Y, Teng T, Wang XH, Song XL (2016) Analysis of fracturing model and caving law of stope roof. Science Technology and Engineering 16(7):156-161

Yang JH, Sun SL, Kong DZ (2015) Effect of working face length and advancing speed on strata behaviors in high-intensity mining. Rock and Soil Mechanics 36(S2):333-339

Wang XF, Gao MZ (2015) Mechanical model of fracture mechanism of stope roof for working face with variable length. Journal of China University of Mining and Technology 41(1):36-45.

Liu ZC, Li WL (2014) Sheet model analysis of roof rupture in island working face. Mining Safety \& Environmental Protection 41(2):104-106

$\mathrm{Pu}$ H, Huang YG, Chen RH (2011) Mechanical analysis for X-O type fracture morphology of stope roof. Journal of China University of Mining \& Technology 40(6):835-840

Zhang YD, Cheng JY, Wang XX, Feng ZJ, Ji M (2010) Thin plate model analysis on roof break of up-dip or down-dip mining stope. Journal of Mining and Safety Engineering 27(4):487-493

Li XY, Gao F, Zhong WP (2008) Analysis of fracturing mechanism of stope roof based on plate model. Journal of Mining \& Safety Engineering 25(2):180-183

Wang JA, Shang XC, Liu H, Hou ZY (2008) Study on fracture mechanism 
and catastrophic collapse of strong roof strata above the mined area. Journal of China Coal Society 33(8):850-855

Wang JC, ZHANG J, Ji LT, Zheng HF (2005) Study on mechanics model of the first cave in main roof for the large cutting height fully mechanized mining under the two hard conditions. Chinese Journal of Rock Mechanics and Engineering 24(S1):5037-5042

Tang XL, Ye ML (2003) The thin plate theory analysis of hard roof and pressure forecast. Ground Pressure and Strata Control 20(2):89-92

He FL, Chen DD, Xie SR (2017) The kDL effect on the first fracture of main roof with elastic foundation boundary. Chinese Journal of Rock
Mechanics and Engineering 36(6):1384-1399

Xu ZL (2006) Elastic mechanics. Higher Education Press, Beijing

Timshenko S, Goodier J (1970) Theory of elasticity. Third Edition. McGraw-Hill, New York

Timshenko S, Woinowsky-krieger S (1959) Theory of plates and shells. McGraw-Hill, New York

Qian MG, Shi PW, Xu JL (2010) Mining pressure and strata control. China University of Mining and Technology Press, Xuzhou

Sun XF, Fang XS, Guan LT (2009) Mechanics of materials. Higher Education Press, Beijing 
Figures
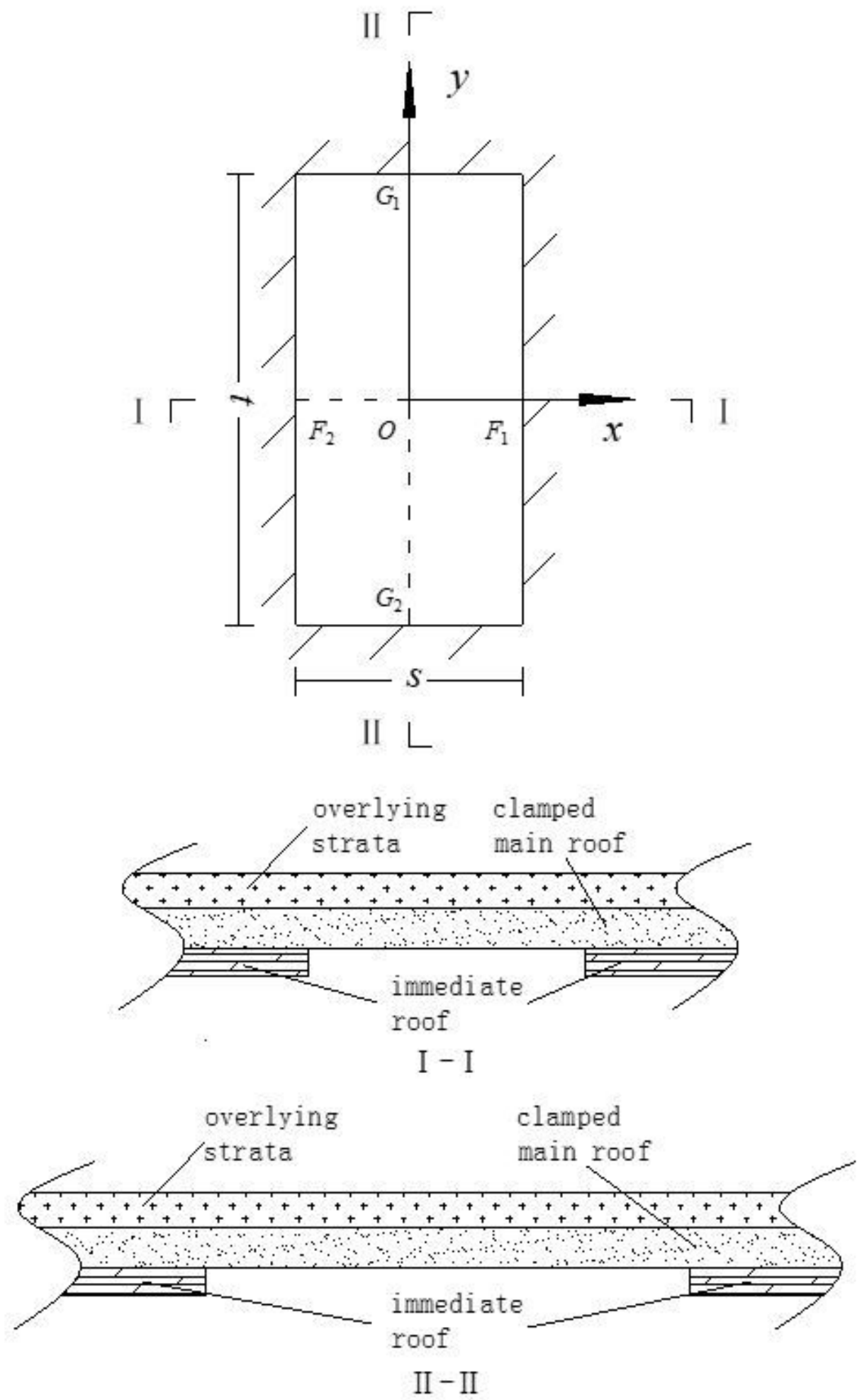

Figure 1

Mechanical model of rectangular thin elastic plate with four fixed boundaries 

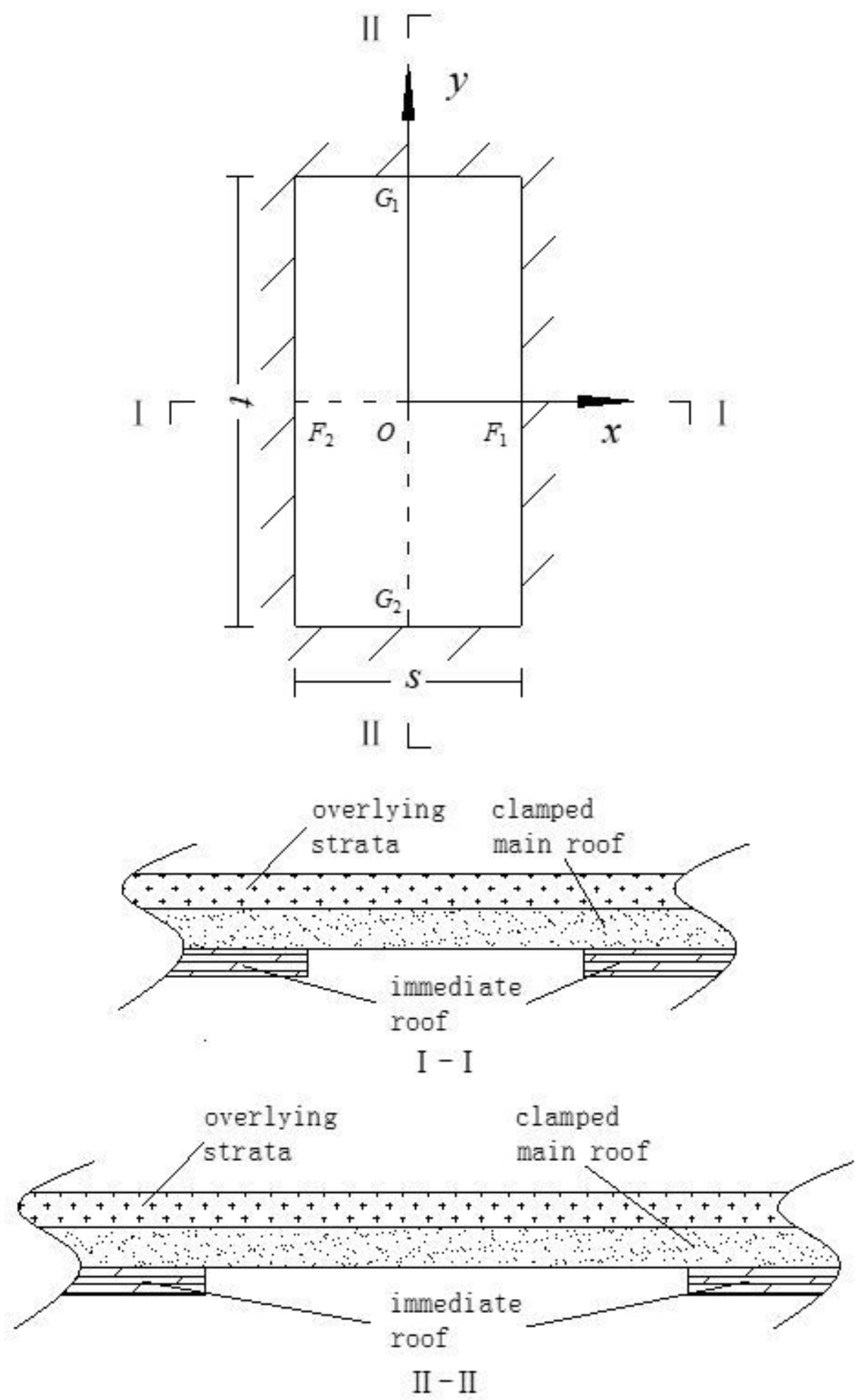

Figure 1

Mechanical model of rectangular thin elastic plate with four fixed boundaries 

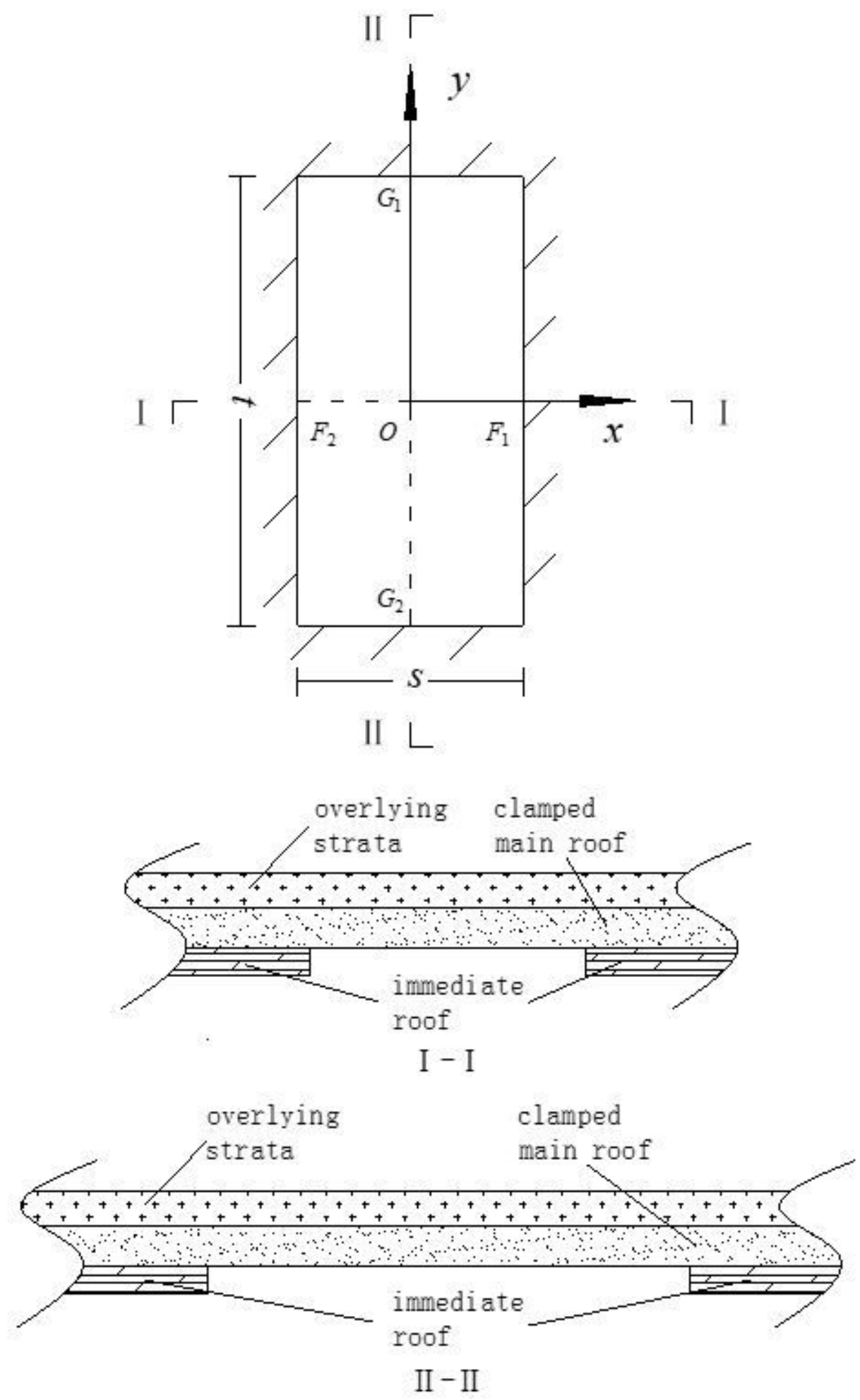

Figure 2

Mechanical model of rectangular thin elastic plate with four fixed boundaries 

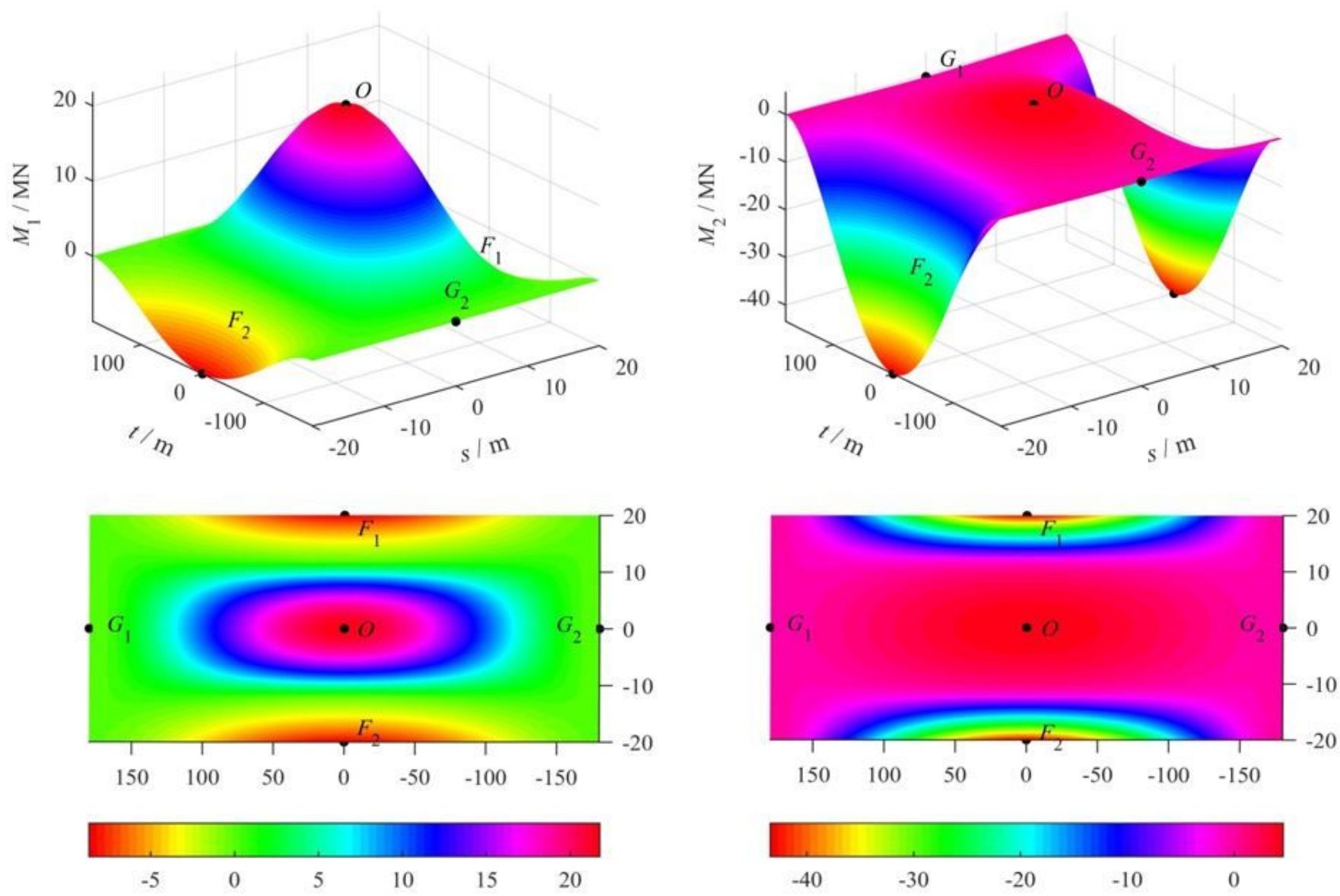

(a) The first principal bending moment

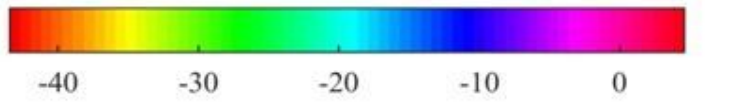

(b) The second principal bending moment

Figure 2

Distribution of main bending moment 

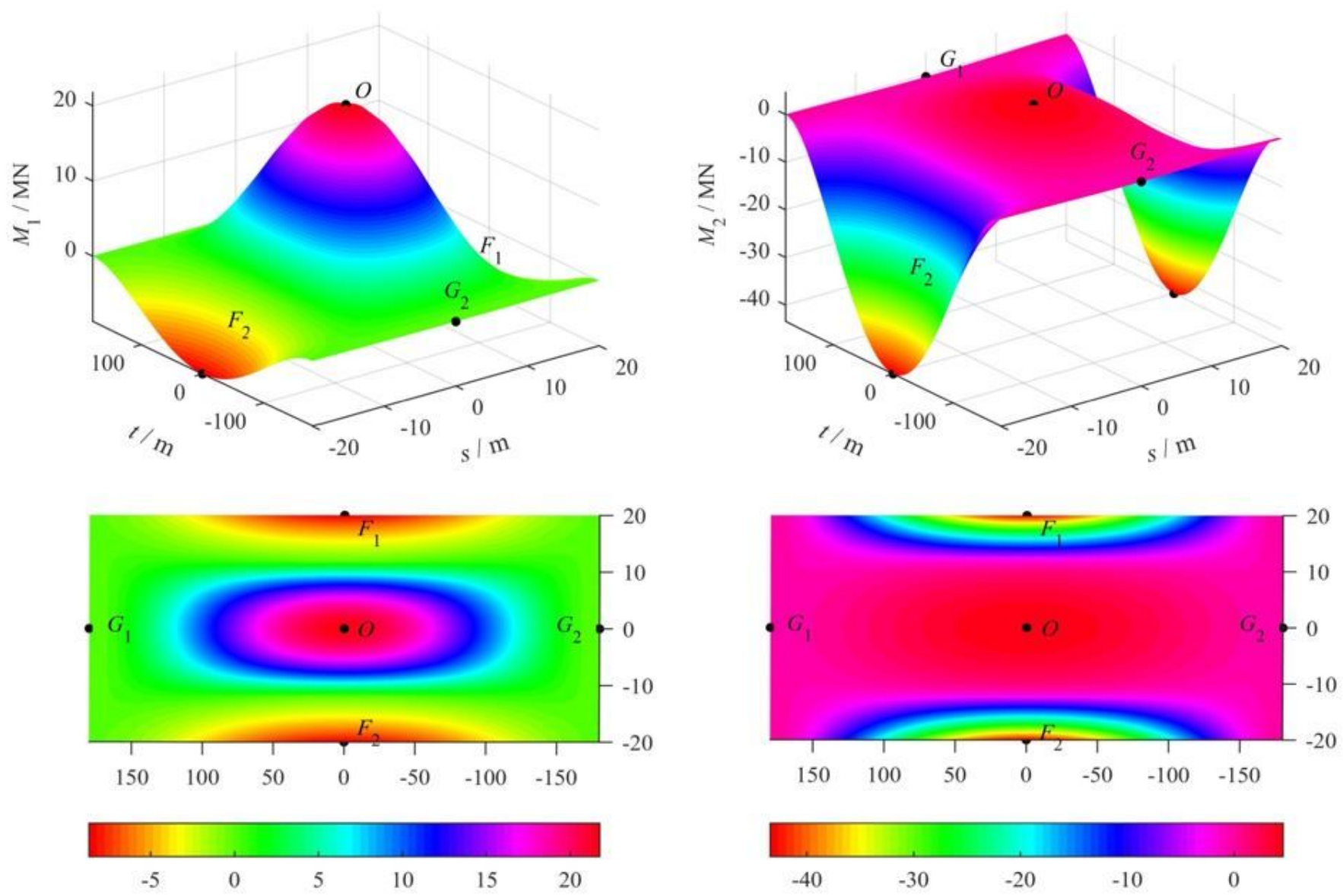

(a) The first principal bending moment

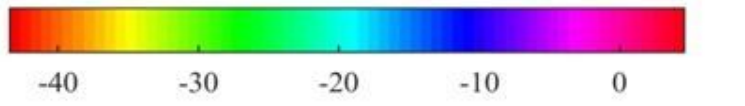

(b) The second principal bending moment

Figure 2

Distribution of main bending moment 

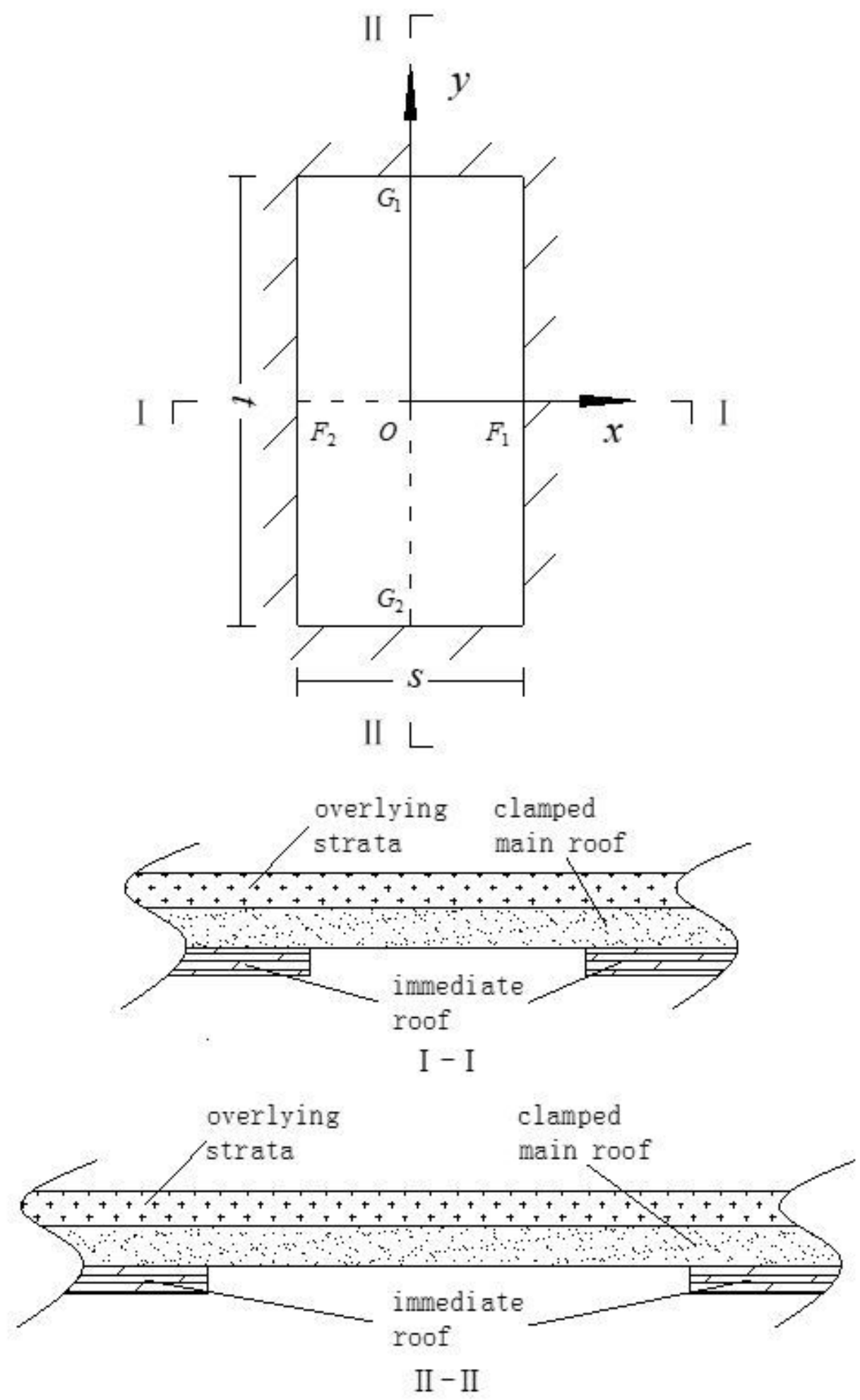

Figure 2

Mechanical model of rectangular thin elastic plate with four fixed boundaries 

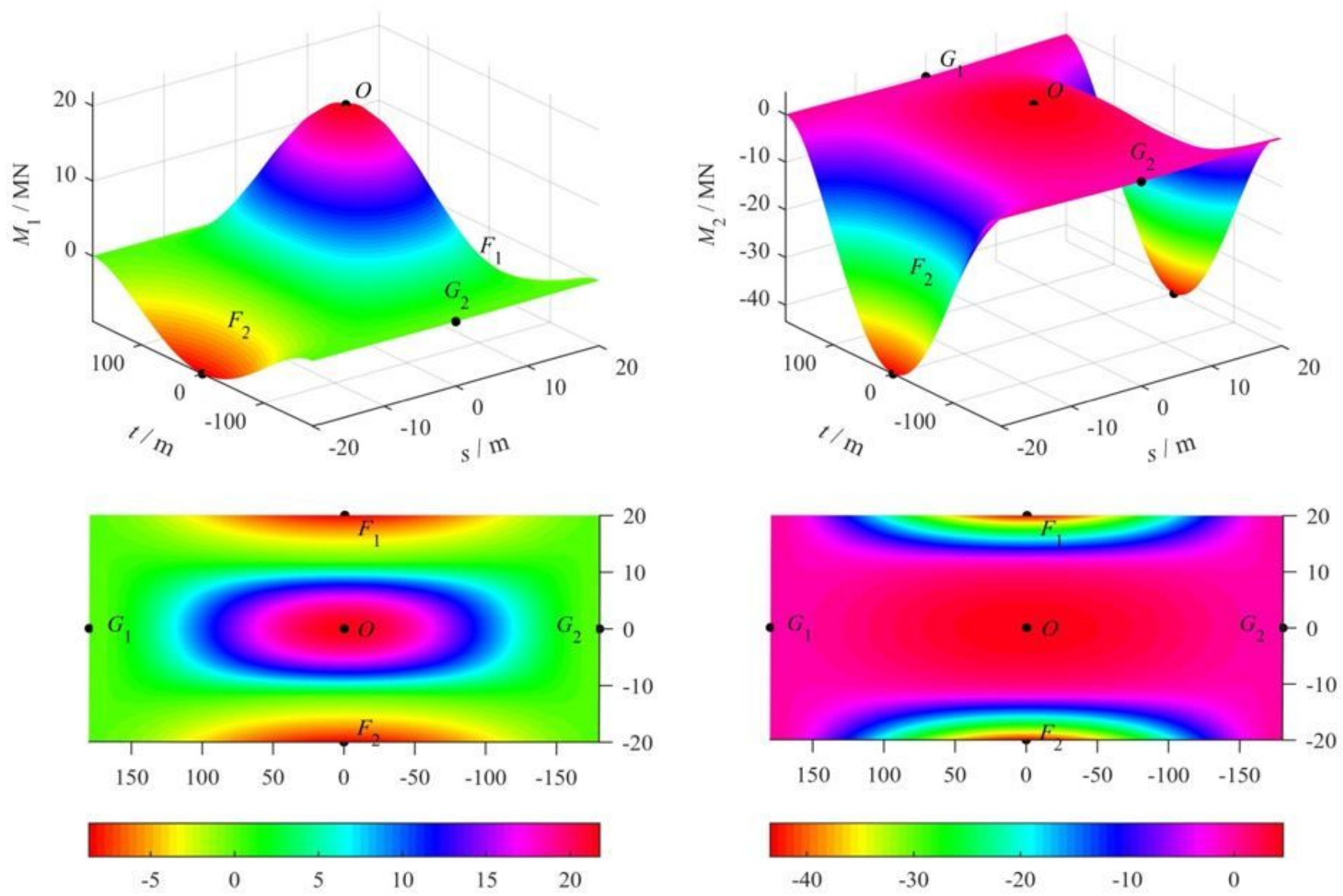

(a) The first principal bending moment

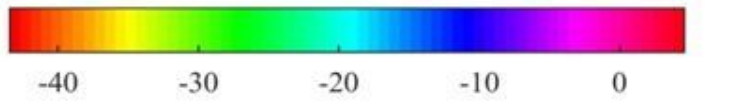

(b) The second principal bending moment

Figure 2

Distribution of main bending moment 


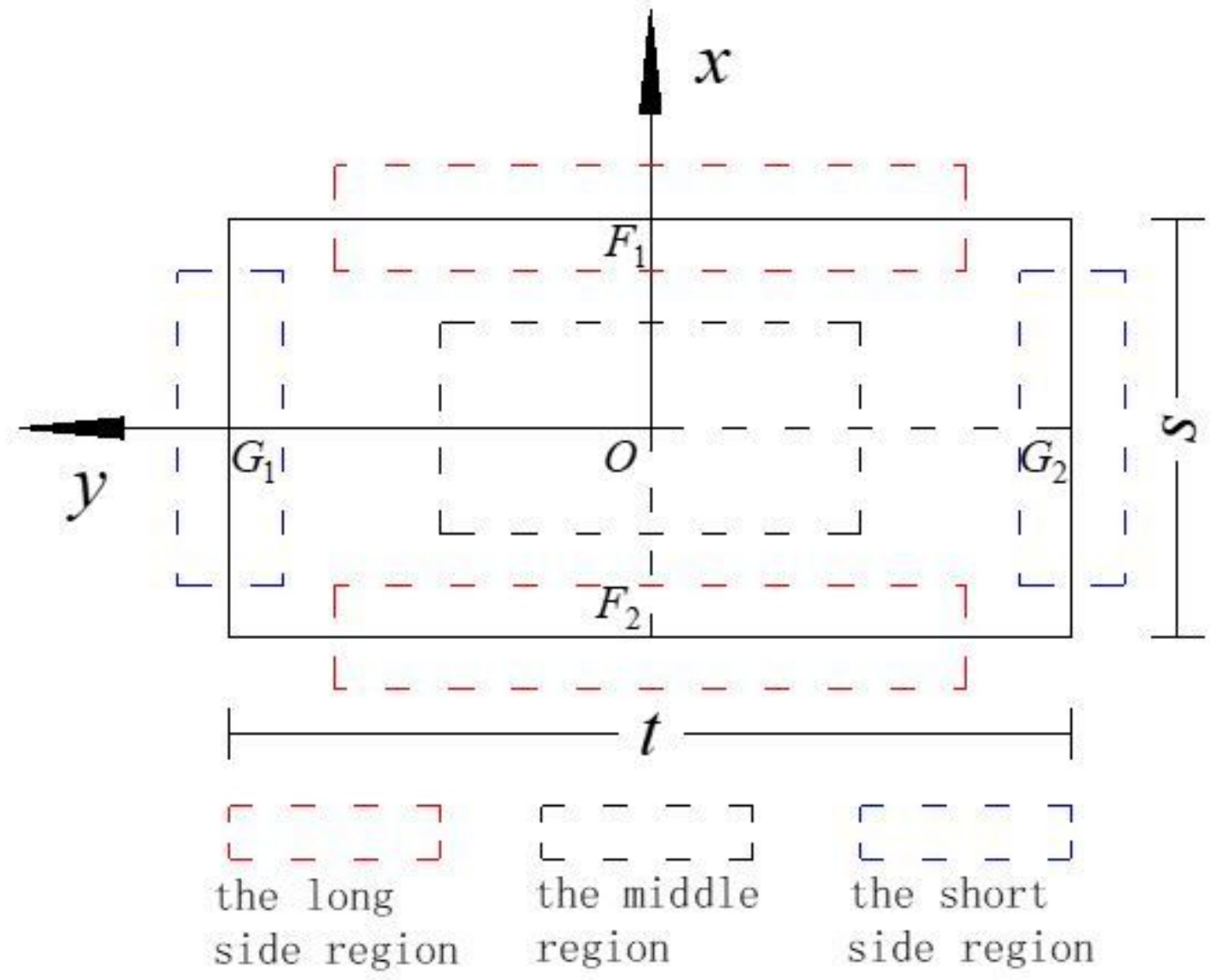

Figure 3

Region division of main roof 

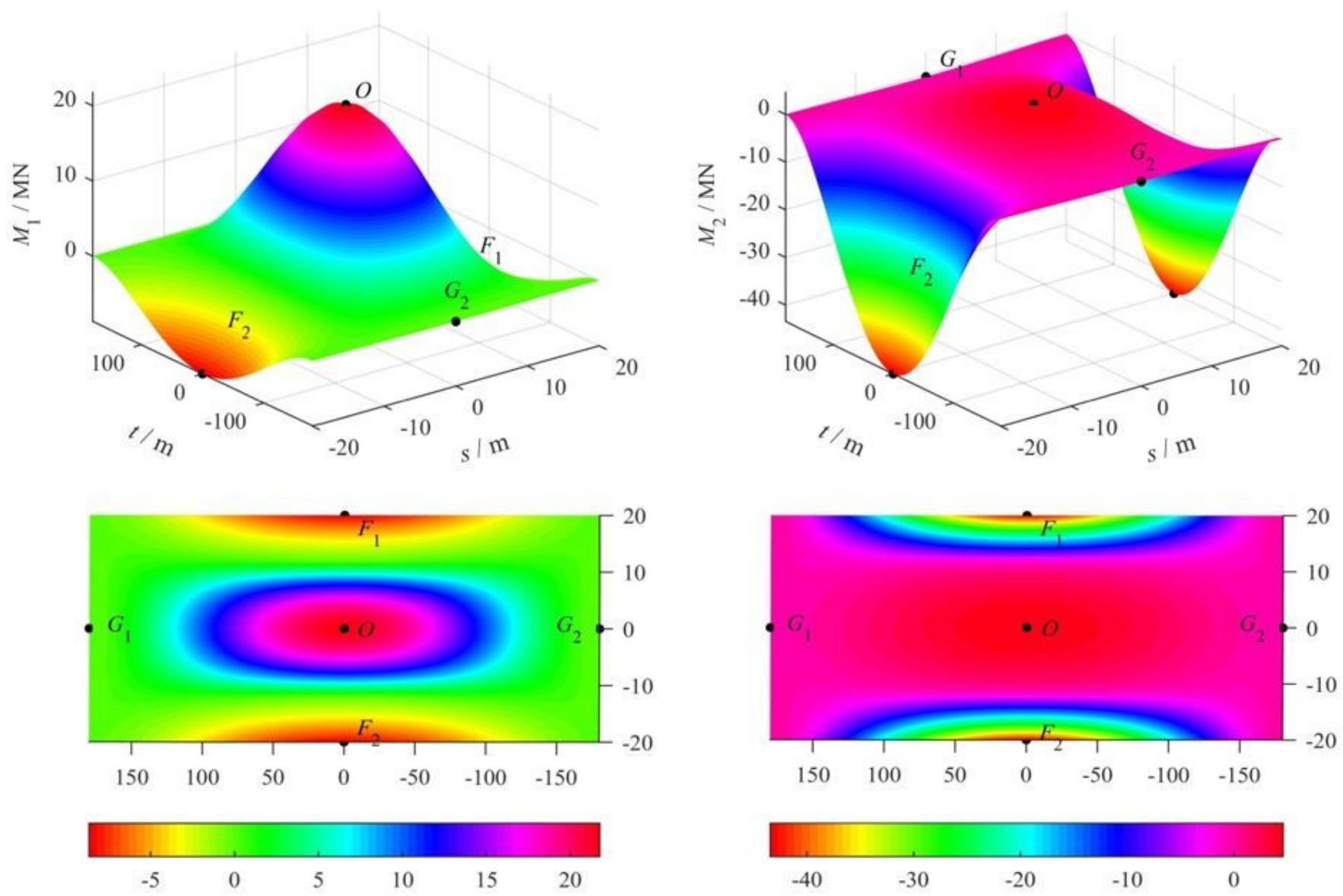

(a) The first principal bending moment

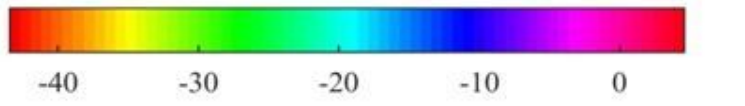

(b) The second principal bending moment

Figure 3

Distribution of main bending moment 


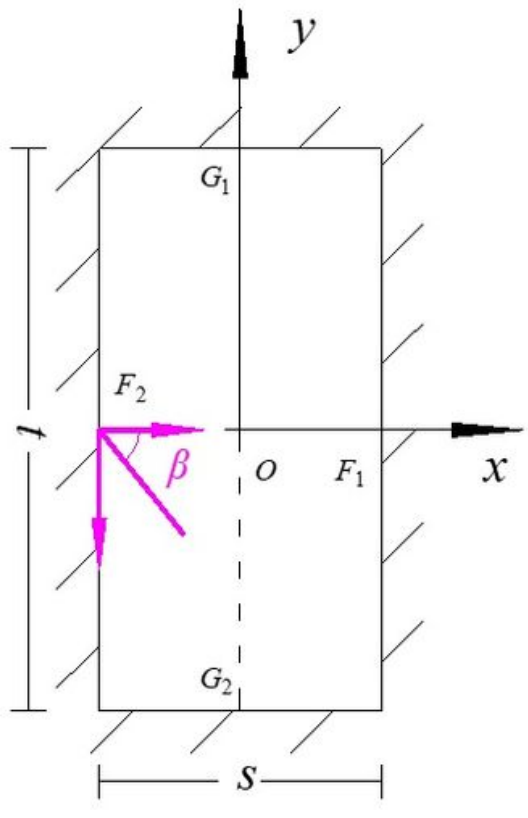

(a)

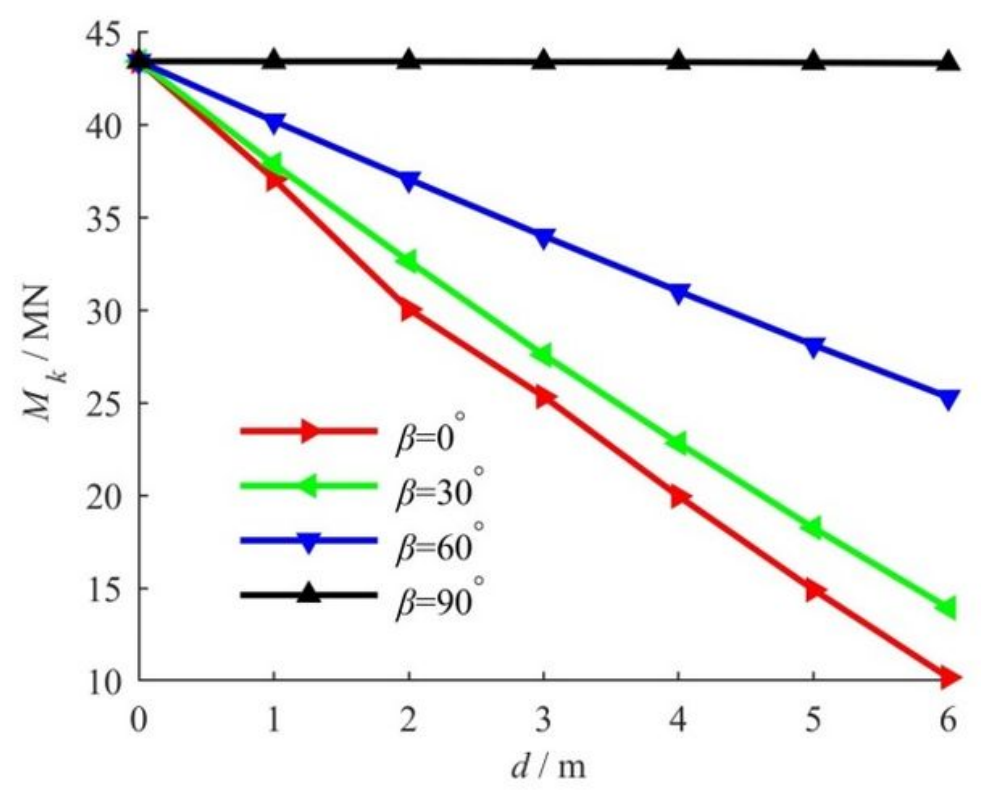

(b)

Figure 4

Variation of Mk of the long side region 


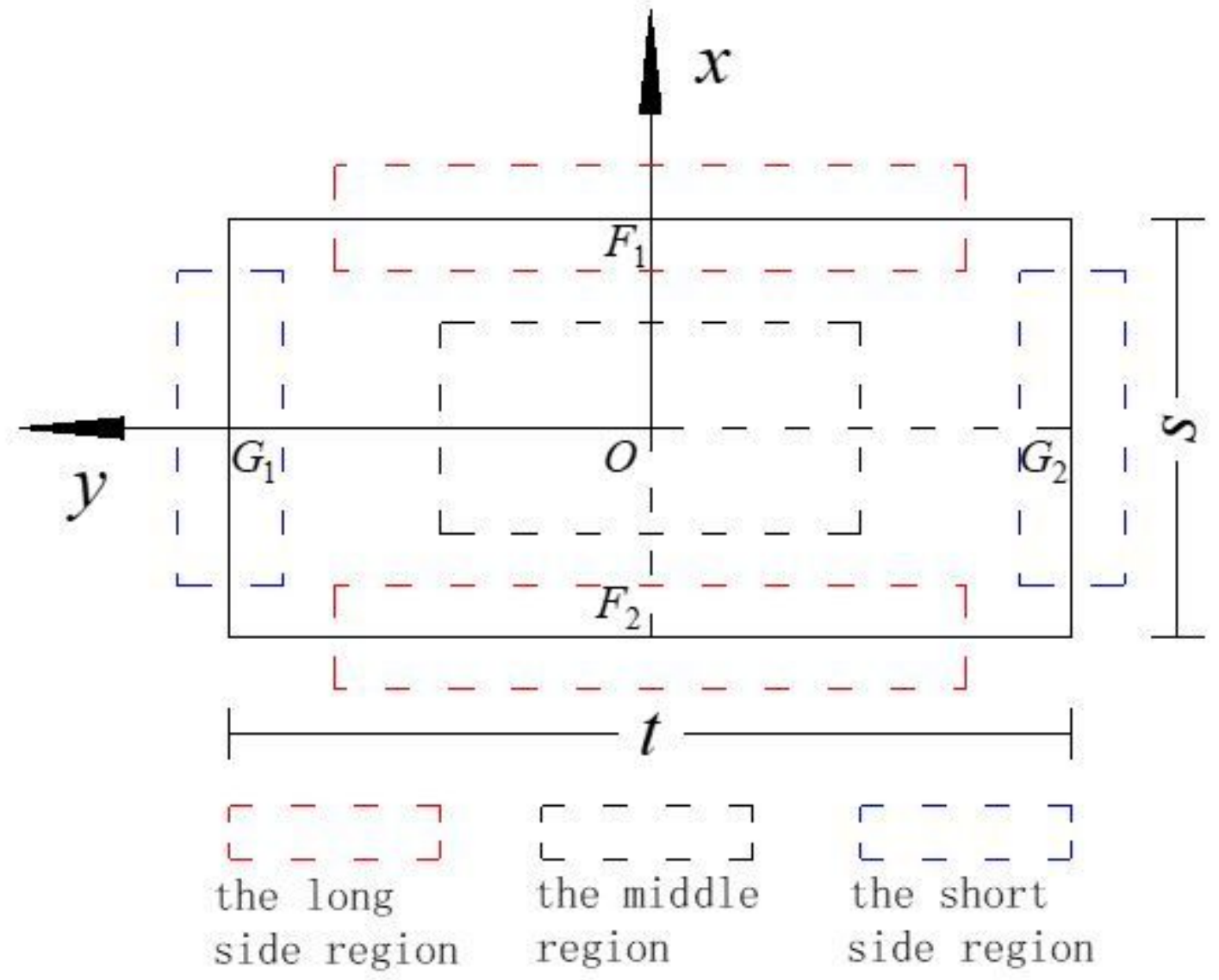

Figure 4

Region division of main roof 


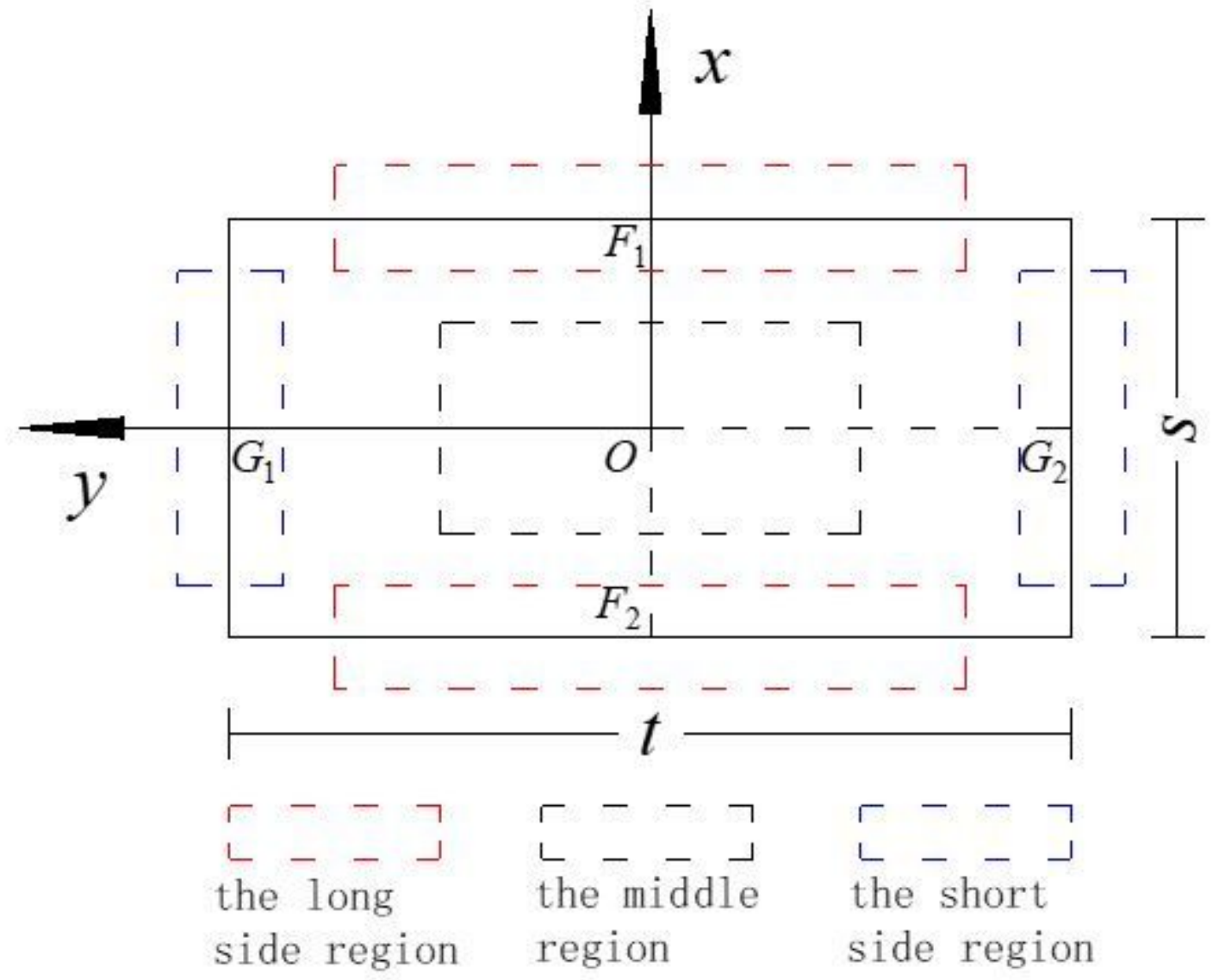

Figure 5

Region division of main roof 


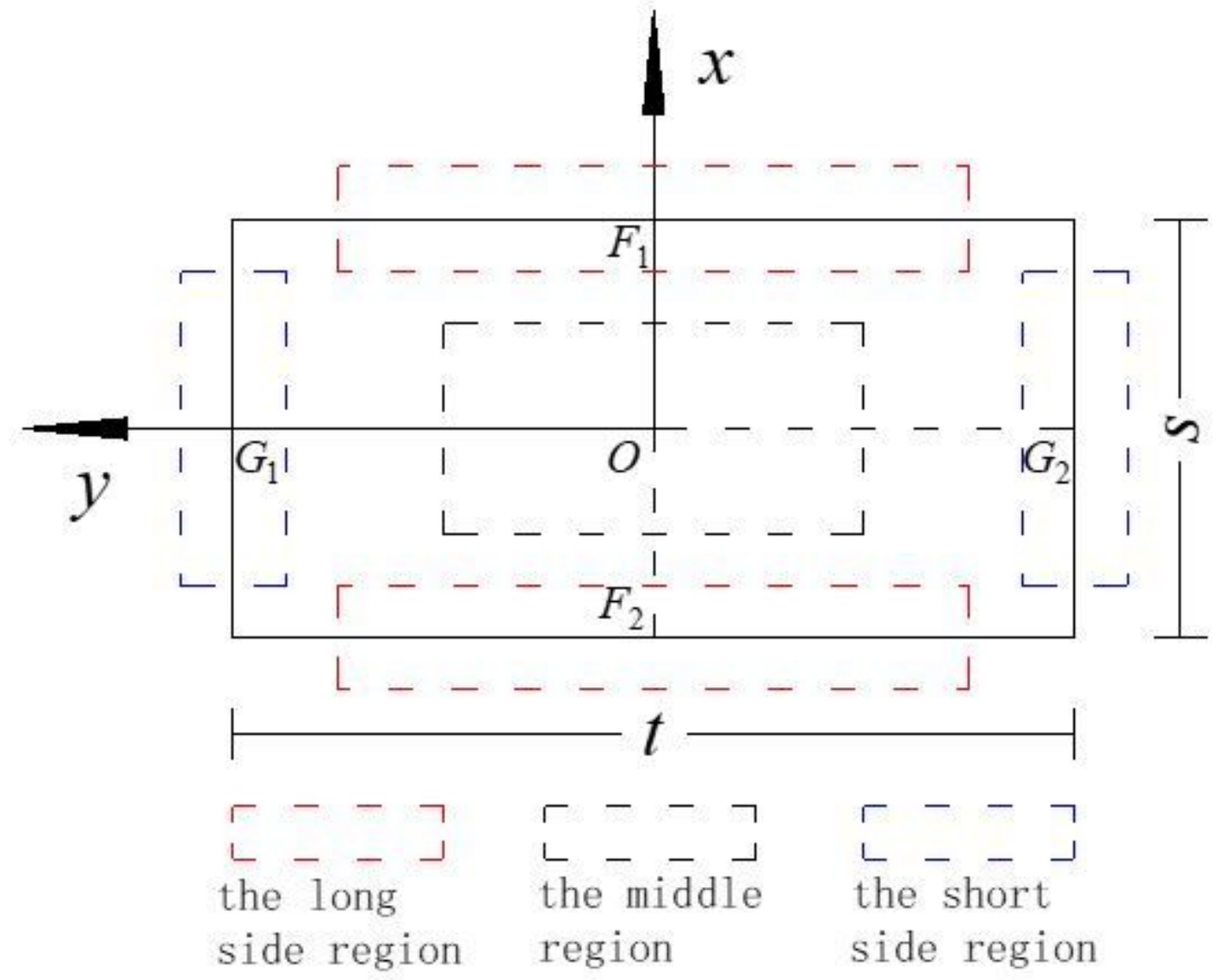

Figure 5

Region division of main roof 


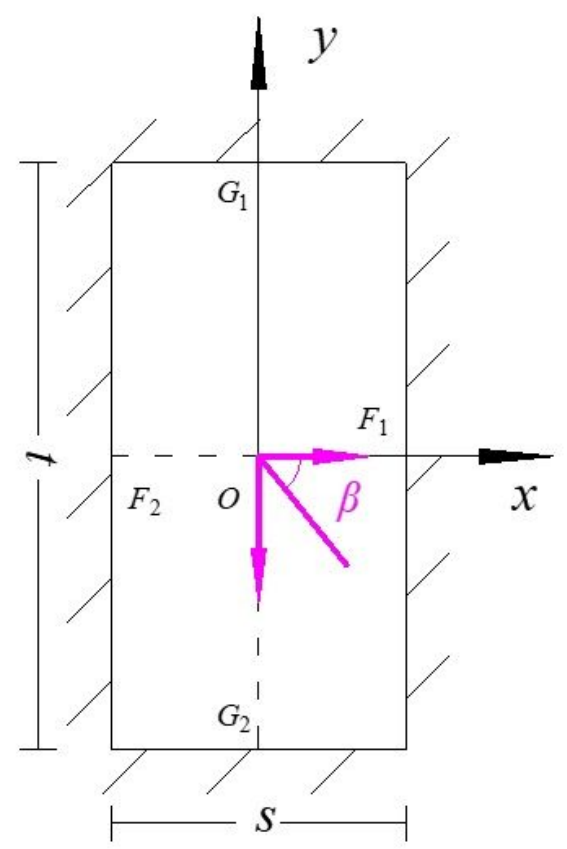

(a)

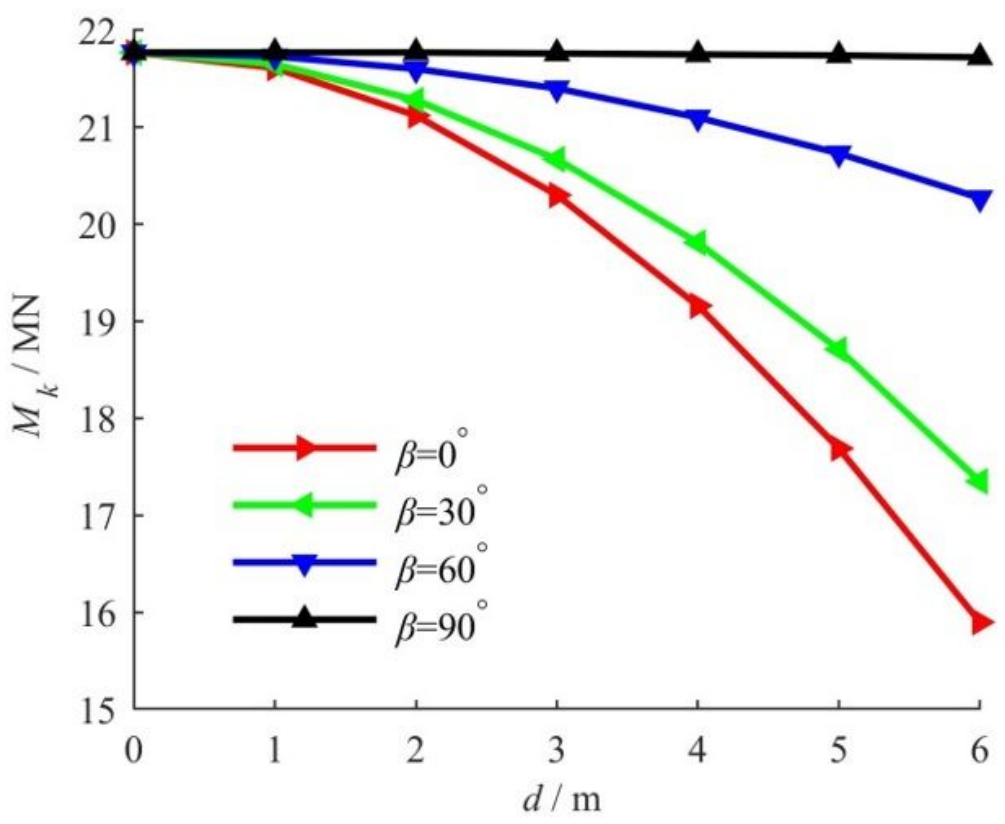

(b)

Figure 6

Variation of Mk of the middle region

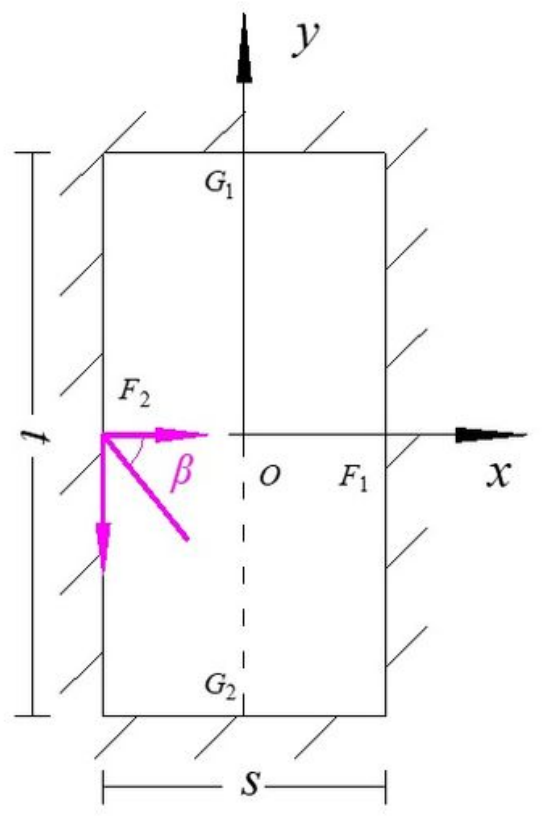

(a)

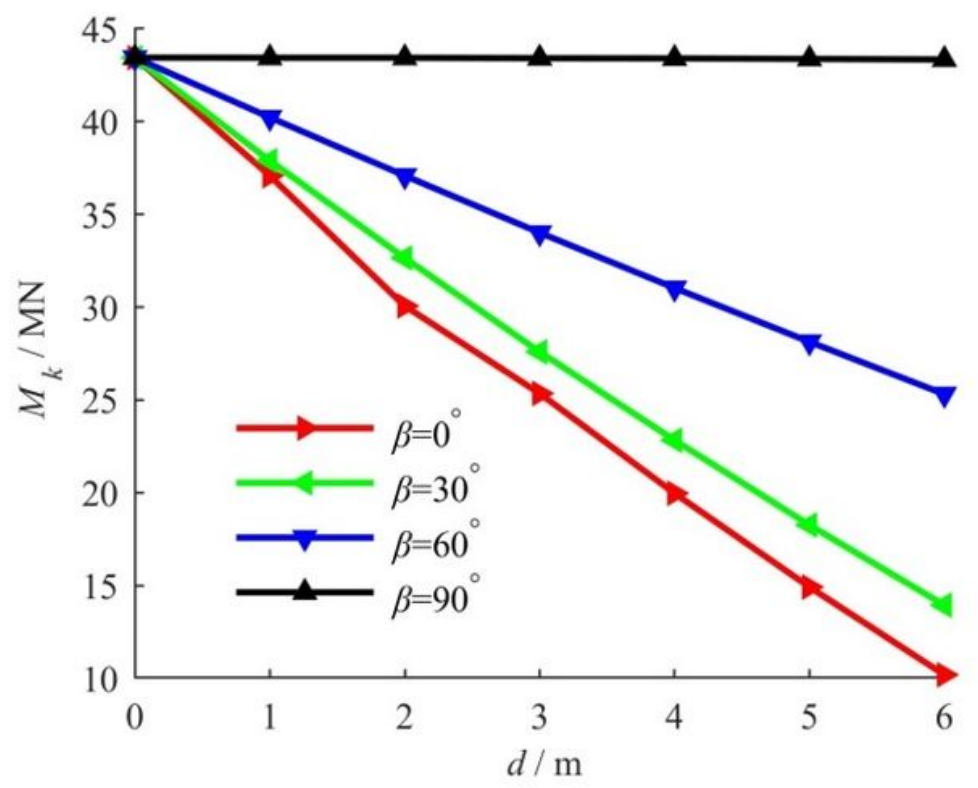

(b) 
Figure 6

Variation of Mk of the long side region
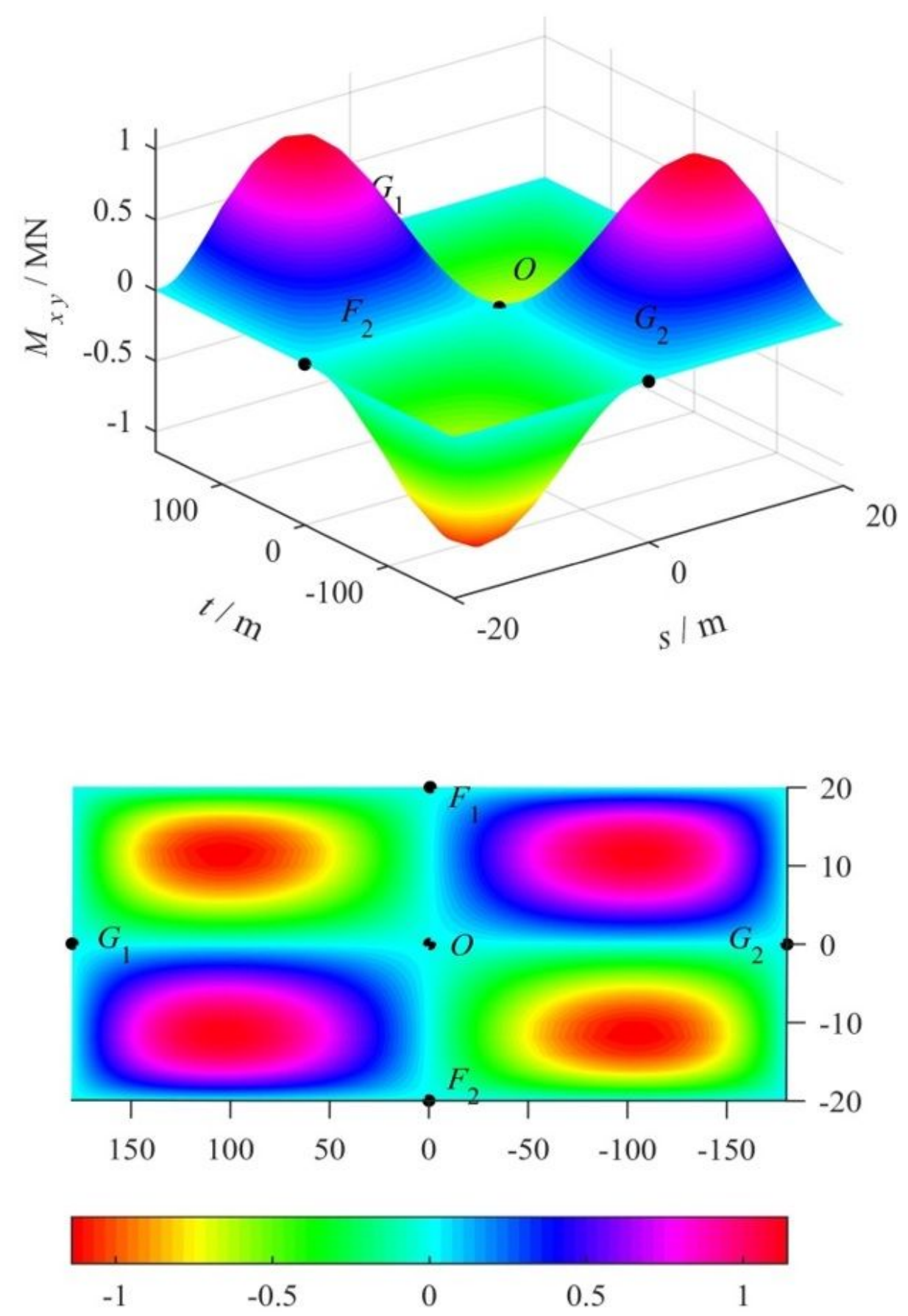

Figure 7

Distribution of torque 

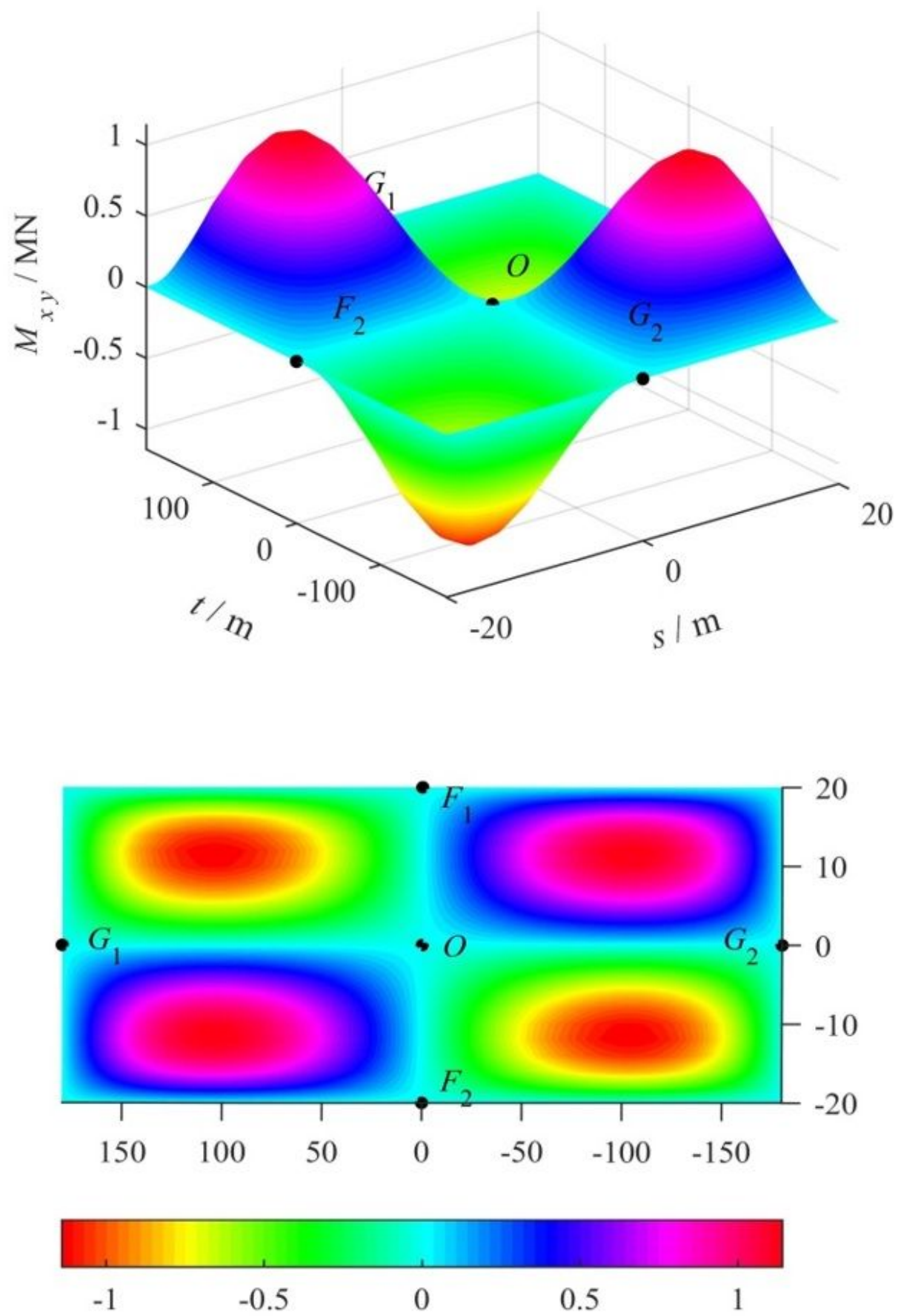

Figure 7

Distribution of torque 

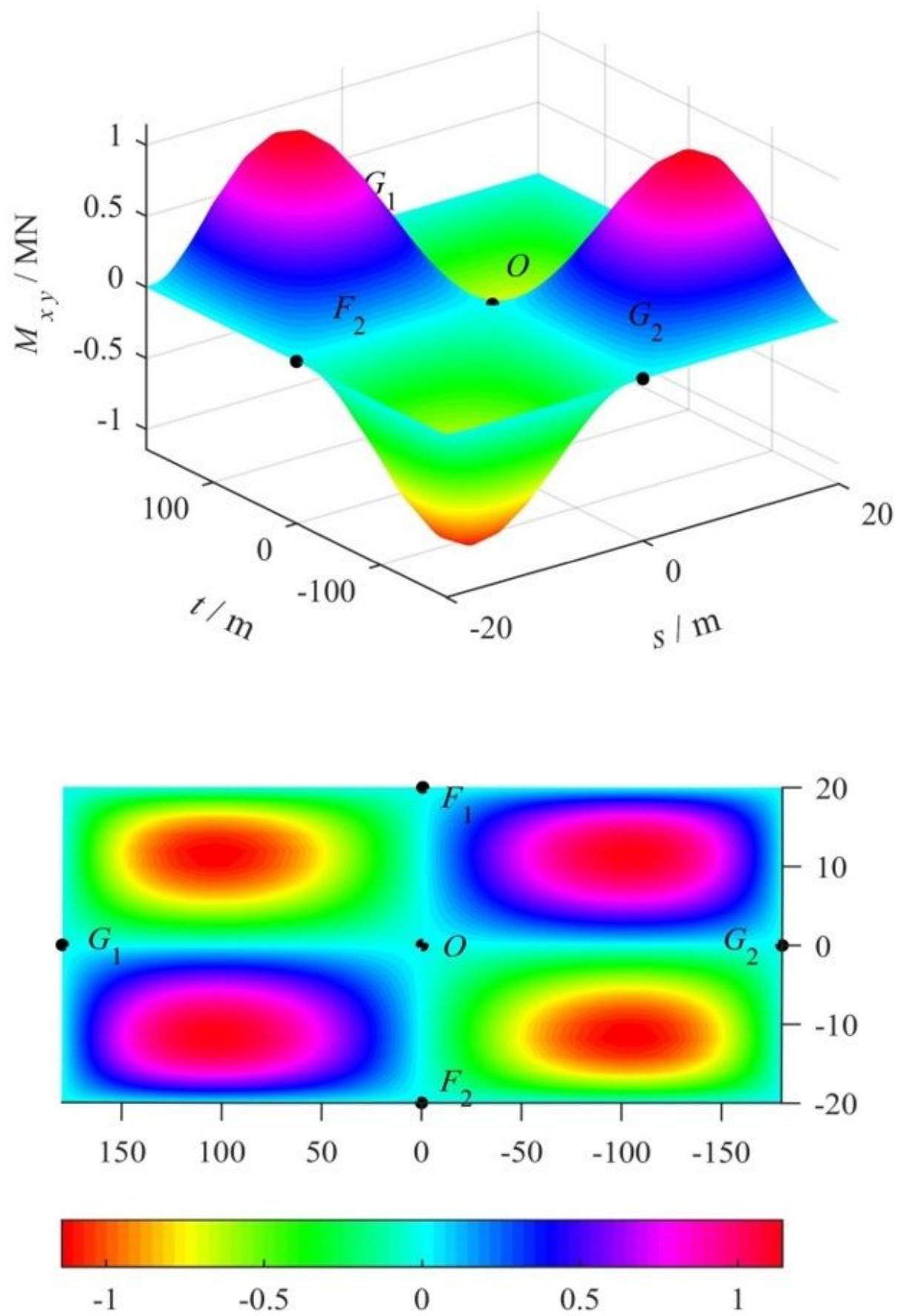

Figure 7

Distribution of torque 


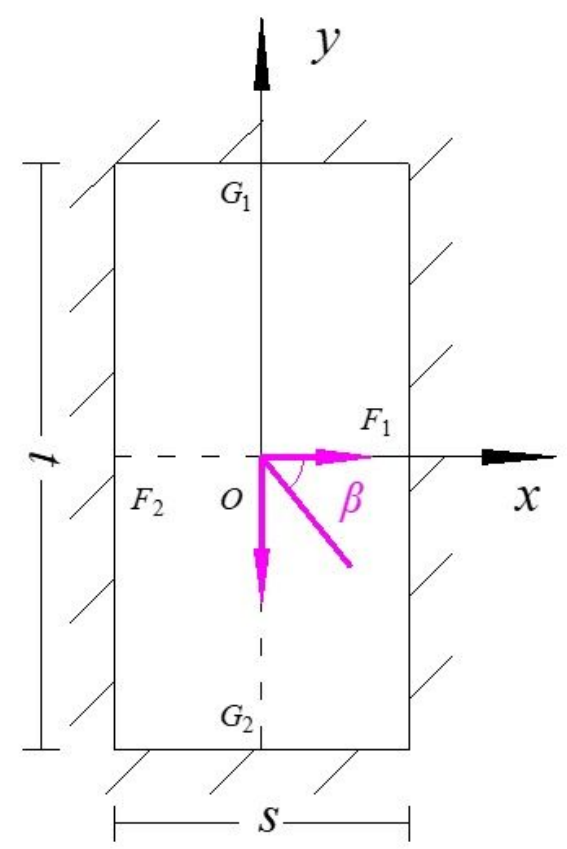

(a)

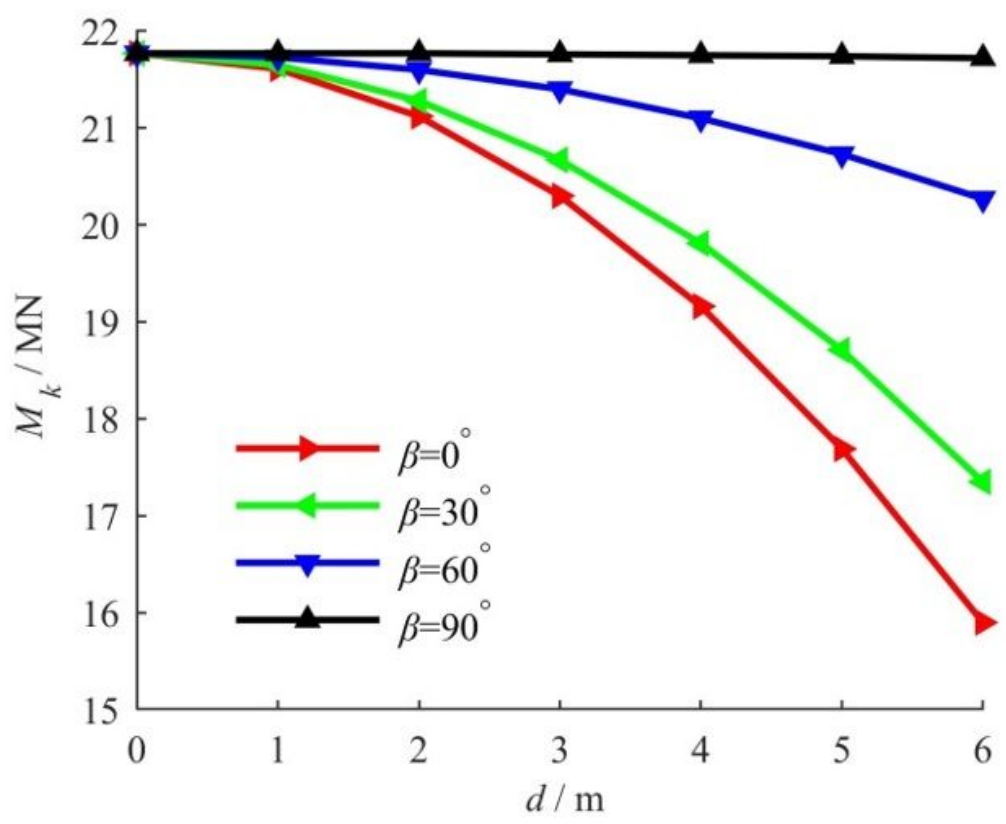

(b)

Figure 8

Variation of Mk of the middle region

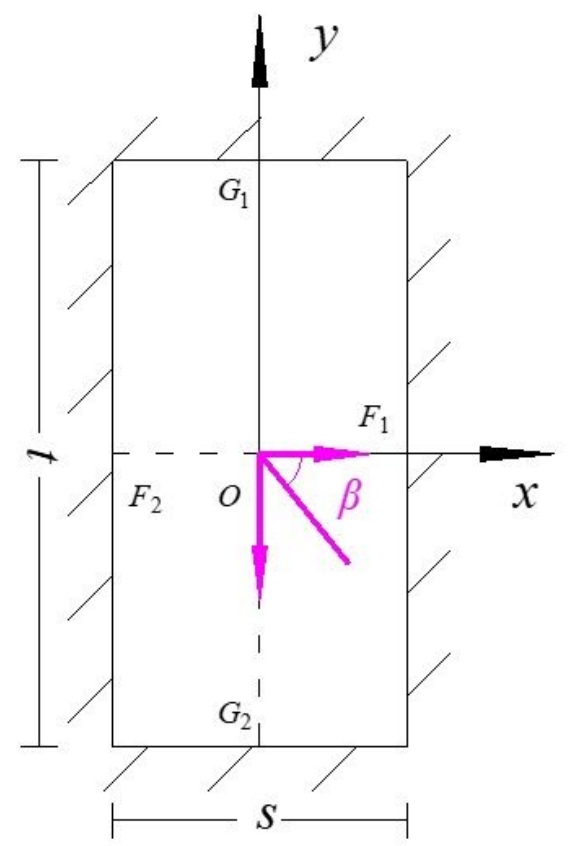

(a)

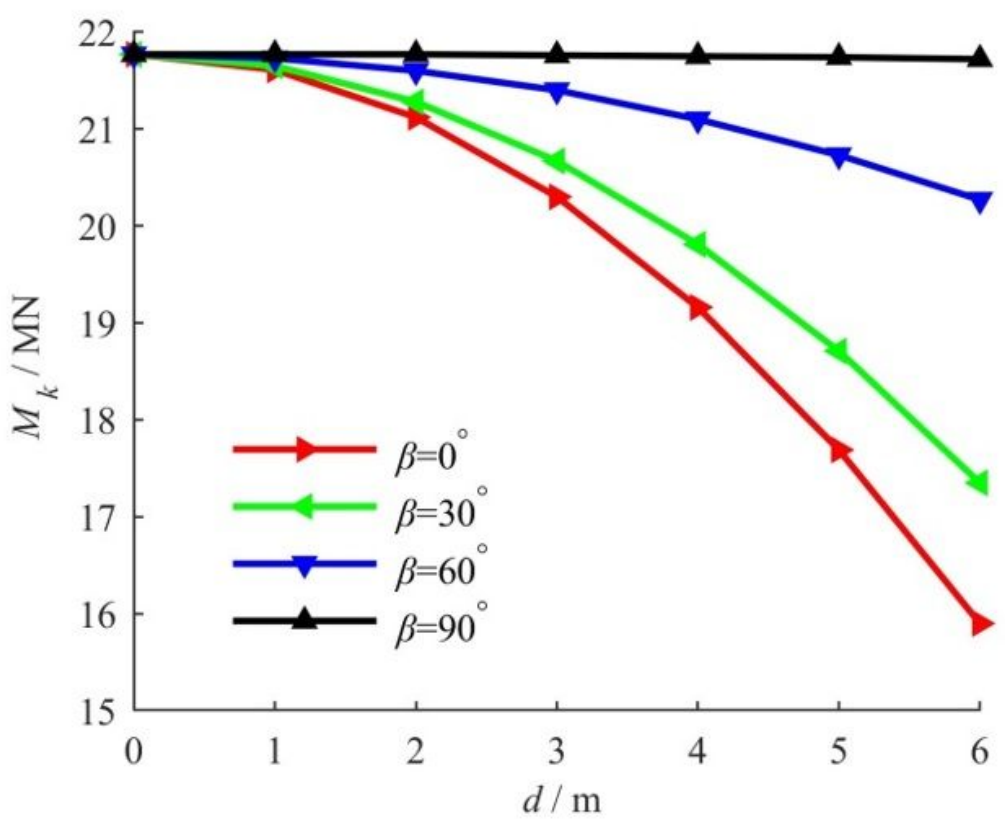

(b)

Figure 8 
Variation of $\mathrm{Mk}$ of the middle region

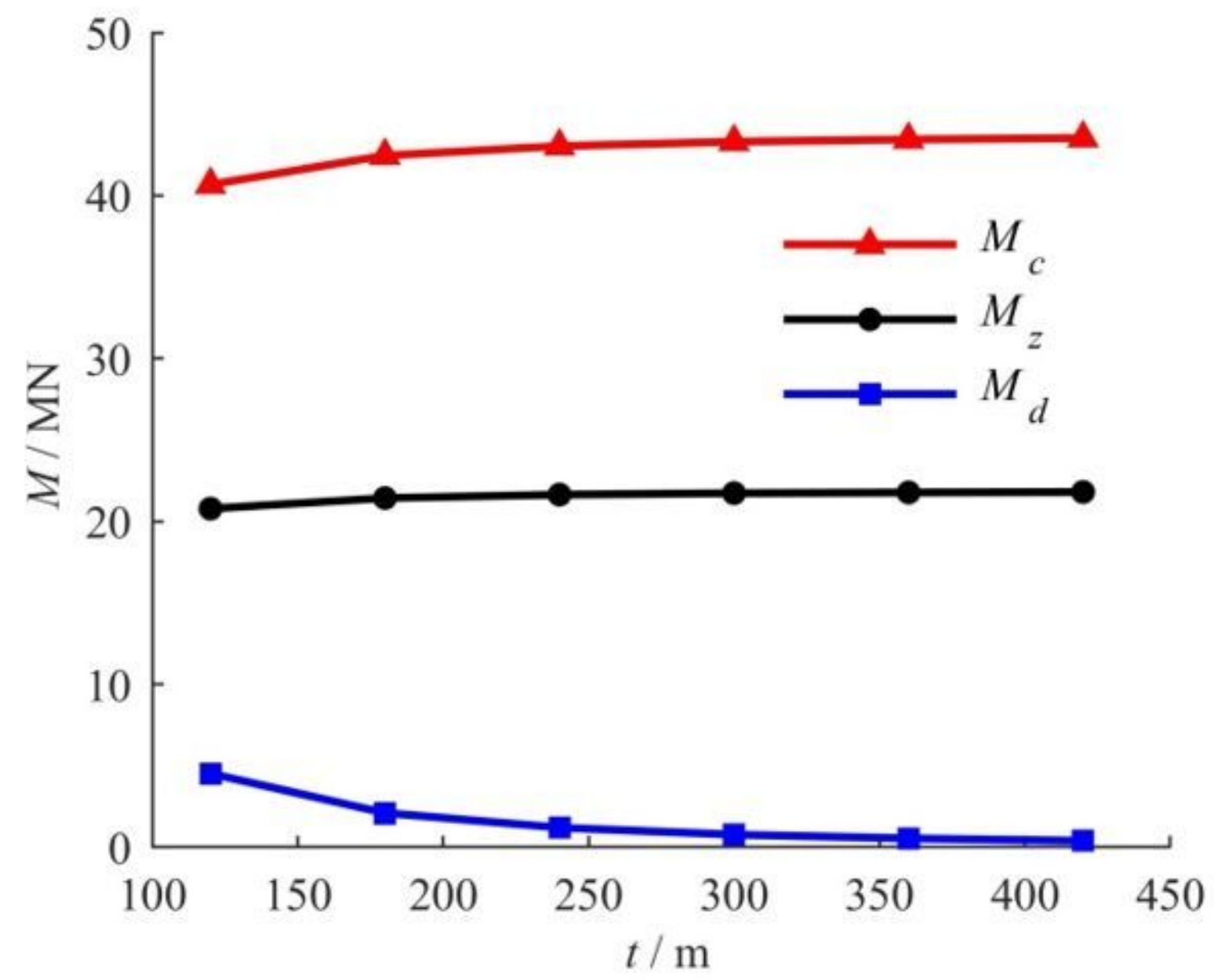

Figure 9

The effect of $t$ 


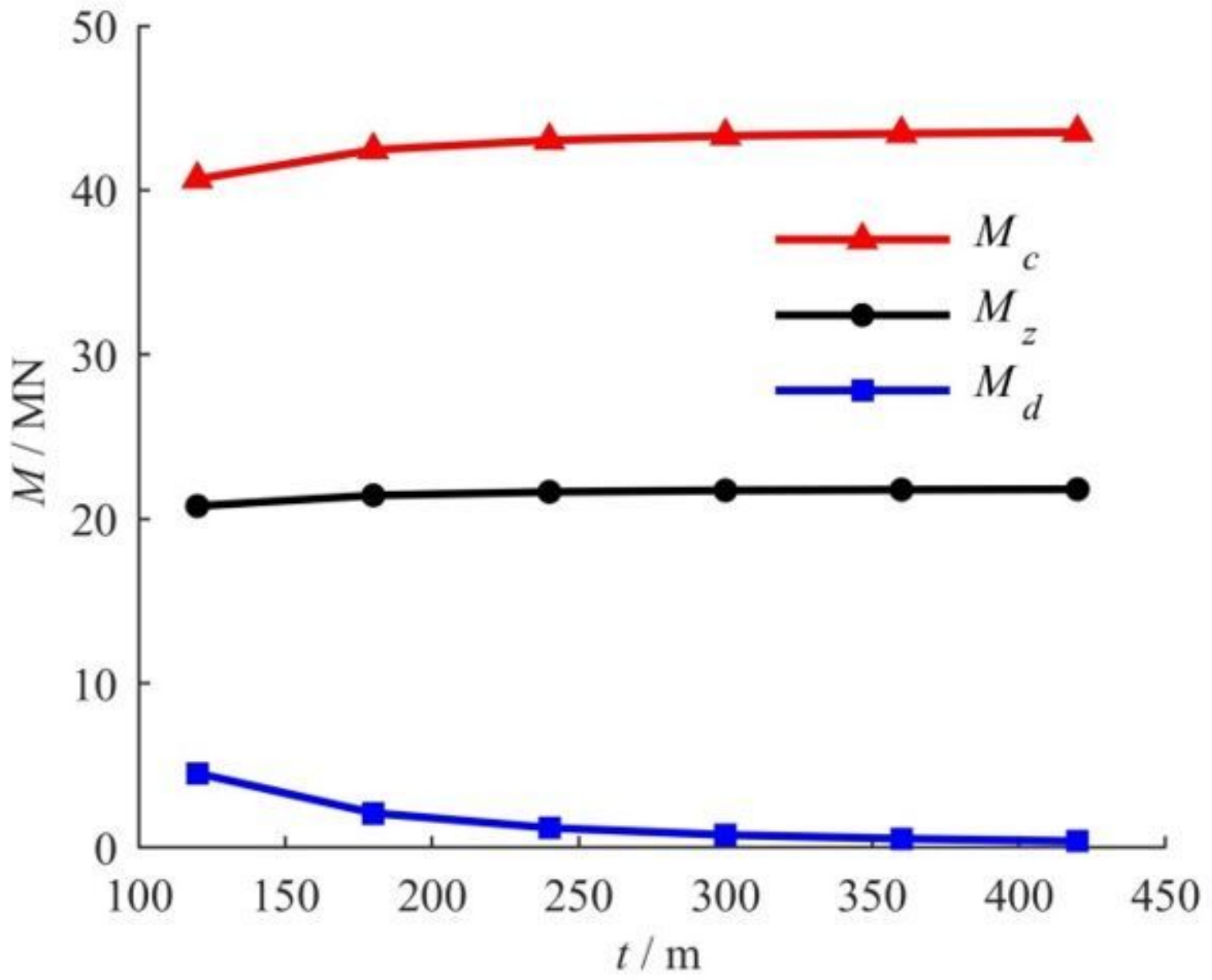

Figure 9

The effect of $t$ 


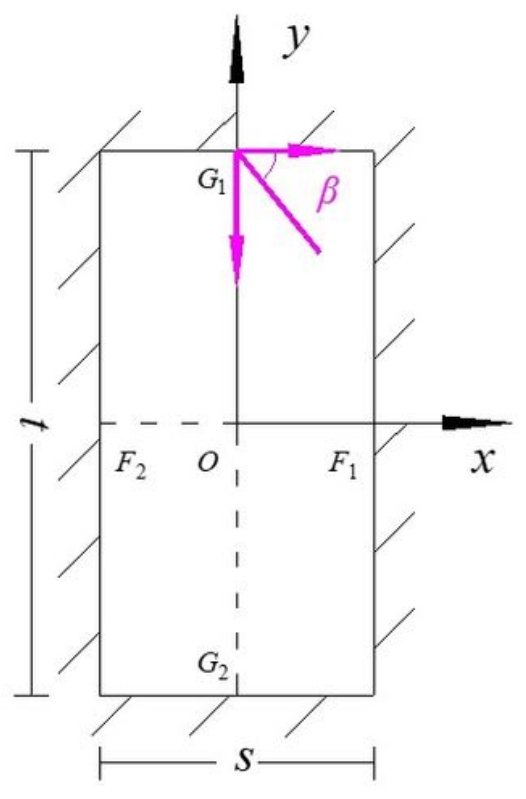

(a)

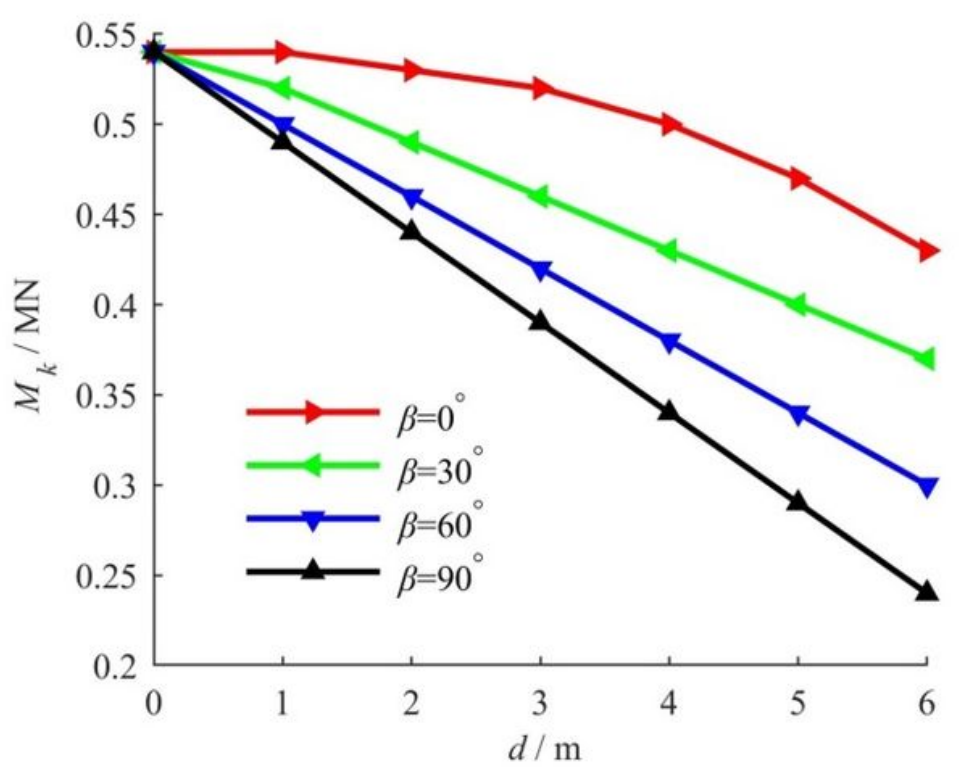

(b)

\section{Figure 9}

Variation of Mk of the short side region

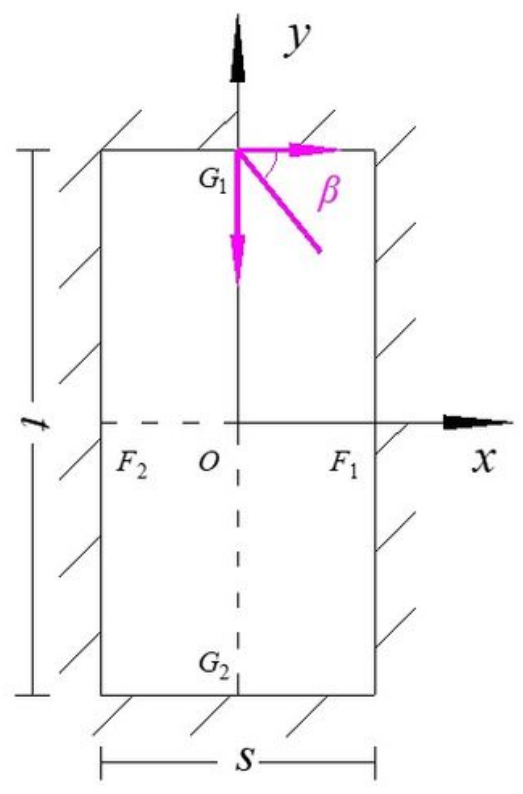

(a)

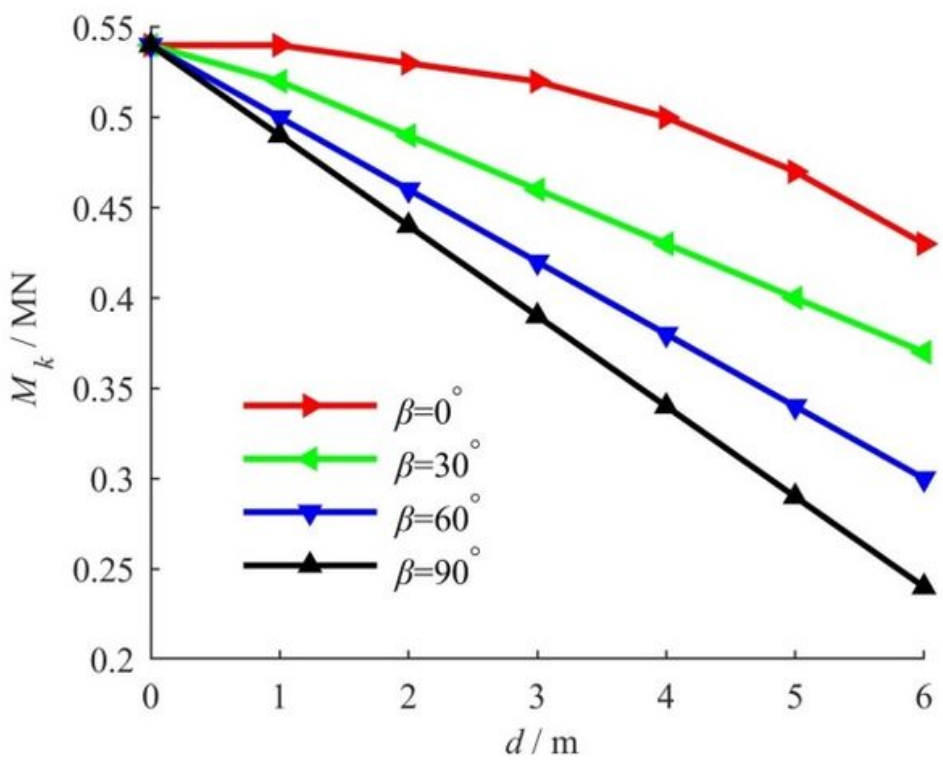

(b) 
Figure 9

Variation of $\mathrm{Mk}$ of the short side region

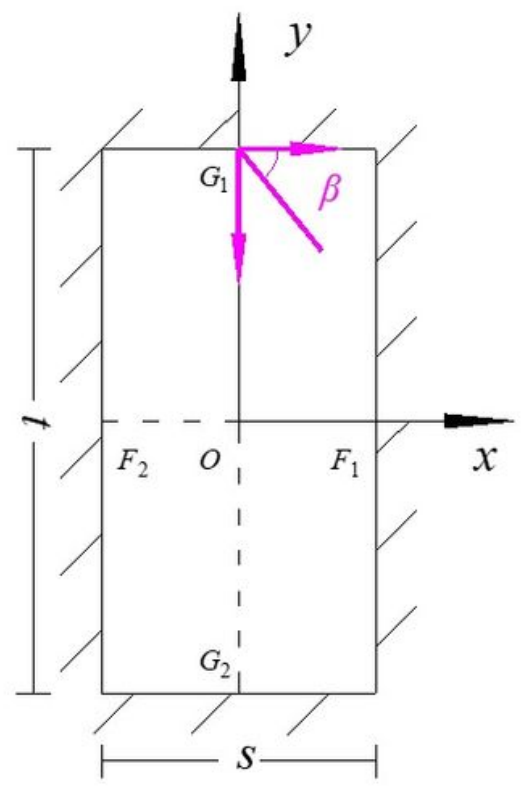

(a)

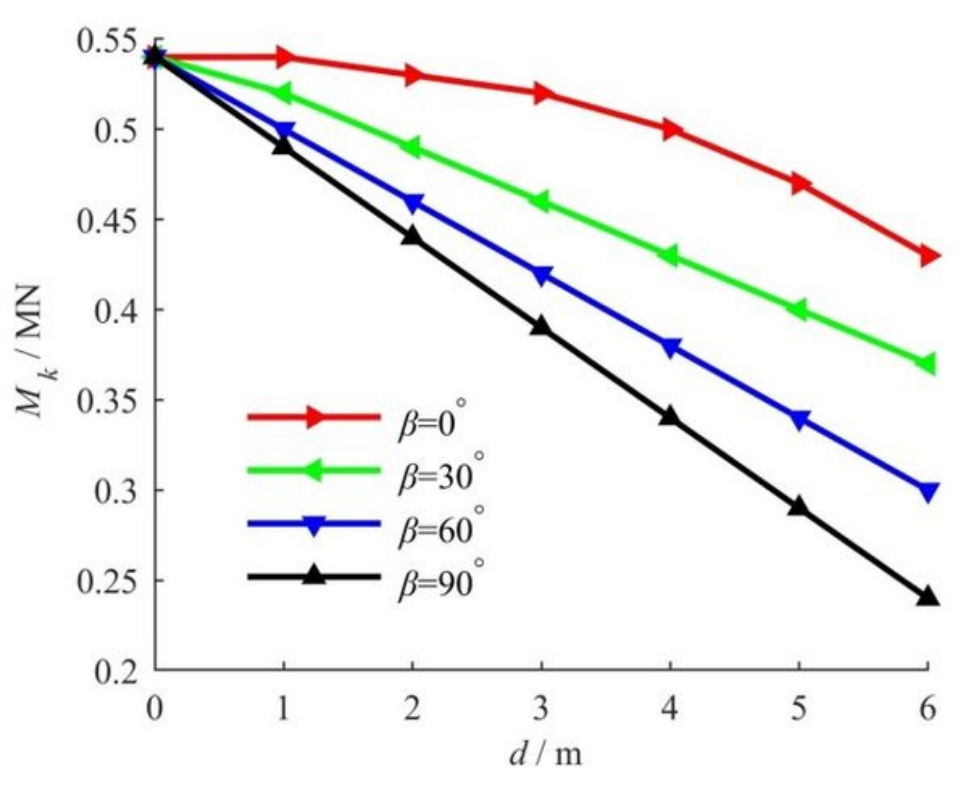

(b)

\section{Figure 9}

Variation of Mk of the short side region 


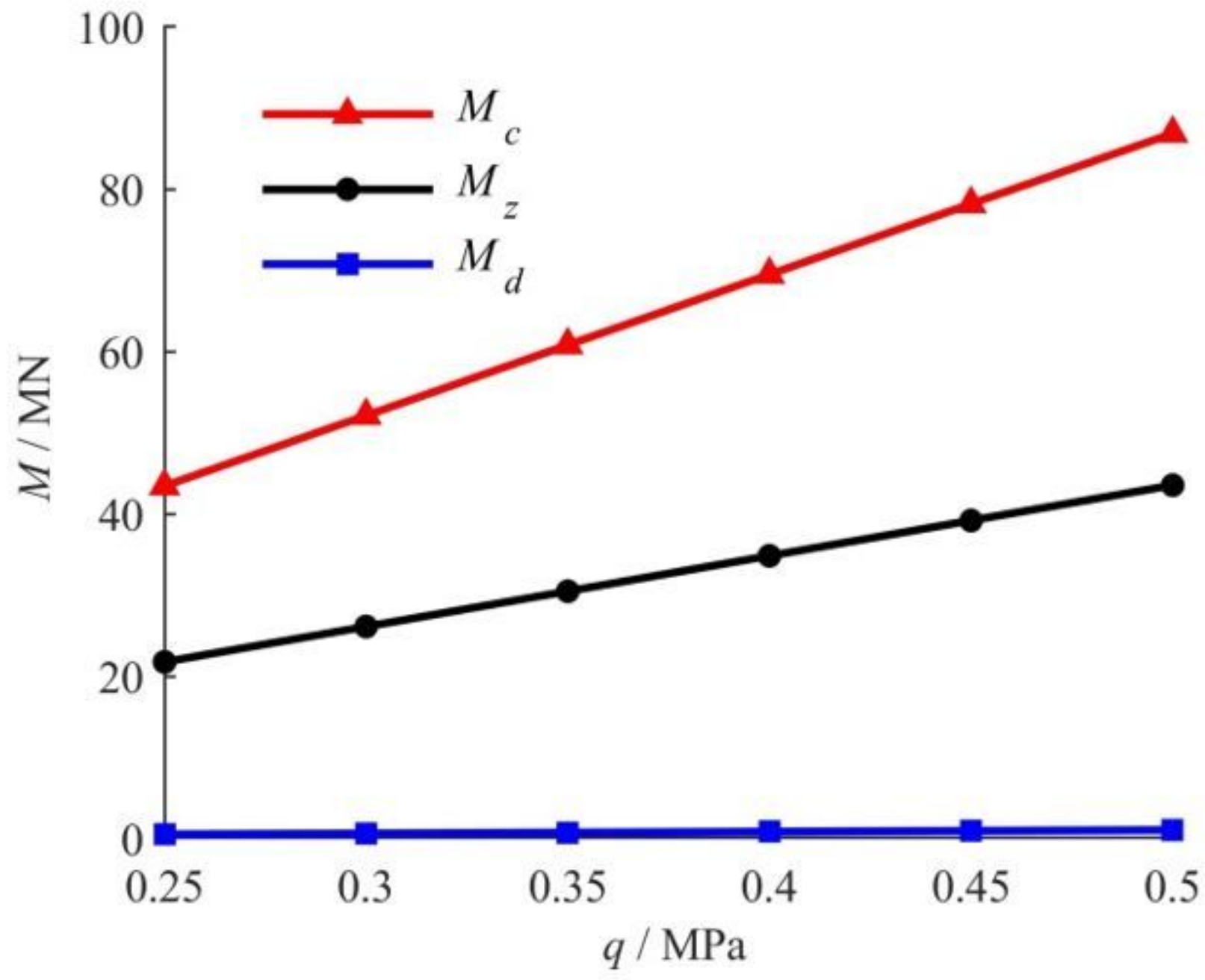

Figure 10

The effect of q 


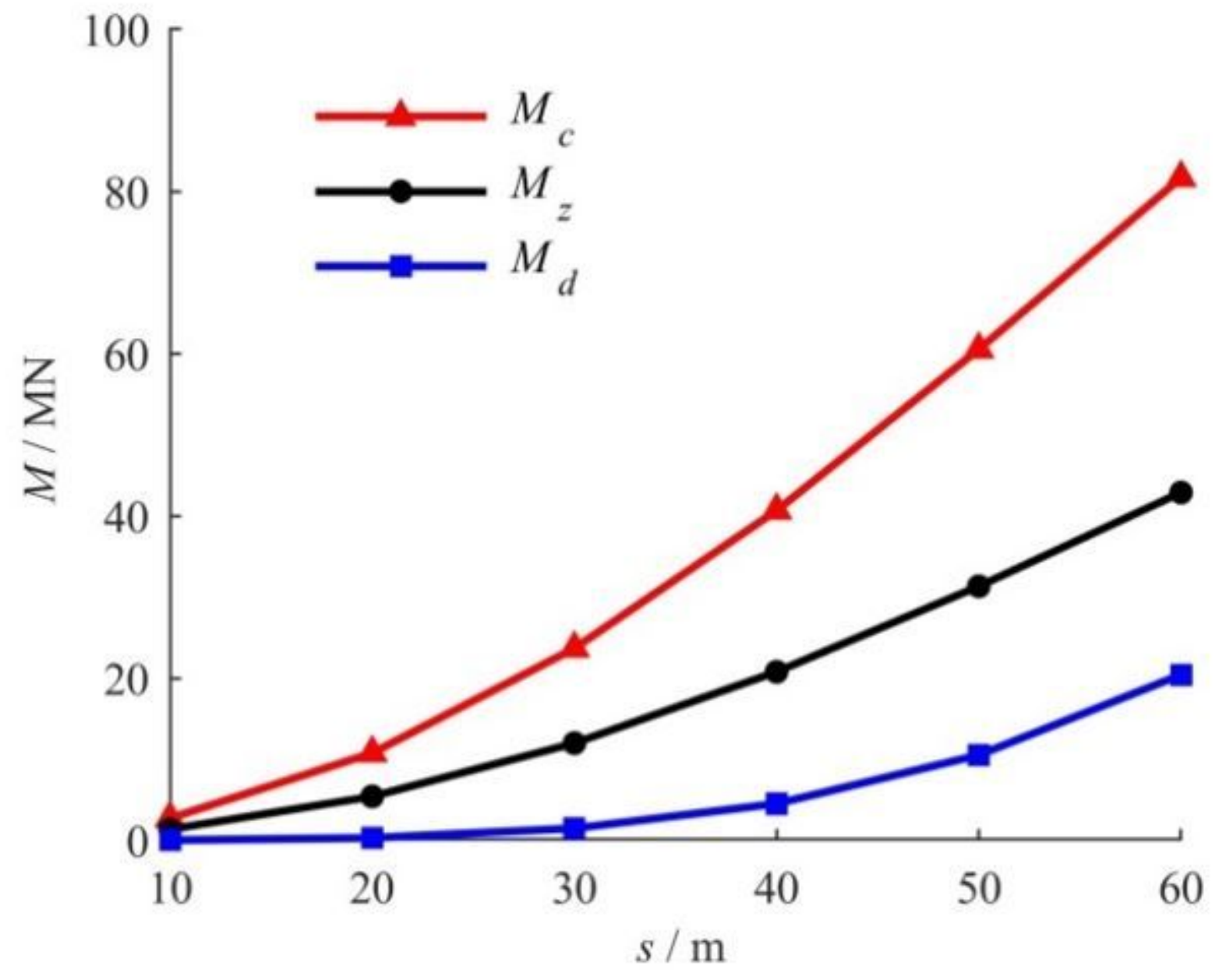

Figure 10

The effect of $s$ 


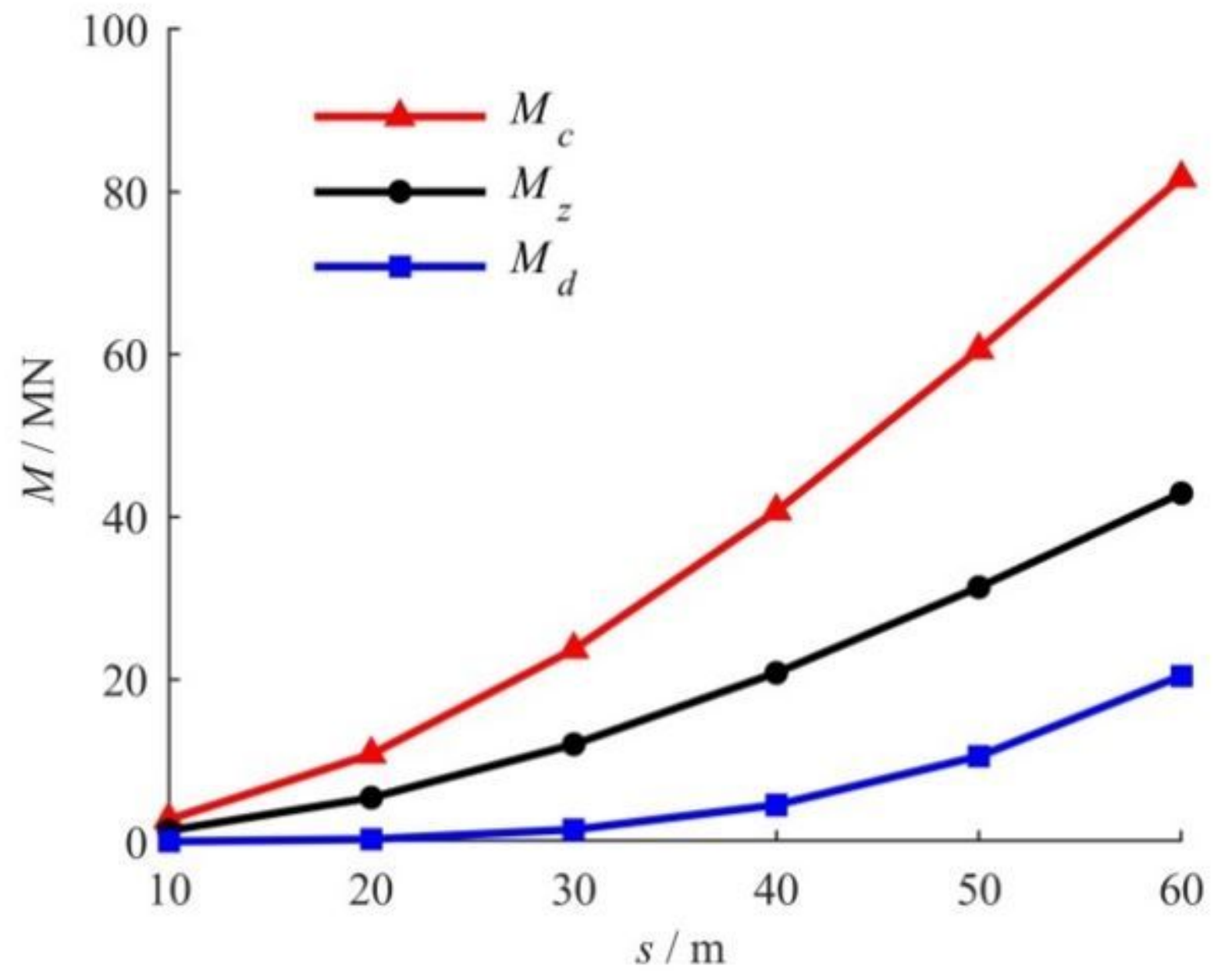

Figure 10

The effect of $s$ 


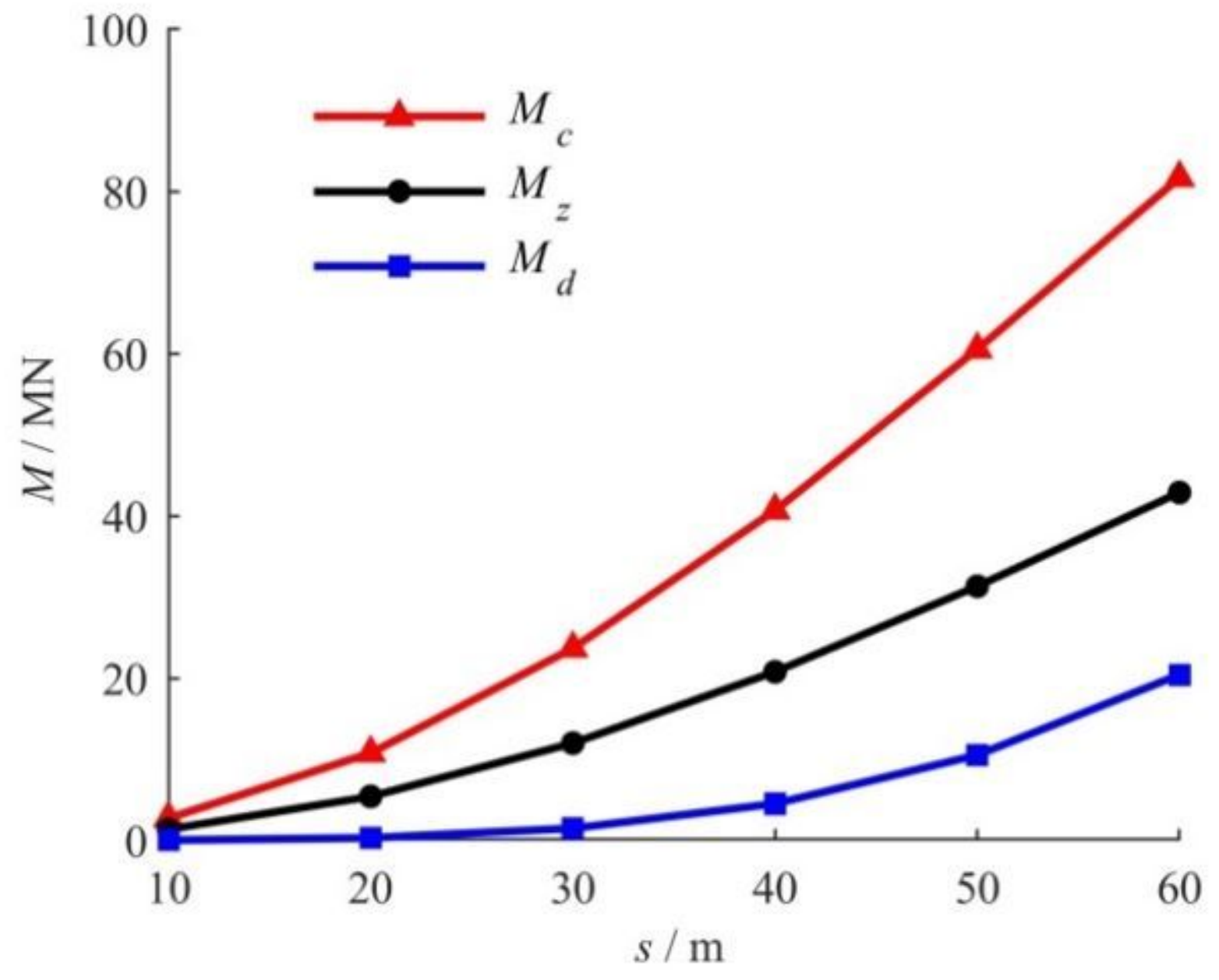

Figure 10

The effect of $s$ 


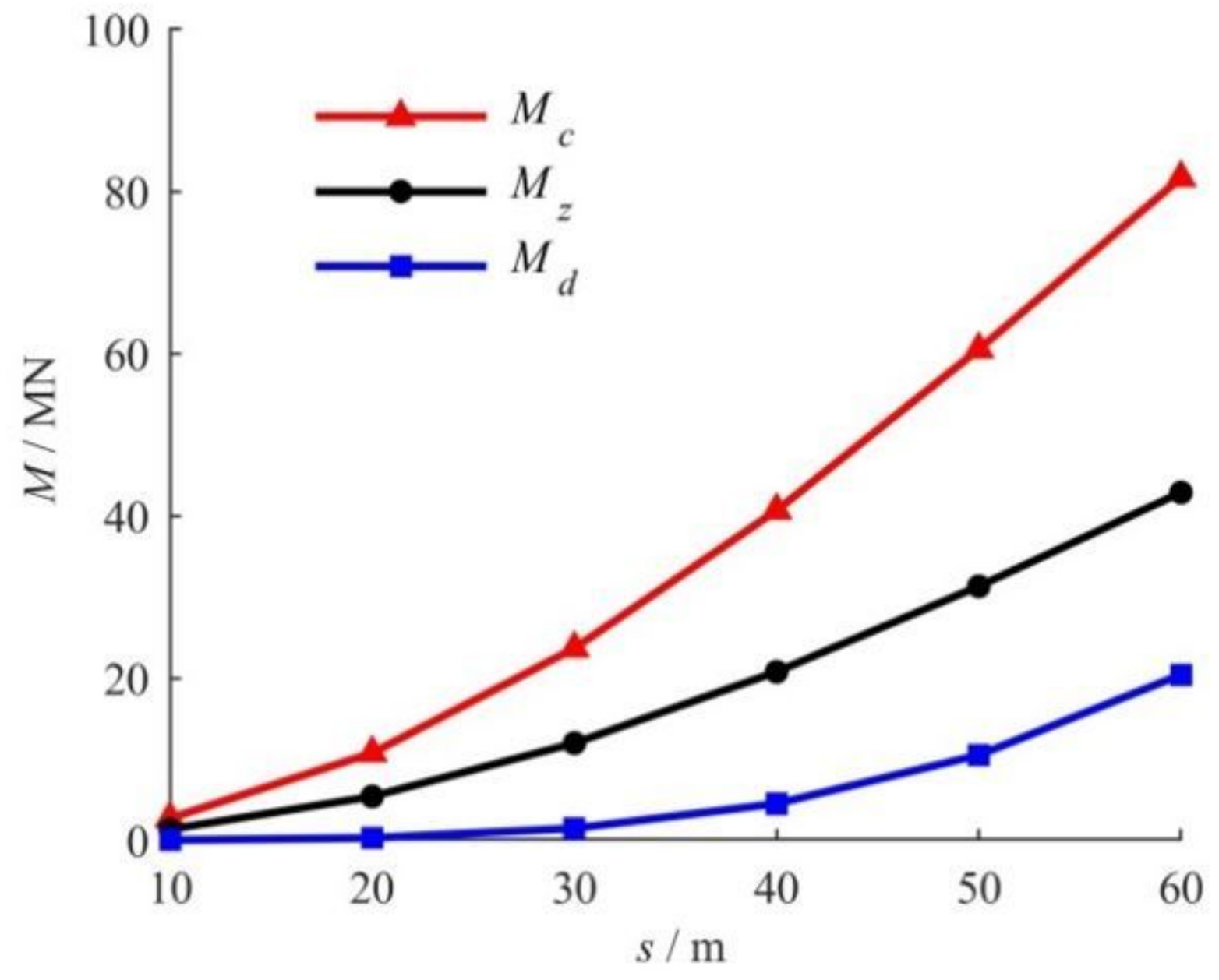

Figure 10

The effect of $s$ 


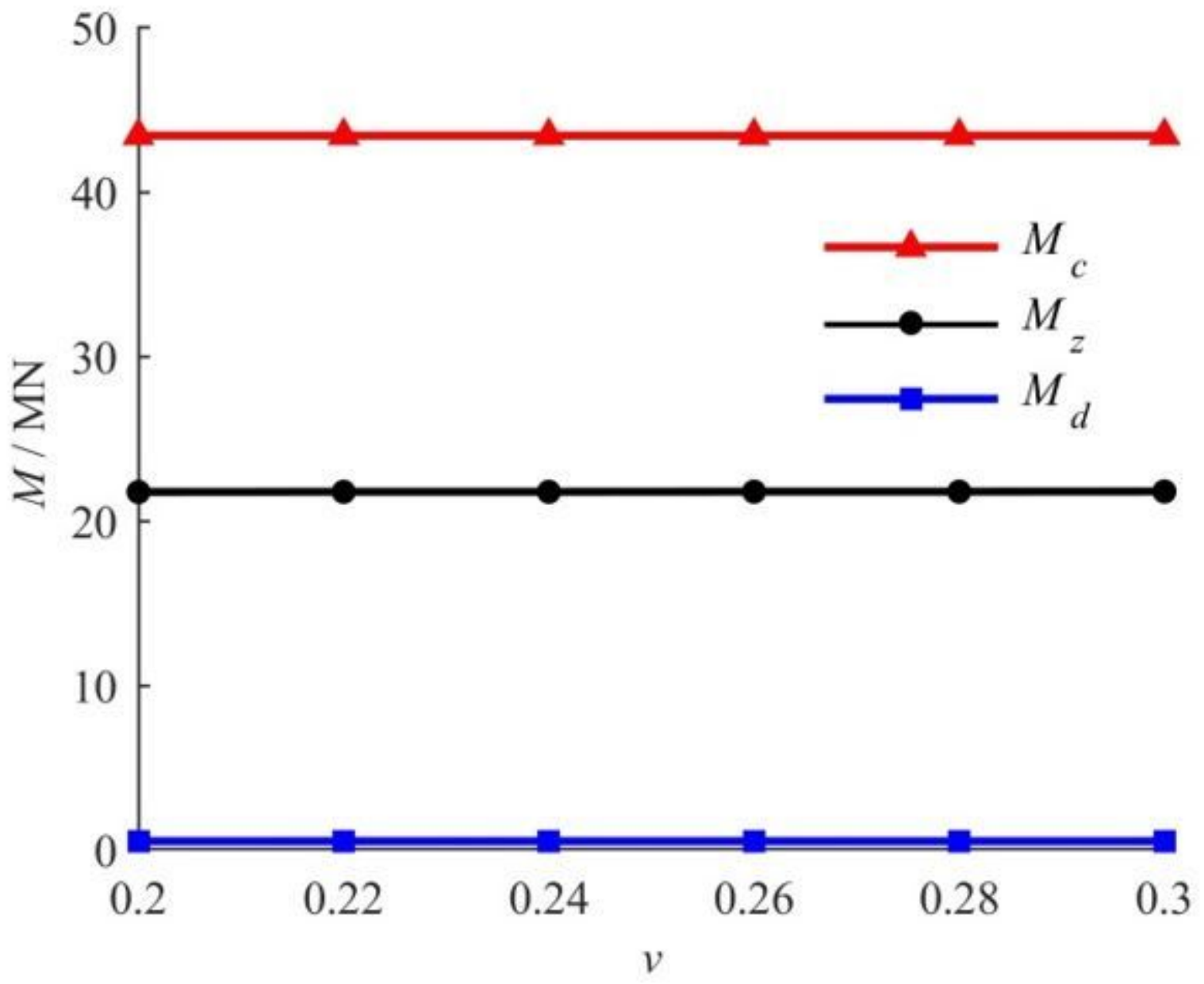

Figure 11

The effect of $v$ 


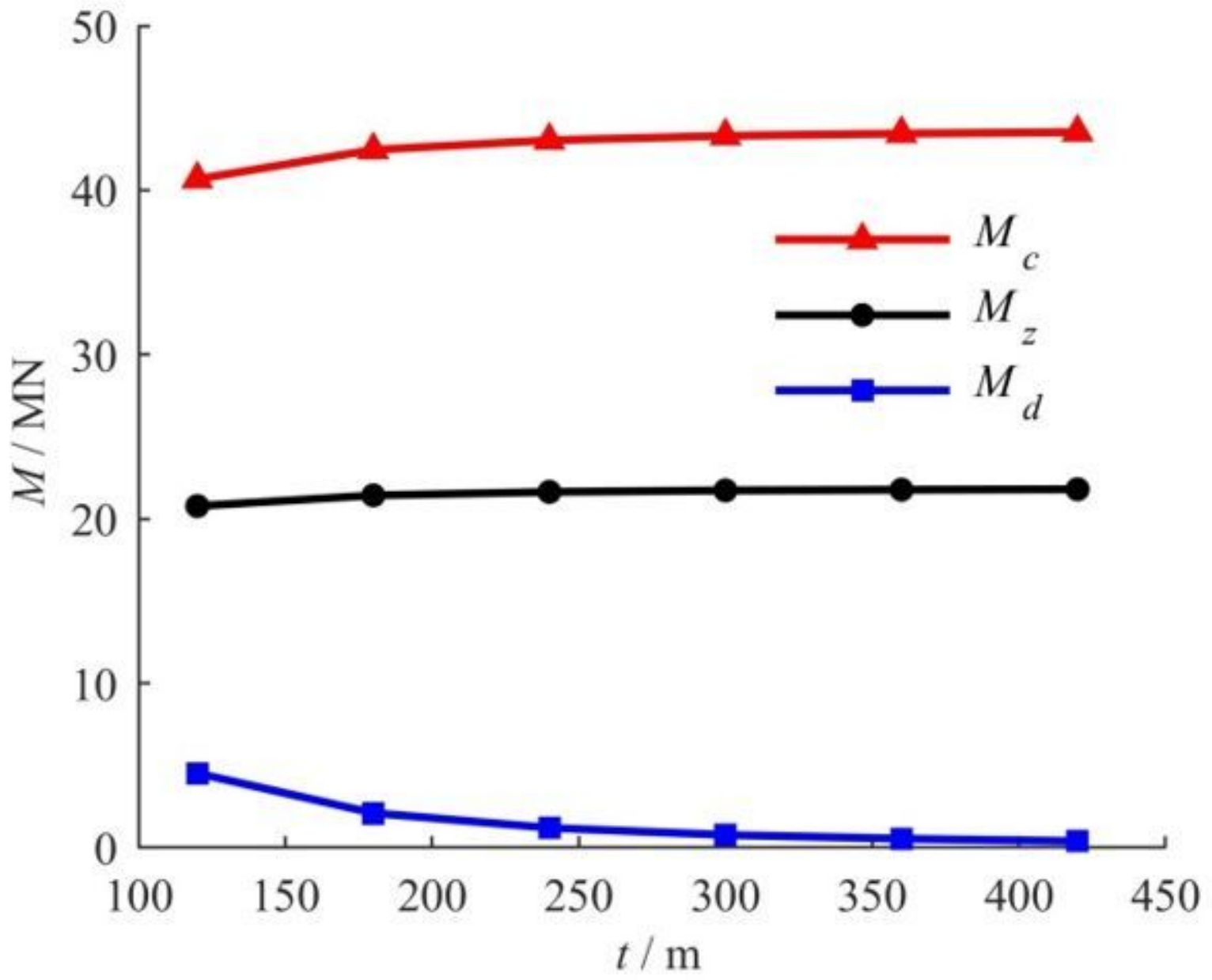

Figure 11

The effect of $t$ 


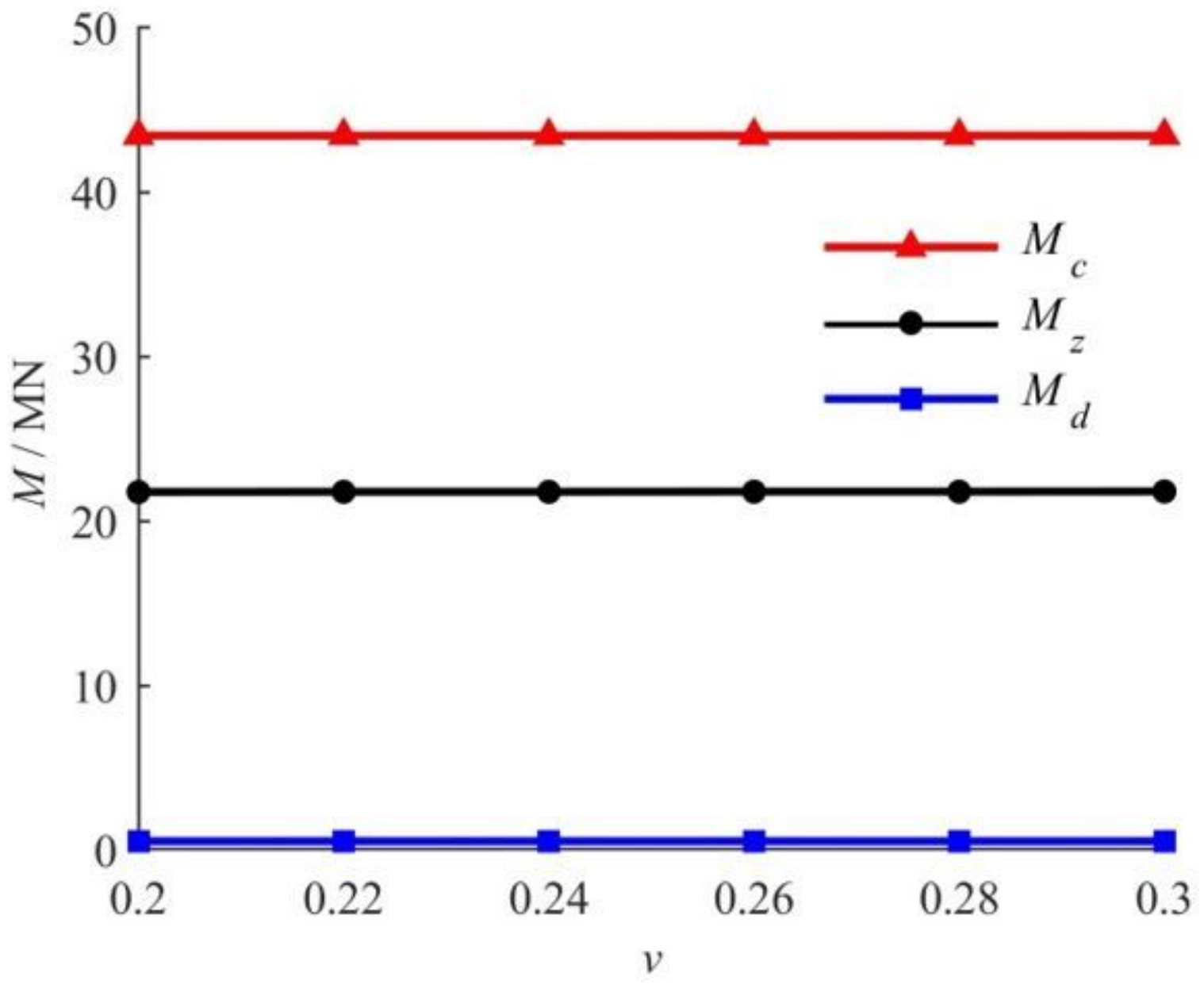

Figure 11

The effect of $v$ 


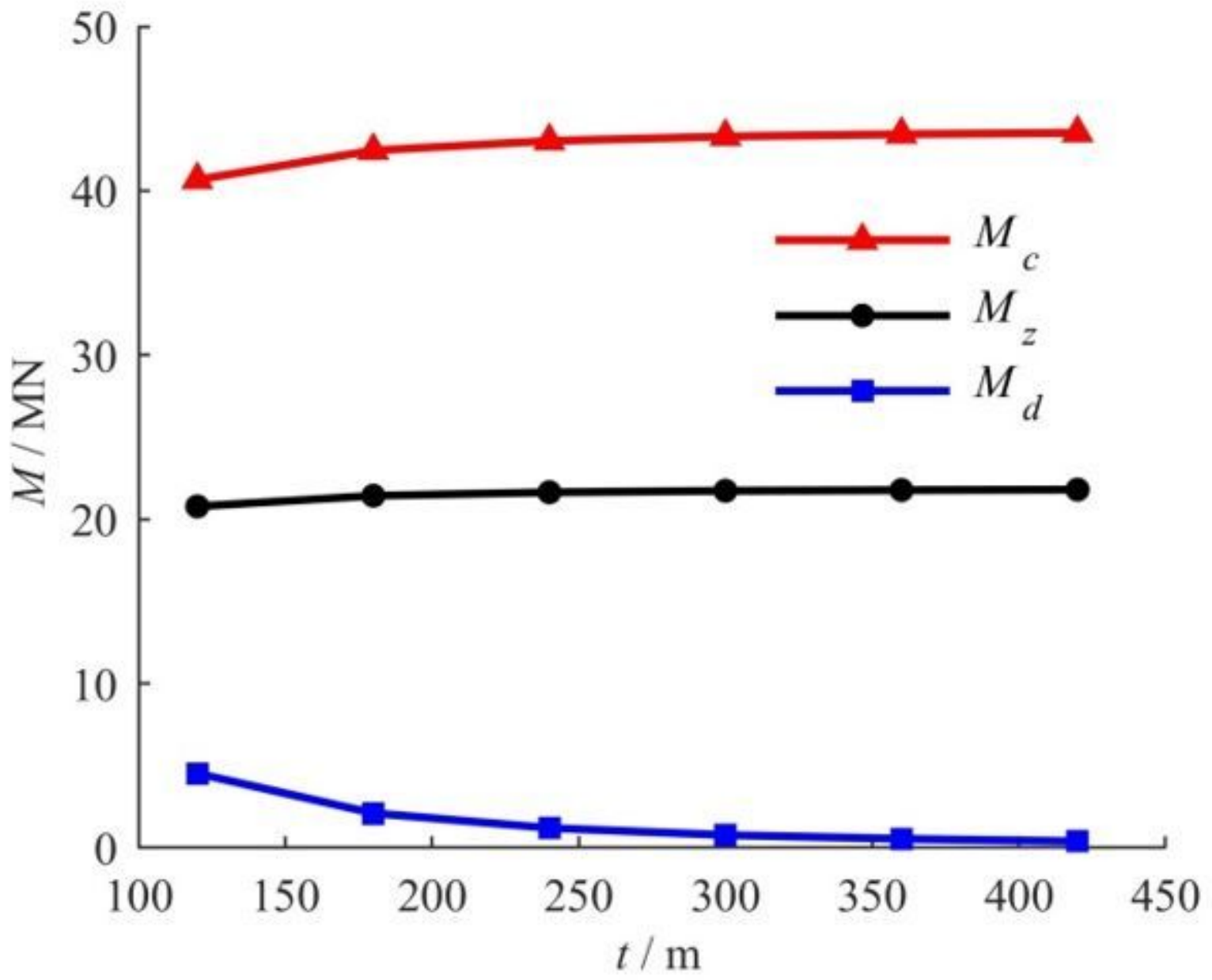

Figure 11

The effect of $t$ 


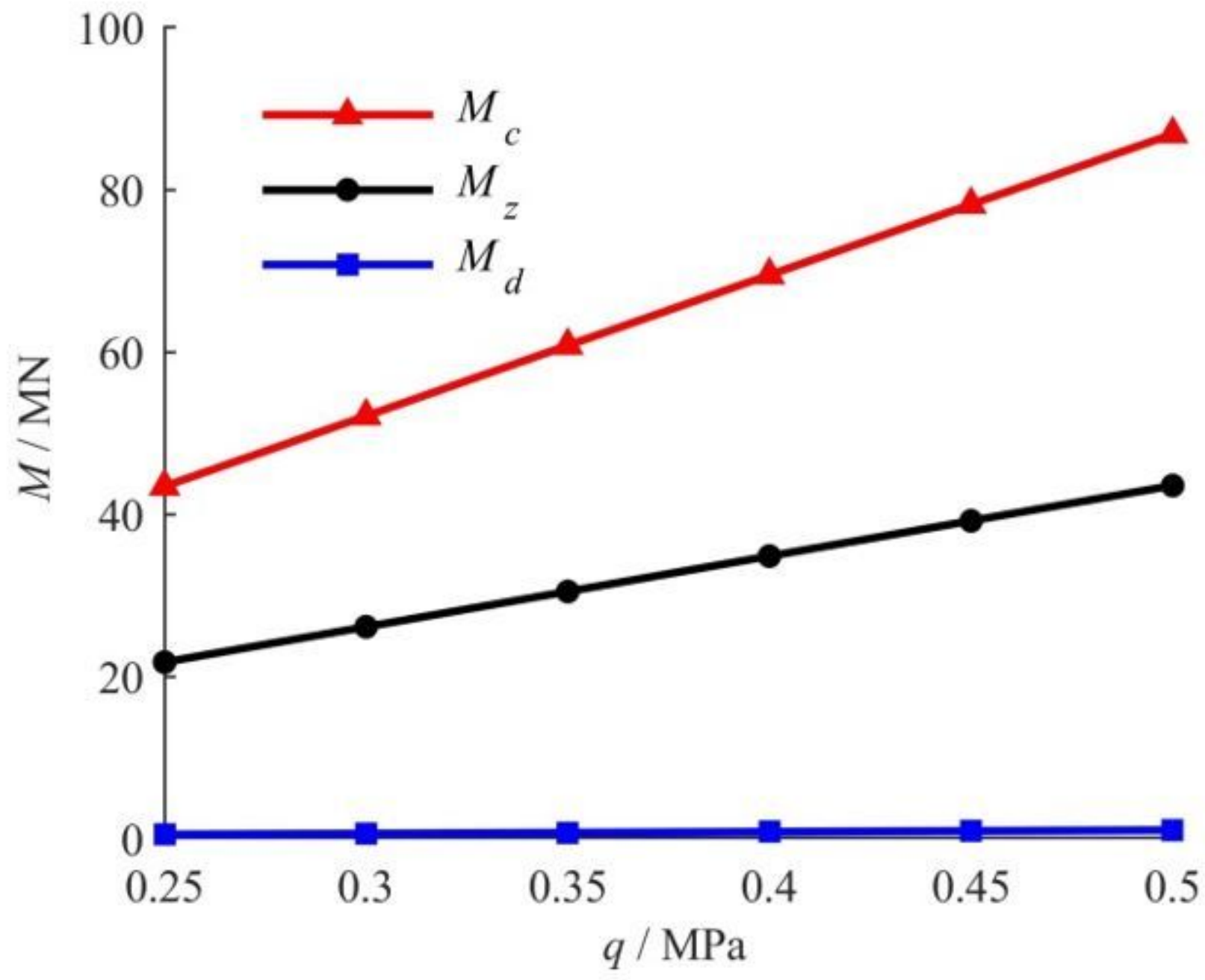

Figure 12

The effect of q 


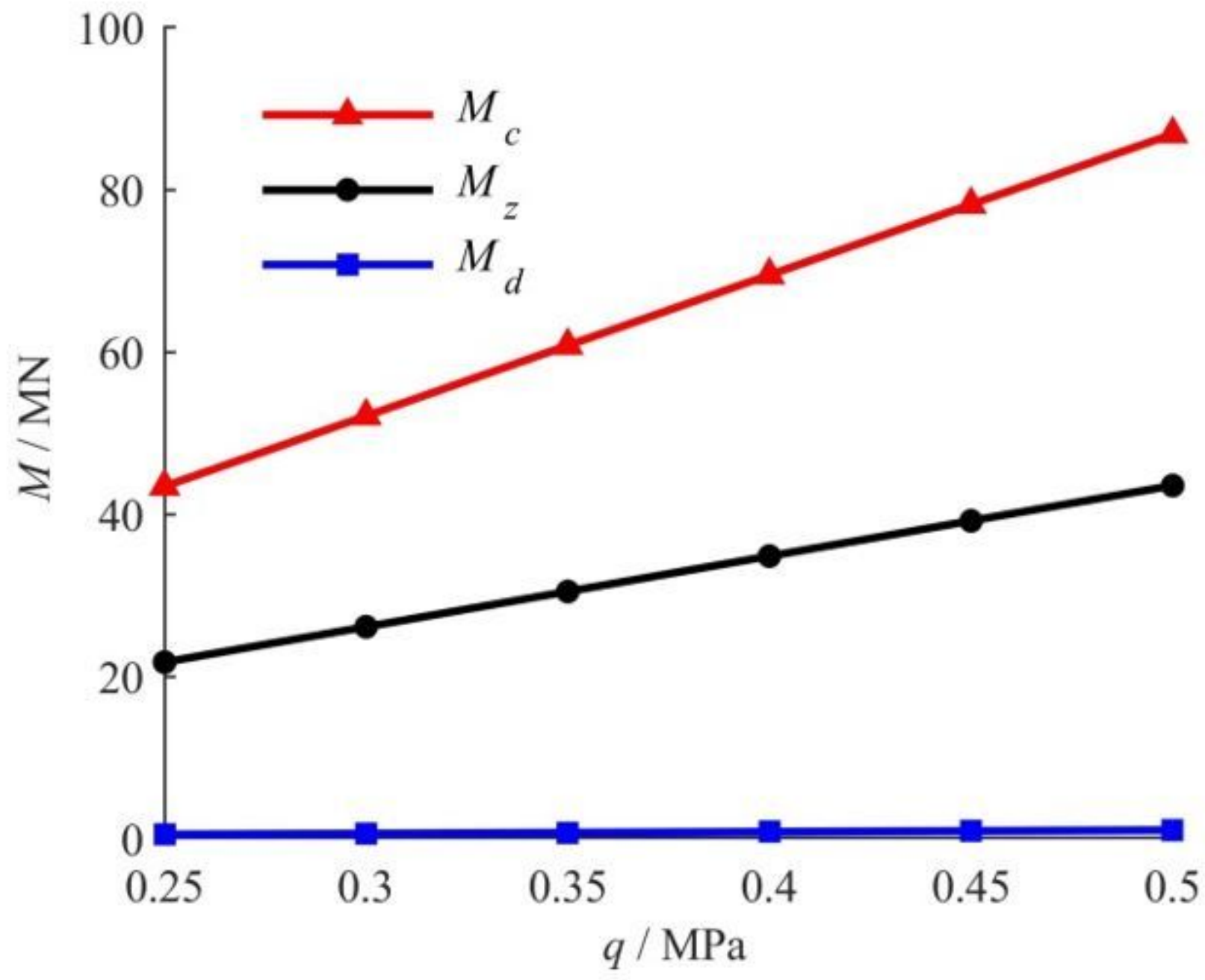

Figure 13

The effect of q 


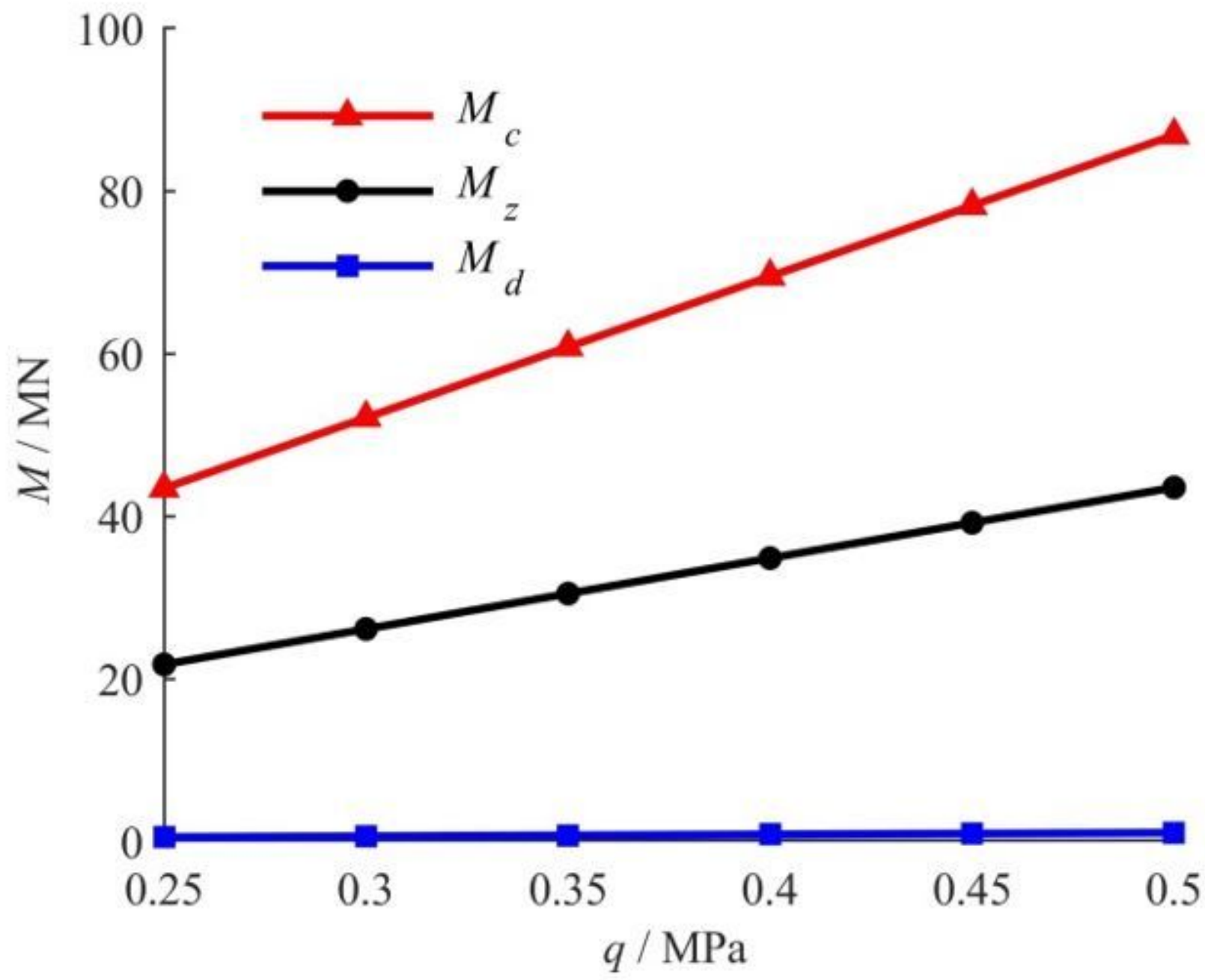

Figure 13

The effect of $q$

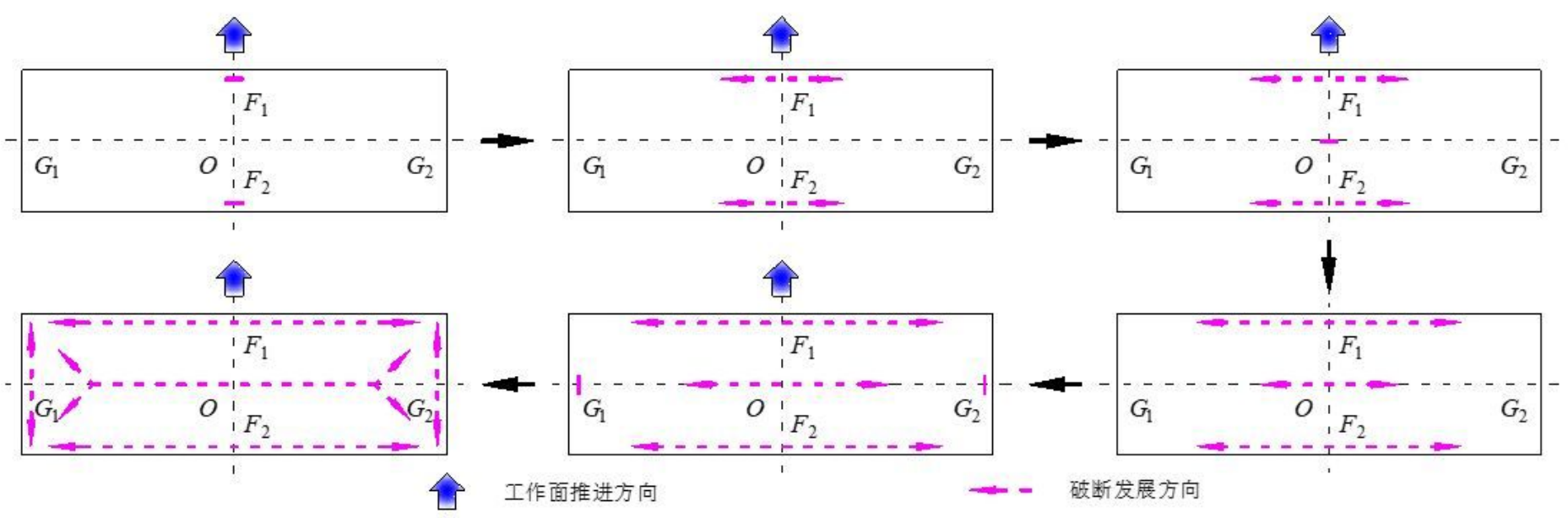

Figure 14 
The primary breaking pattern of main roof above the first working face

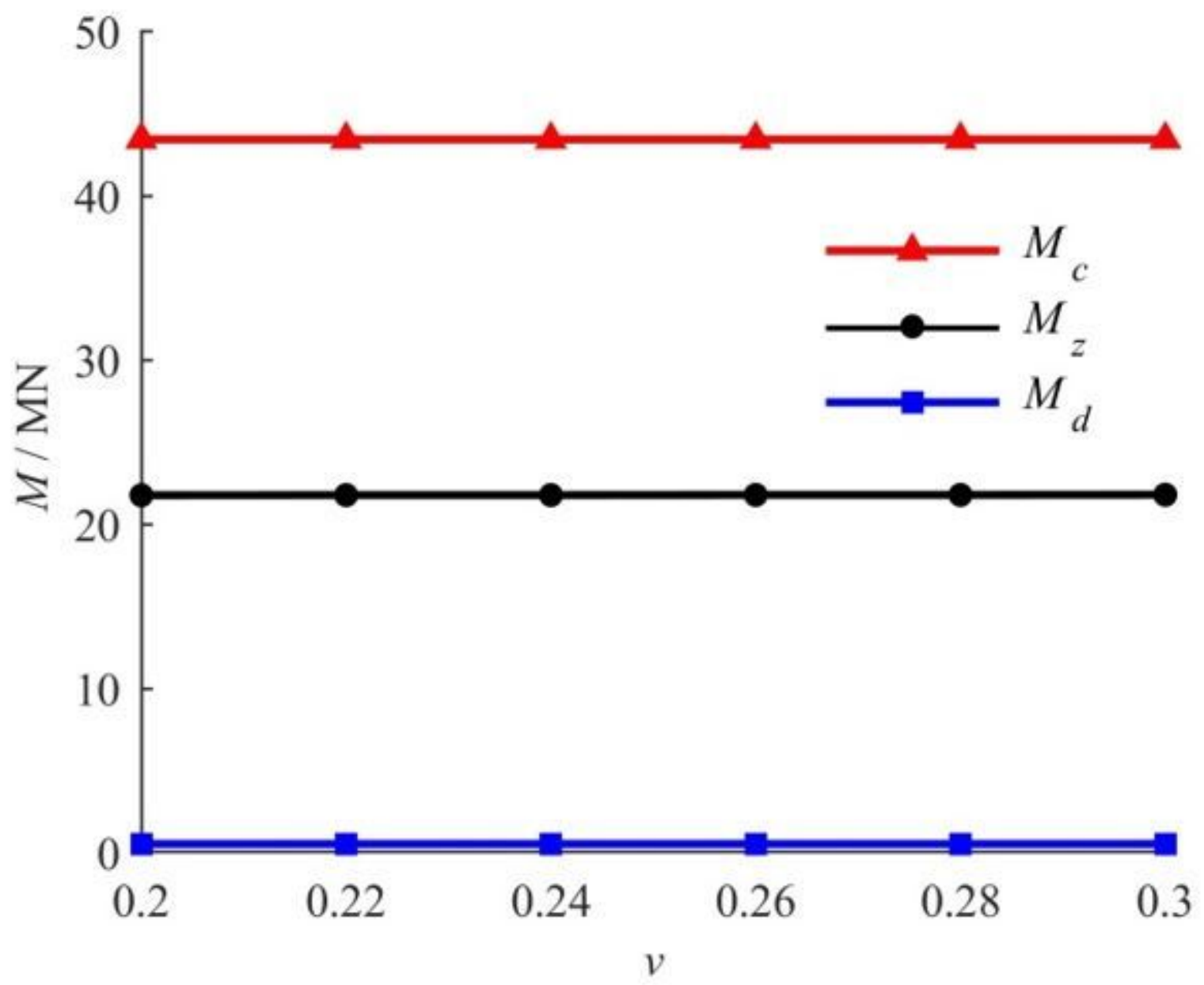

Figure 14

The effect of $v$ 


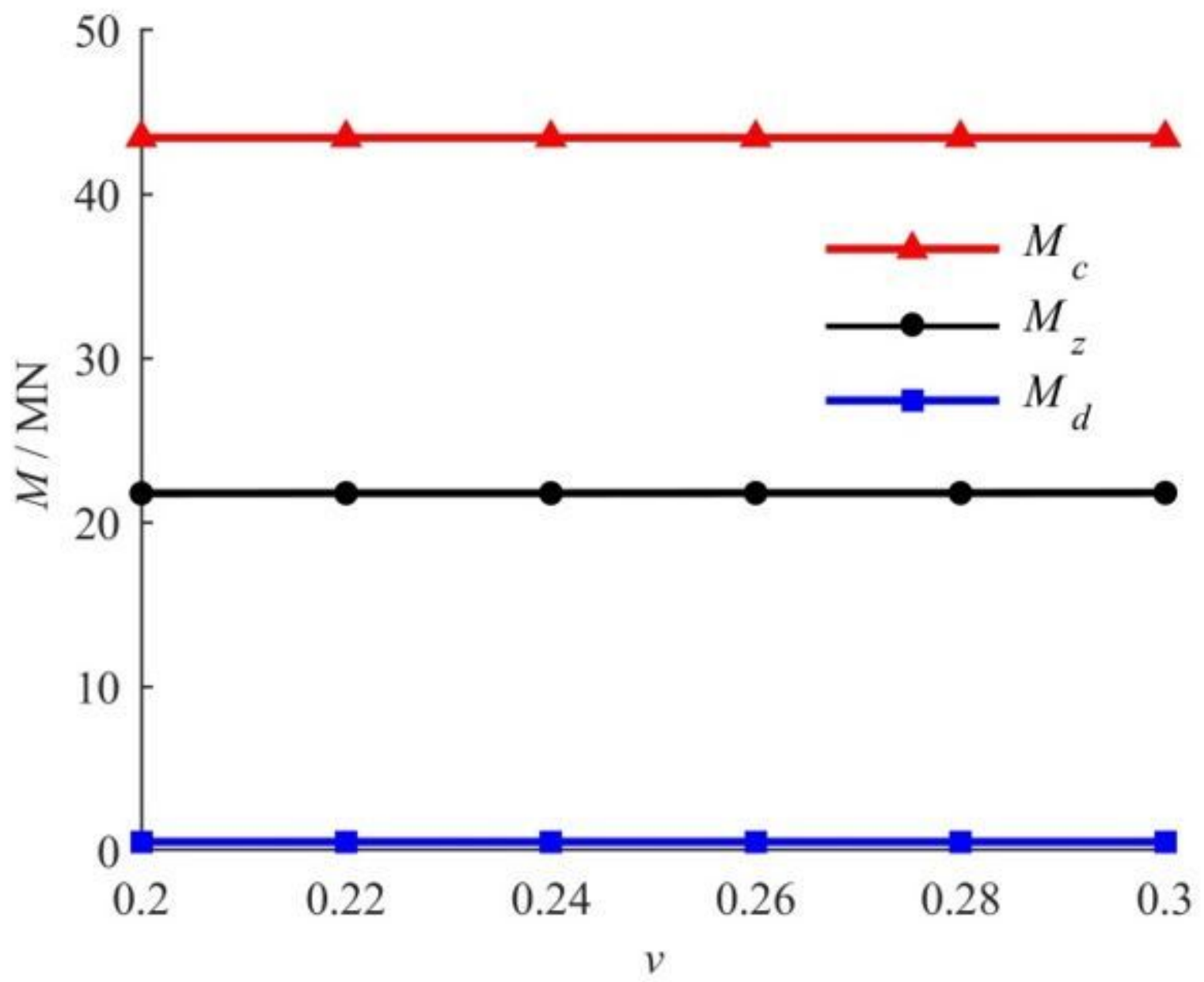

Figure 14

The effect of $v$

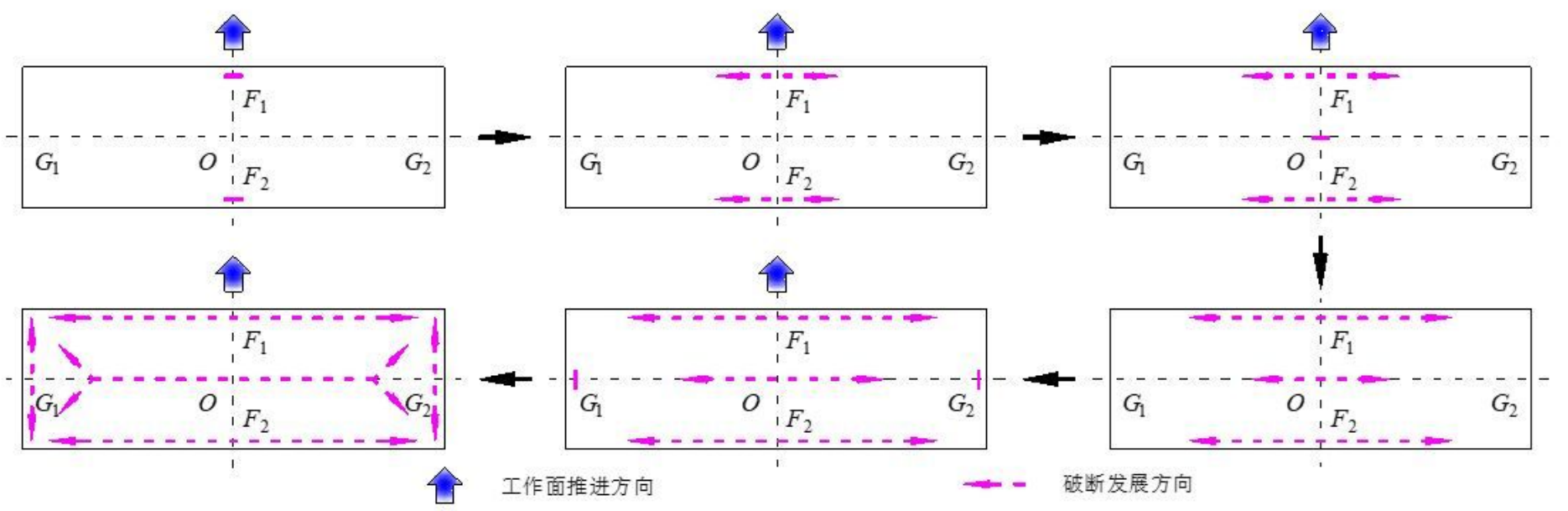

Figure 14

The primary breaking pattern of main roof above the first working face 


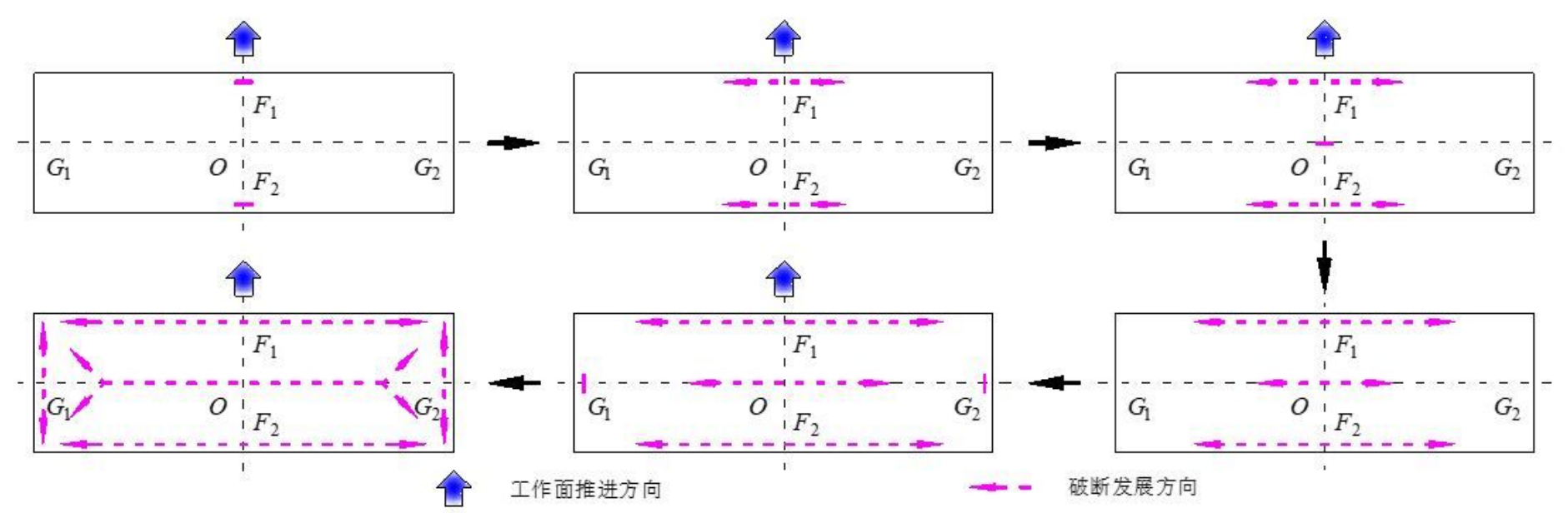

\section{Figure 16}

The primary breaking pattern of main roof above the first working face

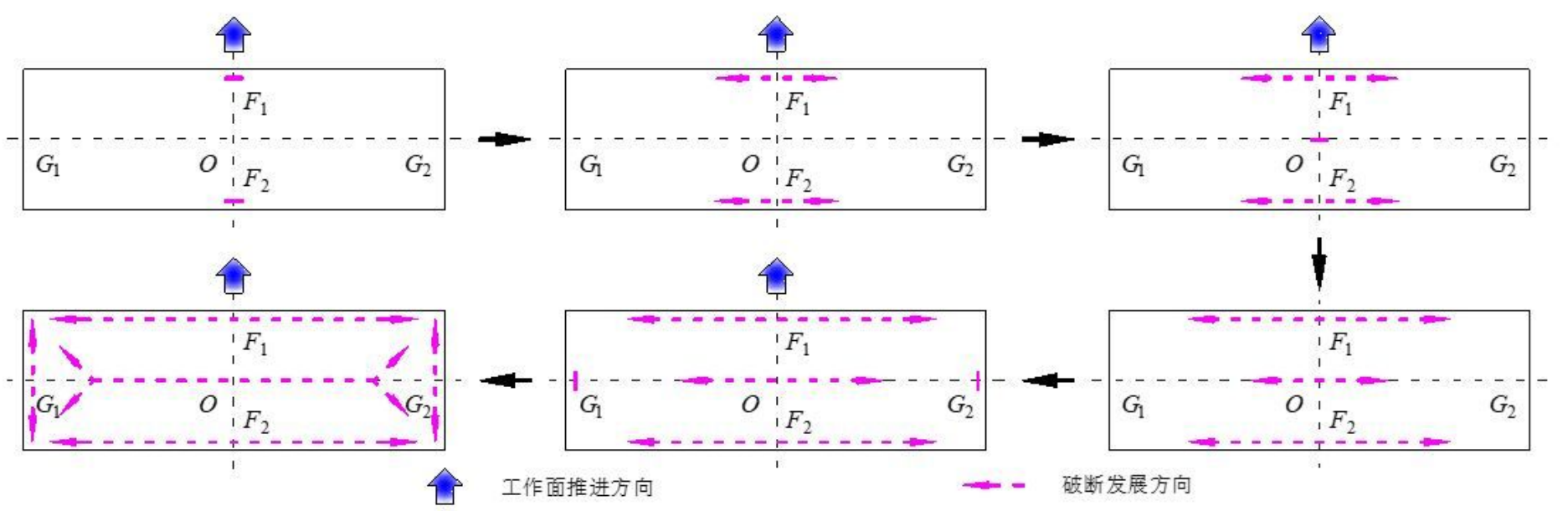

\section{Figure 16}

The primary breaking pattern of main roof above the first working face 